\title{
Asymmetric [2,3]-Sigmatropic Rearrangement of Allylic Ammonium Ylides
}

\author{
Jan Blid

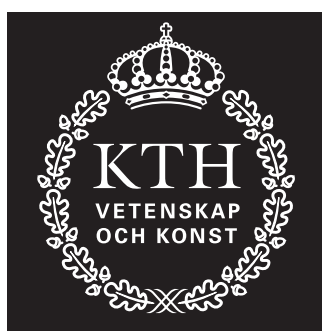 \\ KTH Chemical Science \\ and Engineering \\ Doctoral Thesis

\section{Stockholm 2005}

Akademisk avhandling som med tillstånd av Kungliga Tekniska Högskolan i Stockholm framlägges till offentlig granskning för avläggande av teknologie doktorsexamen i kemi med inriktning mot organisk kemi, fredagen den 7:e oktober, 2005, kl 9.00 i Salongen, KTHB, KTH, Stockholm. Opponent är Prof. James C. Anderson. Avhandlingen försvaras på engelska. 
ISBN 91-7178-135-8

ISRN KTH/IOK/FR--05/97--SE

ISSN 1100-7974

TRITA-IOK

Forskningsrapport 2005:97

(C) Jan Blid, 2005 


\section{Abstract}

This thesis describes the realization of an asymmetric [2,3]-sigmatropic rearrangement of achiral allylic amines. The thesis is divided into two parts; the first part deals with the development of a Lewis acid-mediated [2,3]-sigmatropic rearrangement and the second the asymmetric version thereof. Quaternization of an $\alpha$-amino amide with various Lewis acids established $\mathrm{BBr}_{3}$ and $\mathrm{BF}_{3}$ to be the most appropriate ones. Various allylic amines were subsequently rearranged into the corresponding homoallylic amines in good to excellent syndiastereoselectivities, revealing the endo-transition state to be the preferred pathway. The structures of the intermediate Lewis acid-amine complexes were confirmed by NMR spectroscopy studies and DFT calculations.

Based on this investigation a chiral diazaborolidine was chosen as Lewis acid and was shown to efficiently promote the asymmetric [2,3]-sigmatropic rearrangement furnishing homoallylic amines in good yields and excellent enantiomeric excesses. In contrast to the achiral rearrangement mediated by $\mathrm{BBr}_{3}$ and $\mathrm{BF}_{3}$, the asymmetric version gave the opposite major diastereomer, revealing a preference for the exo-transition state in the asymmetric rearrangement. To account for the observed selectivities, a kinetic and thermodynamic pathway was presented. On the basis of a deuterium exchange experiment on a rearranged Lewis acid-amine complex and an NMR spectroscopic investigation, the kinetic pathway was shown to be favored.

Jan Blid, Asymmetric [2,3]-Sigmatropic Rearrangement of Allylic Ammonium Ylides. Organic Chemistry, School of Chemical Science and Engineering, Royal Institute of Technology, S-100 44 Stockholm, Sweden.

Keywords: asymmetric, [2,3]-sigmatropic rearrangement, allylic amine, ammonium ylide, Lewis acid, enantioselective, boron, phosphazene base, NMR spectroscopy, DFT-calculations. 



\section{Table of Contents}

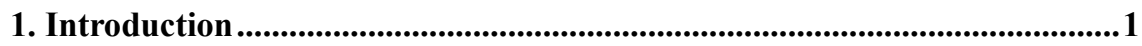

1.1 Sigmatropic rearrangements............................................................ 2

1.2 The [1,2]- and [2,3]-sigmatropic rearrangement of ammonium ylides .......4

1.3 Generation of allylic ammonium ylides ............................................. 7

1.4 Stereochemical control in the [2,3]-sigmatropic rearrangement of allylic

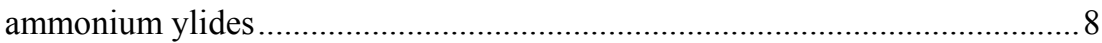

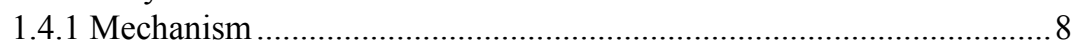

1.4.2 Diastereoselectivity in the rearrangement ...................................... 9

1.4.3 Stereochemistry of the newly formed double bond........................... 10

1.5 Asymmetric [2,3]-sigmatropic rearrangements of ammonium ylides ....... 12

1.5.1 Asymmetric rearrangement via chirality transfer ........................... 12

1.5.2 Asymmetric rearrangement via induction by remote stereogenic

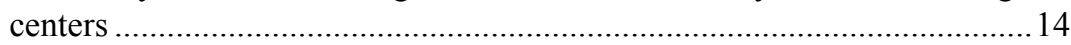

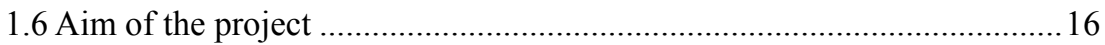

2. Lewis acid-mediated [2,3]-sigmatropic rearrangement of allylic ammonium ylides .......................................................................................................17

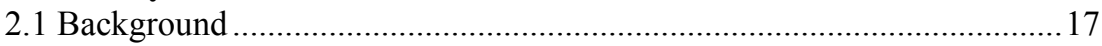

2.2 Screening of Brønsted bases .............................................................. 18

2.3 Screening of Lewis acids ................................................................. 20

2.4 Stereoselectivity of the Lewis acid-mediated rearrangement....................22

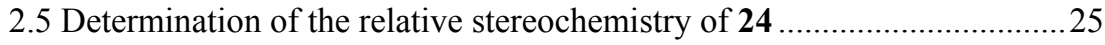

2.6 Proposed mechanism of the rearrangement...........................................26

2.6.1 Density functional calculations ...................................................26

2.6.2 NMR-investigation of the Lewis acid complex $\mathbf{3 4}$ and $\mathbf{3 5}$................. 31

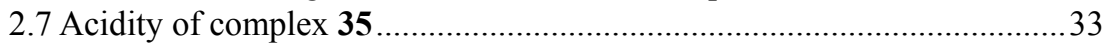

$2.8 \mathrm{BBr}_{3}$-mediated rearrangement of a chiral allylic amine .............................35

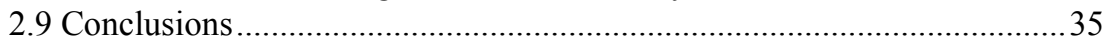

3. Asymmetric [2,3]-sigmatropic rearrangement of allylic ammonium ylides

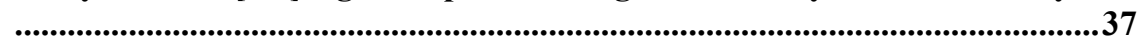

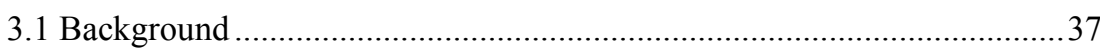

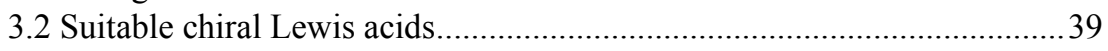

3.3 Initial experiments and optimization of the asymmetric rearrangement ... 41

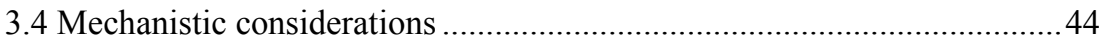

3.5 Scope and limitations of the asymmetric rearrangement...........................46

3.6 Determination of absolute configuration of $\mathbf{2 4 a - c}$...................................5

3.7 Rationalization of the asymmetric induction............................................5

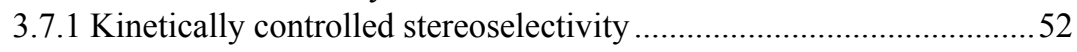

3.7.2 Thermodynamically controlled stereoselectivity............................56

3.7.3 NMR investigation of the transient rearrangement species...............57

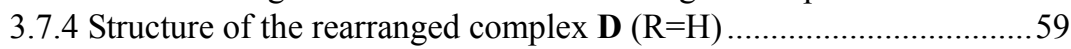

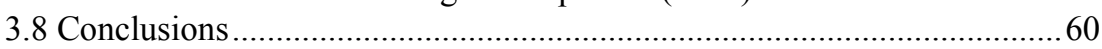

Concluding remarks ..................................................................................661

Acknowledgements...............................................................................62

Appendices A-C ............................................................................................63 


\section{Abbreviations}

Abbreviations and acronyms used are in agreement with the standards of the subject. Only nonstandard and unconventional ones that appear in the thesis are listed here. ${ }^{1}$

$\begin{array}{ll}d s & \text { diastereoselectivity } \\ \text { equiv. } & \text { equivalent } \\ e e & \text { enantiomeric excess } \\ \text { G } & \text { anion-stabilizing group } \\ \text { KHMDS } & \text { potassium hexametyldisilazane } \\ \text { LA } & \text { Lewis acid } \\ \text { LG } & \text { leaving group } \\ \text { n.d. } & \text { not determined } \\ \text { T } & \text { temperature } \\ \text { Ts } & p \text {-toluenesulfonyl } \\ \mathrm{t} & \text { time }\end{array}$

${ }^{1}$ https://paragon.acs.org/paragon/ShowDocServlet?contentld=paragon/menu_content/autho rchecklist/jo_authguide.pdf 


\section{List of publications}

This thesis is based on the following papers, referred to in the text by their Roman numerals:

I. Lewis Acid-Mediated [2,3]-Sigmatropic Rearrangement of Allylic Ammonium Ylides

Jan Blid and Peter Somfai

Tetrahedron Lett. 2003, 44, 3159-3162.

II. Lewis Acid-Mediated [2,3]-Sigmatropic Rearrangement of Allylic $\alpha$ Amino Amides

Jan Blid, Peter Brandt and Peter Somfai

J. Org. Chem. 2004, 69, 3043-3049.

III. Asymmetric [2,3]-Sigmatropic Rearrangement of Allylic Ammonium Ylides

Jan Blid, Olaf Panknin and Peter Somfai

J. Am. Chem. Soc. 2005, 127, 9352-9353.

IV. Asymmetric [2,3]-Sigmatropic Rearrangement of Allylic Ammonium Ylides. Scope and Mechanistic Investigation

Jan Blid, Andreas Fischer and Peter Somfai

Preliminary manuscript. 



\section{Introduction}

Nature provides a plethora of complex organic compounds and many of these possess interesting chemical and vital pharmaceutical properties. To be able to understand these properties it is important to know the structure of organic compounds and how they interact with other molecules, in particular inside the human body. By acquiring such knowledge the construction of new pharmaceutical drugs for medicinal purposes can be realized.

As organic compounds are built on carbon frameworks, selective reactions whereby these backbones can be constructed are of utmost interest and importance. Indeed, the carbon-carbon bond forming reactions are the organic chemists most important tool for making organic molecules. Some pharmaceutical drugs are relatively small and have a simple carbon framework, such as the well-known analgesic acetylsalicylic acid, more commonly known as aspirin (Figure 1). Other drugs have more elaborate carbon structures and required a considerable amount of research and synthetic effort to be produced. For instance Taxol, an effective drug for treatment of certain types of cancer, took more than 30 years from its discovery as a potent compound to being synthesized and marketed in 1993 by Bristol-Myers Squibb. ${ }^{2}$
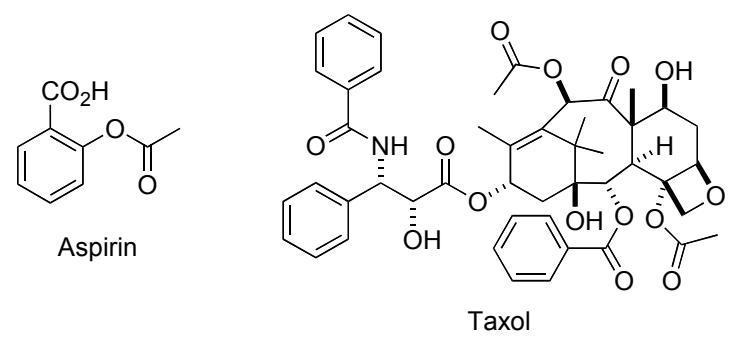

Figure 1. Two commercially available pharmaceutical drugs.

The spatial arrangements of the substituents can have a significant impact on the reactivity and interaction towards other molecules, for instance inside a living tissue. For that reason it is important to be able to control the construction of the carbon framework so that a desired spatial arrangement of the substituents can be achieved. The organic chemist approach to control this construction is by utilization of asymmetric synthesis. A striking example of how two structurally alike compounds can be perceived differently is $(R)$-limonene and its mirror image compound, $(S)$-limonene (Figure 2). While $(R)$-limonene has an orange scent its mirror image smells like lemon. The two mirror images of the

${ }^{2}$ Jacoby, M. C \& EN 2005, 83, 120. 
pharmaceutical compound propanolol has a more dramatic effect on the human body. The $(S)$-enantiomer shows cardiac activity (as a $\beta$-blocker), while the $(R)$-enantiomer acts as a contraceptive (Figure 2$).^{3}$

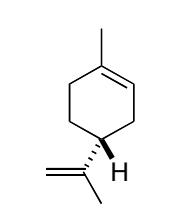

$(R)$-limonene orange scent

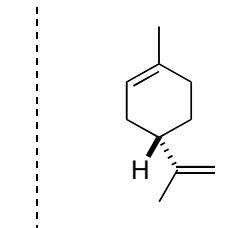

(S)-limonene mirror lemon scent

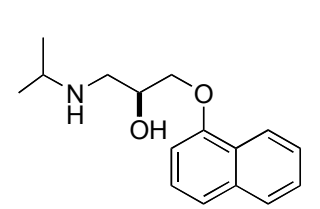

(S)-propanolol cardiac activity

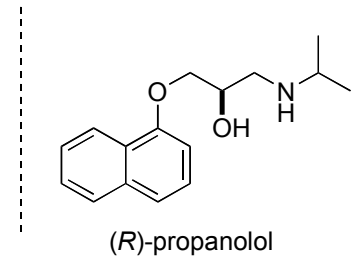
mirror contraceptive

Figure 2. The enantiomers of limonene and propanolol.

Although there are many asymmetric carbon-carbon bond-forming reactions that have been found useful in the synthesis of organic compounds, the pursuit towards new reactions is ongoing to further widen the continuously growing library of asymmetric carbon-carbon bond forming reactions. A class of reactions that include several examples of important and often utilized carbon-carbon bond forming transformations are the sigmatropic rearrangements.

\subsection{Sigmatropic rearrangements}

A sigmatropic rearrangement is a reaction in which a $\sigma$-bond migrates within the transiently conjugated electron system of a molecule to a new site. ${ }^{4}$ To distinguish between different sigmatropic rearrangements the movement of the $\sigma$-bond is given by two numbers in brackets $[a, b]$. Figuratively, the numbers relate to how many atoms the $\sigma$-bond traverses on each side of the cyclic array to form the new bond (Figure 3).
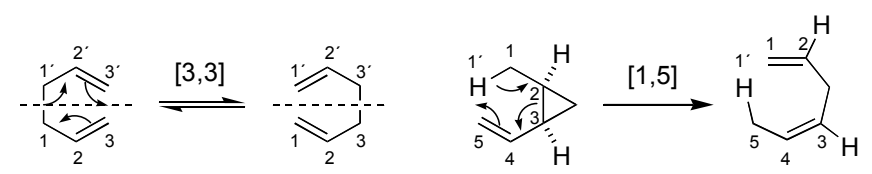

Figure 3. [3,3] and [1,5]-sigmatropic rearrangements.

Sigmatropic rearrangements can take place regio- and stereoselectively, a fact inherent from the concerted nature of several of these processes. However, some sigmatropic reactions are not concerted and proceed via radical or ionic intermediates. ${ }^{4}$ For a sigmatropic rearrangement to be concerted, the involved frontier orbitals (i.e. HOMO and LUMO) must be able to overlap during the

\footnotetext{
${ }^{3}$ Aitken, R. A.; Kilényi, S. N. Asymmetric synthesis; Blackie Academic \& Professional: Glasgow, 1992.

${ }^{4}$ Fleming, I. Frontier Orbitals and Organic Chemical Reactions; Wiley: London, 1976.
} 
reaction, in accordance with the Woodward-Hoffmann rules. ${ }^{4,5}$ For instance, the $[1,5]$-sigmatropic rearrangement is a concerted suprafacial reaction, ${ }^{6}$ which can be seen by the bonding overlap between the HOMO and LUMO shown in Figure $4 \mathrm{a} .{ }^{4}$ On the other hand, if a concerted [1,3]-sigmatropic rearrangement is to take place, the HOMO and LUMO have to interact in an antarafacial process (marked 1, Figure 4b). ${ }^{7}$ As it is geometrically impossible for the orbitals marked 1 to overlap during the rearrangement, while maintaining the overlap between orbitals marked 2 , the concerted [1,3]-rearrangement is virtually unknown.
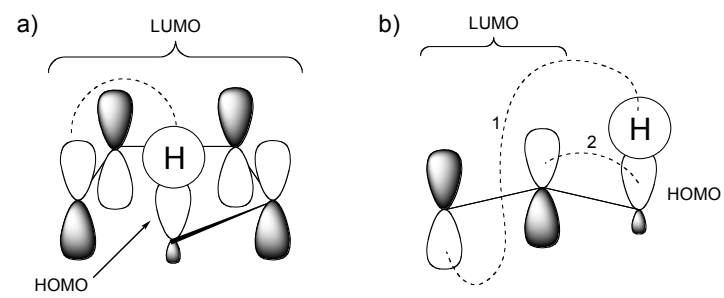

Figure 4. a) Frontier orbitals for suprafacial [1,5]- and b) antarafacial [1,3]sigmatropic rearrangements.

The well-known Claisen rearrangement is a concerted [3,3]-sigmatropic process. It is a valuable transformation and often used as a key step in organic synthesis. $^{8}$ A recent example of a catalytic enantioselective Claisen rearrangement illustrates the progress in this field (Scheme 1). ${ }^{9}$

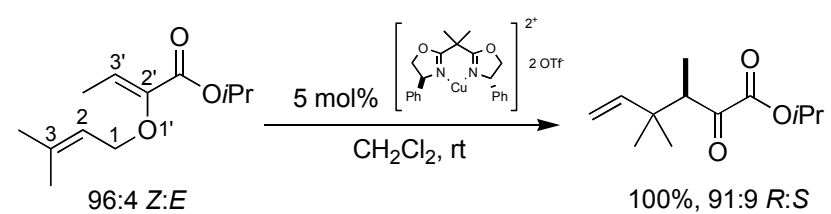

Scheme 1. A catalytic, enantioselective Claisen rearrangement.

\footnotetext{
${ }^{5}$ Woodward, R. B.; Hoffman, R. V. The Conservation of Orbital Symmetry; Verlag Chemie: Weinheim, 1970.

${ }^{6}$ Suprafacial $=$ interaction between orbitals on the same face of the conjugated system.

${ }^{7}$ Antarafacial $=$ interaction between orbitals from opposite faces of the conjugated system.

${ }^{8}$ A recently published total synthesis using a Claisen rearrangement as a key step: Boeckman, R. K. J.; Ferreira, M. R. R.; Mitchell, L. H.; Shao, P. J. Am. Chem. Soc. 2001, 124, 190-191.

${ }^{9}$ Abraham, L.; Czerwonka, R.; Hierseman, M. Angew. Chem., Int. Ed. Engl. 2001, 40, 47004703.
} 


\subsection{The [1,2]- and [2,3]-sigmatropic rearrangement of ammonium ylides}

In 1928 Stevens discovered, while investigating a protecting group for secondary amines, perhaps the first example of a [1,2]-sigmatropic rearrangement of an ammonium ylide, later known as the Stevens rearrangement (Scheme 2). ${ }^{10}$ As predicted by the conservation of orbital symmetry, the concerted [1,2]sigmatropic rearrangement is a symmetry-forbidden reaction. ${ }^{4,5}$ Thus, the Stevens rearrangement is believed to proceed via a homolysis of the heteroatom-carbon bond followed by recombination of the radical fragments to form a new carboncarbon $\sigma$-bond. ${ }^{11}$

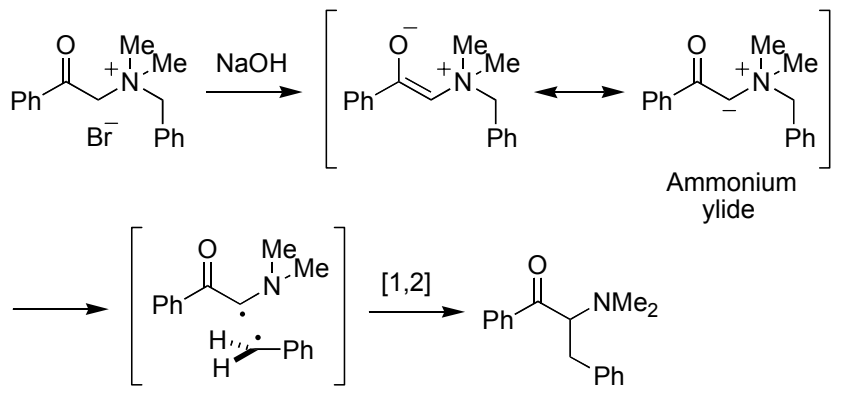

Scheme 2. The Stevens rearrangement of a benzylic ammonium salt.

In the 1960s, during mechanistic studies of allylic analogs to the Stevens rearrangement, a competing reaction to the [1,2]-sigmatropic rearrangement was encountered (Scheme 3). The competing reaction followed a [2,3]-sigmatropic pathway and often predominated over the [1,2]-reaction. For instance, when the cinnamyl ammonium salt $(\mathrm{R}=\mathrm{Ph}$, Scheme 3$)$ was subjected to hot aqueous alkali, a mixture of [1,2]- and [2,3]-rearranged products was obtained, while the crotyl derivative $(\mathrm{R}=\mathrm{Me})$ yielded only the $[2,3]$-rearranged product. $^{12}$ Ollis and Rautenstrauch investigated the reaction and showed that at lower reaction temperatures the [2,3]-rearrangement prevailed. . $^{13-17}$ The [2,3]-sigmatropic rearrangement is a symmetry allowed reaction and believed to proceed via a concerted mechanism with a lower activation energy than the [1,2]-reaction, ${ }^{14,15}$ thus making it possible to exclusively form the [2,3]-rearrangement products by carefully controlling the reaction conditions..$^{16,17}$

${ }^{10}$ Stevens, T. S.; Creigthon, E. M.; Gordon, A. B.; MacNicol, M. J. Chem. Soc. 1928, 31933197.

${ }_{11}$ Ollis, W. D.; Rey, M.; Sutherland, I. O. J. Chem. Soc., Perkin Trans. 1 1983, 1009-1027.

${ }^{12}$ Millard, B. J.; Stevens, T. S. J. Chem. Soc. 1963, 3397-3403.

${ }^{13}$ (a) Jemison, R. W.; Ollis, W. D. J. Chem. Soc., Chem. Commun. 1969, 294-295; (b) Chantrapromma, K.; Ollis, W. D.; Sutherland, I. O. J. Chem. Soc., Chem. Commun. 1978, 673-675.

${ }^{14}$ Rautenstrauch, V. Helv. Chim. Acta 1972, 55, 2233-2240.

${ }^{15}$ Mageswaran, S.; Ollis, W. D.; Sutherland, I. O. Chem. Comm. 1973, 656-657.

${ }^{16}$ Jemison, R. W.; Laird, T.; Ollis, W. D.; Sutherland, I. O. J. Chem. Soc., Perkin Trans. 1 1980, 1436-1449. 


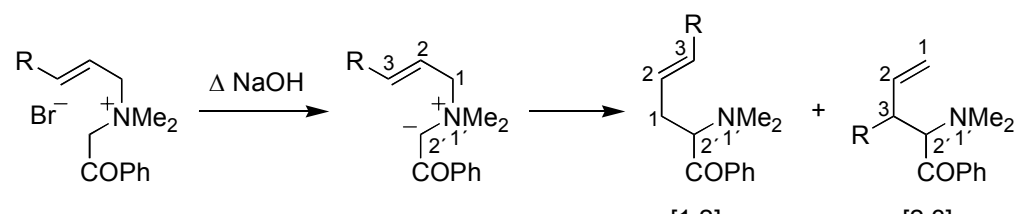

$[1,2]$

$[2,3]$

Scheme 3. Competing [1,2]- and [2,3]-sigmatropic rearrangements.

A related [2,3]-sigmatropic reaction is the [2,3]-Wittig rearrangement of allylic ethers (Scheme 4). The reaction is well-known and has been thoroughly investigated. ${ }^{18}$ The fundamental difference between these two rearrangements, besides the heteroatom, is the charge of the rearrangement precursors. The Wittig rearrangement has an anionic precursor while the Stevens counterpart has a zwitter-ionic or ylidic rearrangement precursor (compare Scheme 4 with Scheme $3)$.

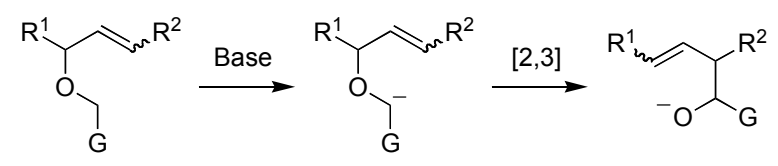

Scheme 4. The $[2,3]$-Wittig rearrangement $(\mathrm{G}=$ anion-activating group, e.g. $\left.\mathrm{CO}_{2} \mathrm{Me}, \mathrm{C} \equiv \mathrm{CMe}\right)$.

Although the replacement of oxygen with a nitrogen may seem trivial in this case, only a few examples of [2,3]-Wittig rearrangements of allylic amines exist. Since nitrogen has a lower electronegativity than oxygen and does not as readily accept a negative charge, the thermodynamic force for rearrangement is effectively diminished. The first example of an unequivocal aza-[2,3]-Wittig rearrangement was published by Durst, who utilized the relief in ring strain of 1-benzyl-4-vinyl-2-azetidinone to furnish in virtually quantitative yield the seven-membered unsaturated lactam 1 (Scheme 5). ${ }^{19}$ On a similar basis the group of Somfai introduced $N$-substituted vinylaziridines to provide synthetically useful piperidines $2 .{ }^{20}$ An interesting acyclic aza-[2,3]-sigmatropic rearrangement was introduced by Anderson, in which allylic amines 3 were smoothly rearranged by employing electron withdrawing groups on the nitrogen atom,

17 Jemison, R. W.; Laird, T.; Ollis, W. D.; Sutherland, I. O. J. Chem. Soc., Perkin Trans. 1 1980, 1450-1457.

${ }^{18}$ (a) Marshall, J. A. In Comprehensive Organic Synthesis; Trost, B. M., Fleming, I., Eds.; Pergamon: Oxford, 1991; Vol. 3, pp. 975-1014; (b) Nakai, T.; Mikami, K. In Org. React.; Paquette, L. A., Ed.; Wiley: New York, 1994; Vol. 46, pp. 105-209.

${ }^{19}$ Durst, T.; Elzen, R. V. D.; LeBelle, M. J. J. Am. Chem. Soc. 1972, 94, 9261-9263.

${ }^{20}$ (a) Åhman, J.; Somfai, P. J. Am. Chem. Soc. 1994, 116, 9781-9782; (b) Åhman, J.; Somfai, P. Tetrahedron 1995, 51, 9747-9756. (c) Åhman, J.; Jarevång, T.; Somfai, P. J. Org. Chem. 1996, 61, 8148-8159. A similar rearrangement of a vinylaziridine derivative was reported by the group of Coldham: Coldham, I.; Collis, A. J.; Mould, R. J.; Rathmell, R. E. Tetrahedron Lett. 1995, 36, 3557-3560; 
thereby stabilizing the formed amide during the transition state. ${ }^{21,22}$

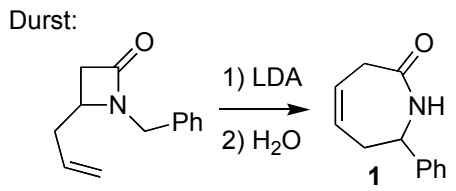<smiles>C=CC1C(C(C)(C)C)N1CC(=O)OCC(=O)OCC(C)C</smiles>

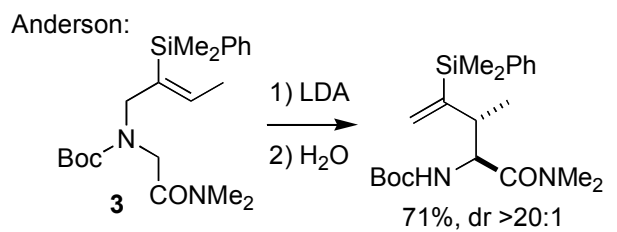

Scheme 5. Aza-[2,3]-Wittig rearrangement of various tertiary amines.

In contrast, the [2,3]-sigmatropic rearrangement of ammonium ylides proceeds readily and can be explained by the formation of a stable tertiary amine. ${ }^{23}$ Other heteroatom analogs, such as sulfonium, ${ }^{24}$ oxonium, ${ }^{25}$ selenonium ${ }^{26}$

\footnotetext{
${ }^{21}$ (a) Anderson, J. C.; Siddons, D. C.; Smith, S. C.; Swarbrick, M. E. J. Chem. Soc., Chem. Commun. 1995, 1385-1386; (b) Anderson, J. C.; Siddons, D. C.; Smith, S. C.; Swarbrick, M. E. J. Org. Chem. 1996, 61, 4820-4823. (c) Anderson, J. C.; Flaherty, A.; Swarbrick, M. E. J. Org. Chem. 2000, 65, 9152-9156. A similar acyclic aza-[2,3]-Wittig rearrangement utilized a phosphoramide electron withdrawing group on nitrogen: Manabe, S. Tetrahedron Lett. 1997, 38, 2491-2492.

${ }^{22} \mathrm{~A}$ recent publication presented an asymmetric rearrangement of an acyclic allylic amine by employing various chiral auxiliaries: Anderson, J. C.; O'Loughlin, J. M. A.; Tornos, J. A. Org. Biomol. Chem. 2005, 3, 2741-2749.

${ }^{23}$ Some recent examples: (a) Simonneaux, G.; Galardon, E.; Paul-Roth, C.; Gulea, M.; Masson, S. J. Organomet. Chem. 2001, 617-618, 360-363; (b) Clark, J. S.; Hodgson, P. B.; Goldsmith, M. D.; Street, L. J. J. Chem. Soc., Perkin Trans. 1 2001, 3312-3324; (c) Clark, J. S.; Hodgson, P. B.; Goldsmith, M. D.; Blake, A. J.; Cooke, P. A.; Street, L. J. J. Chem. Soc. Perkin Trans. 1 2001, 3325-3337; (d) Smith, R. S.; Bentley, P. D. Tetrahedron Lett. 2002, 43, 899-902; (e) Clark, J. S.; Middleton, M. D. Org. Lett. 2002, 4, 765-768; (f) Heath, P.; Roberts, E.; Sweeney, J. B.; Wessel, H. P.; Workman, J. A. J. Org. Chem. 2003, 68, 40834086.

${ }^{24}$ Selected examples and references cited therein: (a) Blackburn, G. M.; Ollis, W. D.; Plackett, J. D.; Smith, C.; Sutherland, I. O. J. Chem. Soc., Chem. Commun. 1968, 186-188; (b) Baldwin, J. E.; Hackler, R. E.; Kelly, D. P. J. Chem. Soc., Chem. Commun. 1968, 537538; (c) Chappie, T. A.; Weekley, R. M.; MCMills, M. C. Tetrahedron Lett. 1996, 37, 65236526; (d) Gulea, M.; Marchand, P.; Masson, G.; Saquet, M.; Collignon, N. Synthesis 1999, 1635-1639; (e) Aggarwal, V. K.; Ferrara, M.; Hainz, R.; Spey, S. E. Tetrahedron Lett. 1999, 40, 8923-8927; (f) Zhou, C.-Y.; Yu, W.-Y.; Chan, P. W. H.; Che, C.-M. J. Org. Chem. 2004, 69, 7072-7082.

${ }^{25}$ (a) Doyle, M. P.; Griffin, J. H.; Chinn, M. S.; van Leusen, D. J. Org. Chem. 1984, 49, 19171925; (b) Pirrung, M. C.; Werner, J. A. J. Am. Chem. Soc. 1986, 108, 6060-6062; (c) Roskamp, E. J.; Johnson, C. R. J. Am. Chem. Soc. 1986, 108, 6062-6063; (d) Hodgson, D. M.; Pierard, F. Y. T. M.; Stupple, P. A. Chem. Soc. Rev. 2001, 30, 50-61.

${ }^{26}$ (a) Gassman, P. G.; Miura, T.; Mossman, A. J. Org. Chem. 1982, 47, 954-959; (b) Nishibayashi, Y.; Ohe, K.; Uemura, S. Chem. Commun. 1995, 1245-1264; (c) Kurose, N.; Takahashi, T.; Koizumi, T. J. Org. Chem. 1997, 62, 4562-4563.
} 
and iodonium ylides ${ }^{27}$ also participate in [2,3]-sigmatropic rearrangements.

\subsection{Generation of allylic ammonium ylides}

The two most important strategies for preparation of ammonium ylides involve either alkylation of an appropriate amine and subsequent deprotonation by base or capture of allylic amines by carbenes (Scheme 6). ${ }^{28,29}$ Traditionally the alkylation method has predominated, but recent advances in the field have relied much on the latter alternative. The potential problem with cyclopropanation usually associated with this method has been reduced by introducing transition metal carbenoids to generate the ammonium ylides. ${ }^{30}$

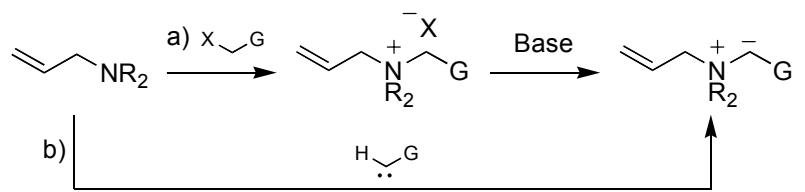

Scheme 6. Generation of ammonium ylides via a) alkylation or b) capture by carbenes.

Vedejs introduced a method to provide nonstabilized ylides by alkylating tertiary amines with $\mathbf{4}$ and treating the resulting ammonium salt with cesium fluoride (Scheme 7). ${ }^{31}$ The reaction conditions are mild and useful for substrates such as 5, where direct deprotonation by strong bases would lead to regiochemical problems. For instance, $N$-cinnamyl piperidine $\mathbf{5}$ was smoothly rearranged under these reaction conditions providing the product in acceptable yield. ${ }^{32}$

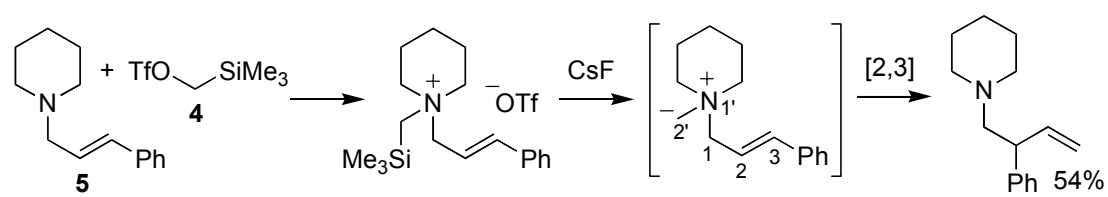

Scheme 7. Generation of an ammonium ylide and subsequent [2,3]-sigmatropic rearrangement under mild reaction conditions.

${ }^{27}$ (a) Doyle, M. P.; Tamblyn, W. H.; Bagheri, V. J. Org. Chem. 1981, 46, 5094-5102; (b) Simonneaux, G.; Galardon, E.; Paul-Roth, C.; Gulea, M.; Masson, S. J. Organomet. Chem. 2001, 617-618, 360-363.

${ }^{28}$ Markó, I. E. In Comprehensive Organic Synthesis; Trost, B. M., Fleming, I., Eds.; Pergamon: Oxford, 1991; Vol. 3, pp. 913-974.

${ }^{29}$ Kallmerten, J. In Houben-Weyl: Stereoselective Synthesis; Helmchen, G., Ed.; Thieme: Stuttgart, 1996, pp 3757-3801.

${ }^{30}$ Zhou, C.-Y.; Yu, W.-Y.; Chan, P. W. H.; Che, C.-M. J. Org. Chem. 2004, 69, 7072-7082 and references therein.

${ }^{31}$ Vedejs, E.; West, F. G. Chem. Rev. 1986, 86, 941-955. Aggarwal recently reported an alternative approach to obtain nonstabilized ammonium ylides: Aggarwal, V. K.; Fang, G.; Charmant, J. P. H.; Meek, G. Org. Lett. 2003, 5, 1757-1760.

${ }^{32}$ Vedejs, E.; Martinez, G. R. J. Am. Chem. Soc. 1979, 101, 6452-6454. 
1.4 Stereochemical control in the [2,3]-sigmatropic rearrangement of allylic ammonium ylides

\subsubsection{Mechanism}

The [2,3]-sigmatropic rearrangement of ammonium ylides is a symmetry allowed concerted suprafacial reaction, that is considered to follow a six-electron five-membered transition state where the forming carbon-carbon bond and the breaking heteroatom-carbon bond are almost in parallel (Figure 5)..$^{14,33,34}$ This can be understood by examining the HOMO of the allyl anion and the LUMO of the carbon-nitrogen double bond during the rearrangement (or the LUMO of the allyl anion and HOMO of the carbon-nitrogen double bond, Figure 5). Maximized overlap of the frontier orbitals is achieved when these bonds are parallel. ${ }^{4,35} \mathrm{Ab}$ initio calculations of the [2,3]-sigmatropic rearrangement of an allylic ammonium ylide as well as of the related [2,3]-Wittig rearrangement further support this transition state structure. ${ }^{36,37}$

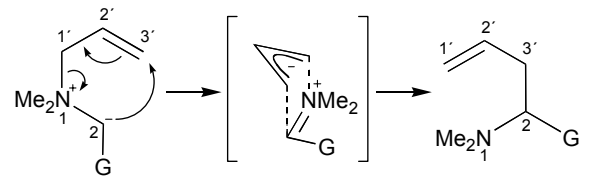

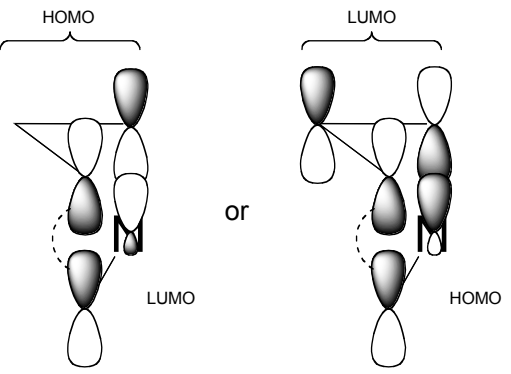

Figure 5. Proposed transition state of the [2,3]-sigmatropic rearrangement.

Although the 5-membered transition state offers conformational flexibility, the rearrangement can display very high selectivities. This has been frequently precendented for the [2,3]-Wittig rearrangement for a wide range of allylic ethers with different olefinic moieties and anion-stabilizing groups. ${ }^{18}$ The ylidic $[2,3]$ sigmatropic rearrangement has not been as fully investigated, but mechanistic studies of ammonium and sulphonium ylides have given a valuable insight into the stereochemical aspects of the rearrangement. . $1,17,34,38^{-1}$

\footnotetext{
${ }^{33}$ Mageswaran, S.; Ollis, W. D.; Sutherland, I. O.; Thebtaranonth, Y. Chem. Comm. 1971, $1494-1495$.

${ }^{34}$ Mageswaran, S.; Ollis, W. D.; Sutherland, I. O. J. Chem. Soc., Perkin Trans. 1 1981, 1953-1962.

${ }^{35}$ Baldwin, J. E.; Patrick, J. E. J. Am. Chem. Soc. 1971, 93, 3556-3558.

${ }^{36}$ Jursic, B. S. J. Mol. Struct. (Theochem) 1995, 339, 161-168.

${ }^{37}$ Mikami, K.; Uchida, T.; Hirano, T.; Wu, Y.-d.; Houk, K. N. Tetrahedron 1994, 50, 59175926.

${ }^{38}$ Ollis, W. D.; Sutherland, I. O.; Thebtaranonth, Y. J. Chem. Soc., Perkin Trans. 1 1981, 1963-1968.
} 


\subsubsection{Diastereoselectivity in the rearrangement}

In a [2,3]-sigmatropic rearrangement, the newly formed stereogenic centers can be formed with syn or anti diastereoselectivity (Scheme 8 ). This is governed by the conformational preferences of the migrating allylic moiety and the anionic stabilizing group in the transition state (endo-TS/exo-TS, Scheme 8). The energy difference between these transition states is often small and, therefore, mixtures are frequently obtained.

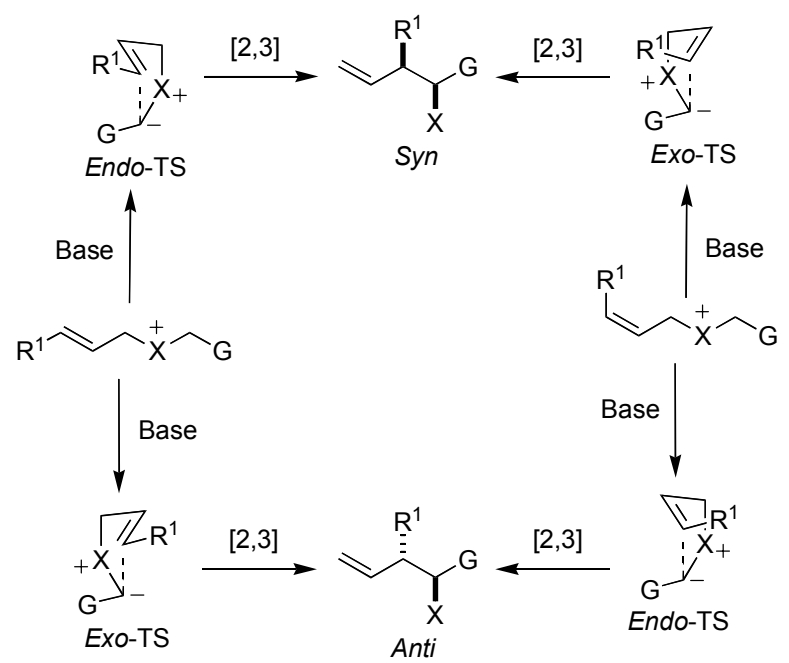

Scheme 8. Endo- and exo-transition states $\left(\mathrm{X}=\mathrm{NR}_{2}^{2}\right)$.

Table 1. Selected results of diastereoselective [2,3]-sigmatropic rearrangements of ammonium ylides.

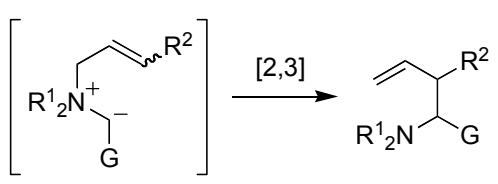

\begin{tabular}{llllll}
\hline $\mathrm{R}^{1}$ & $\mathrm{R}^{2}$ & $\mathrm{G}$ & Yield & Syn:anti & $\begin{array}{l}\text { Transition } \\
\text { state }\end{array}$ \\
\hline $\mathrm{Me}$ & $(E)-\mathrm{Ph}$ & $\mathrm{C} \equiv \mathrm{CPh}$ & 91 & $86: 14$ & Endo $^{16}$ \\
$\mathrm{Me}$ & $(E)-\mathrm{Ph}$ & $\mathrm{C} \equiv \mathrm{CH}$ & 99 & $100: 0$ & Endo $^{16}$ \\
$\mathrm{Me}$ & $(Z)-\mathrm{Ph}$ & $\mathrm{C} \equiv \mathrm{CPh}$ & 85 & $10: 90$ & Endo $^{16}$ \\
$\mathrm{Me}$ & $(E)-\mathrm{Ph}$ & $\mathrm{COPh}$ & 98 & $17: 83$ & Exo $^{17,34}$ \\
$\mathrm{Me}$ & $(Z)-\mathrm{Ph}$ & $\mathrm{COPh}$ & n.d. & $67: 33$ & Exo $^{34}$ \\
$\mathrm{Me}$ & $(E)-\mathrm{Me}$ & $\mathrm{CO} \mathrm{Me}_{2} \mathrm{Me}$ & 58 & $40: 60$ & Exo $^{39}$ \\
$\mathrm{Et}$ & $(E)-\mathrm{Ph}$ & $\mathrm{PO}(\mathrm{O} i-\mathrm{Pr})_{2}$ & 77 & $0: 100$ & Exo $^{40}$ \\
\hline
\end{tabular}

${ }^{39}$ Coldham, I.; Middleton, M. L.; Taylor, P. L. J. Chem. Soc., Perkin Trans. 1 1997, $2951-$ 2952. 
Although the diastereoselective results obtained from the rearrangements of ammonium ylides are not sufficient to draw reliable conclusions, some trends can be discerned. Acyclic ammonium ylides with an alkynyl moiety as an anionstabilizing group tend to rearrange via an endo-transition state and with high diastereoselectivities $(\mathrm{G}=\mathrm{C} \equiv \mathrm{CR}$, Table 1$)$. When $\mathrm{G}$ is a carbonyl group the selectivities are generally lower and follow an exo-transition state. ${ }^{28}$ This is, in fact, opposite to what is observed for [2,3]-Wittig rearrangements of the corresponding allylic ethers. ${ }^{18}$

In contrast to the acyclic ammonium salts possessing a carbonyl as an anionstabilizing group, 1,2,5,6-tetrahydropyridinium salts $\mathbf{6}$ containing an endocyclic double bond exhibited highly syn-selective rearrangements, affording the ringcontracted pyrrolidines 7 (Scheme 9). Ollis rationalized this selectivity by invoking a second orbital interaction between the anion-stabilizing carbonyl and the olefin, thereby favoring the endo-transition state. ${ }^{34,41,42}$ Why such an interaction is more important for $\mathbf{6}$ than for the acyclic ammonium salts $\mathbf{6}$ was not explained.

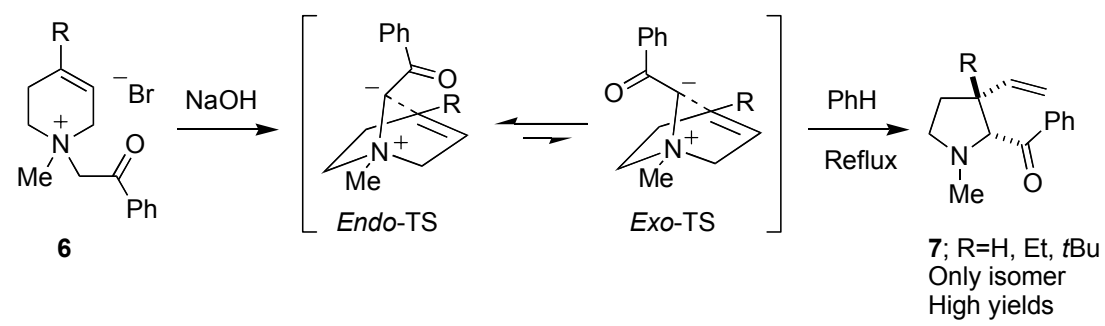

Scheme 9. Highly diastereoselective [2,3]-sigmatropic rearrangement of 1,2,5,6tetrahydropyridinium salts 6.

\subsubsection{Stereochemistry of the newly formed double bond}

The [2,3]-sigmatropic rearrangement generally proceeds with high $(E)$-selectivity at the newly formed carbon-carbon double bond (Scheme 10). The $\mathrm{R}$ group prefers the pseudo-equatorial orientation in the five-membered transition state in order to minimize the $\mathrm{A}^{1,3}$-strain, which leads to an olefin with an $(E)$ -

40 Gulea-Purcarescu, M.; About-Jadet, E.; Collignon, N.; Saquet, M.; Masson, S. Tetrahedron 1996, 52, 2075-2086.

${ }^{41}$ Other [2,3]-sigmatropic rearrangements with a 1,2,5,6-tetrahydropyridine core structure: (a) Burns, B.; Coates, B.; Neeson, S. J.; Stevenson, P. J. Tetrahedron Lett. 1990, 31, 43514354; (b) Sweeney, J. B.; Tavassoli, A.; Carter, N. B.; Hayes, J. F. Tetrahedron 2002, 58, 10113-10126; (c) Roberts, E.; Sancon, J. P.; Sweeney, J. B.; Workman, J. A. Org. Lett. 2003, 5, 4775-4777; (d) Roberts, E.; Sancon, J.; Sweeney, J. B. Org. Lett. 2005, 7, $2075-$ 2078.

${ }^{42}$ A related ring-contracting rearrangement affording piperidines: Neeson, S. J.; Stevenson, P. J. Tetrahedron Lett. 1988, 29, 3993-3996. 
configuration. ${ }^{28,43}$ However, this preference can easily be disturbed by nonbonding interactions or even completely reversed due to sterical hindrance. ${ }^{44}$

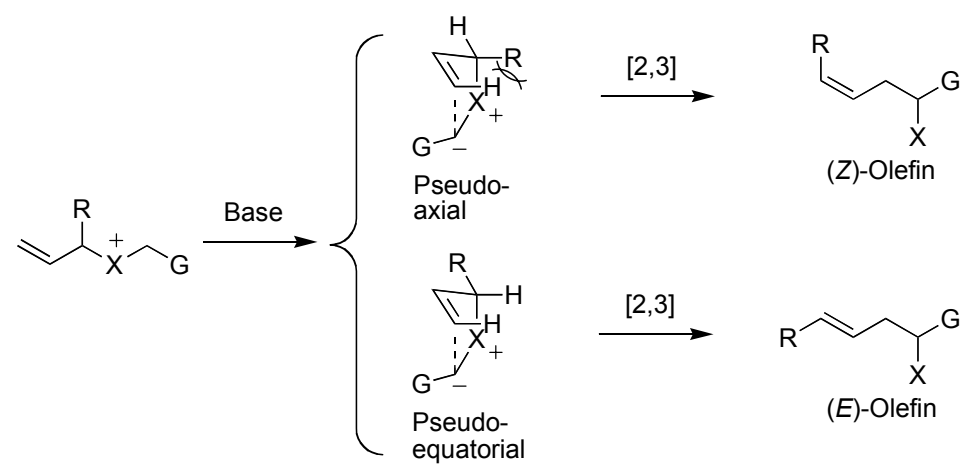

Scheme 10. Pseudo equatorial/axial orientation $\left(X=\mathrm{NR}_{2}\right)$.

Honda et al. presented an interesting rearrangement of various ammonium ylides where the configuration of the formed double bond could be controlled by employing different reaction conditions. ${ }^{44 a}$ Either the $(Z)$ - or $(E)$-homoallylic amines could selectively be obtained from $\mathbf{8}$ by subjecting it to MeI and $\mathrm{NaNH}_{2} / \mathrm{NH}_{3}$ or 4 and $\mathrm{CsF} / \mathrm{HMPA}$, respectively (Scheme 11). Although both rearrangements should proceed via the same ylidic intermediate $\mathbf{9}$, the transition state geometries must differ.

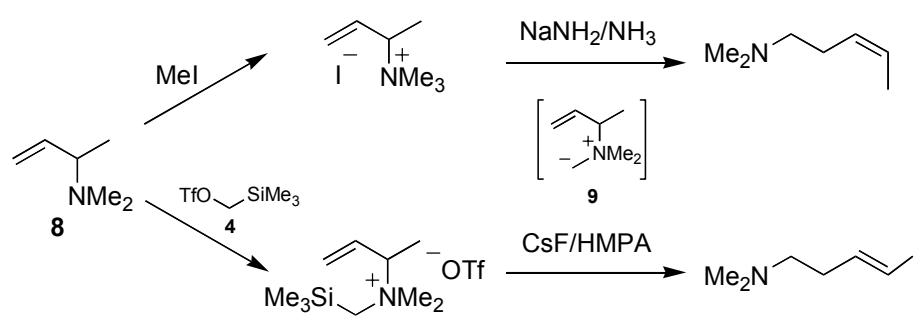

Scheme 11. Controlling the olefin geometry by choice of reaction conditions.

${ }^{43}$ Honda, K.; Inoue, S.; Sato, K. J. Org. Chem. 1992, 57, 428-429.

${ }^{44}$ Some notable (Z)-selective rearrangements: (a) Honda, K.; Inoue, S.; Sato, K. J. Am. Chem. Soc. 1990, 112, 1999-2001; (b) Honda, K.; Igarashi, D.; Asami, M.; Inoue, S. Synlett 1998, 685-687. 


\subsection{Asymmetric [2,3]-sigmatropic rearrangements of ammonium ylides}

There are principally two different methods to induce asymmetry in [2,3]sigmatropic rearrangements. There can either be one or several stereogenic centers embedded in the substrate inducing chirality in the rearrangement (i.e. substrate control) or an external source providing the chiral induction (i.e. reagent control). In both cases the obtained stereoselectivity reflects the energy difference between the diastereomeric transition states (see Scheme 12).

While there are a number of substrate-controlled asymmetric [2,3]-sigmatropic rearrangements of ammonium ylides, no reagent-controlled transformation has been reported..$^{45}$ This may not be surprising, as the nitrogen is quaternary and thereby cannot coordinate to a chiral Lewis acid. Furthermore, chiral bases or solvents have not been explored. ${ }^{46}$

\subsubsection{Asymmetric rearrangement via chirality transfer}

An interesting and valuable type of substrate-controlled rearrangement is a process in which chirality is transferred within the five-membered cyclic transition state (Scheme 12). The original stereogenic center, which resides either on the $\mathrm{C} 1$ carbon or the nitrogen, is destroyed, while two new stereogenic centers can be created at the rearrangement terminus. ${ }^{28}$

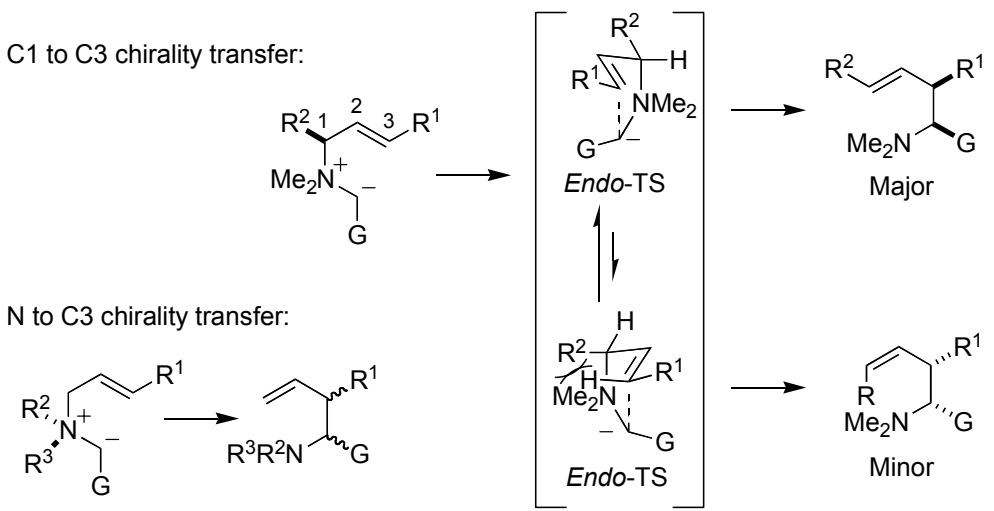

Scheme 12. Chirality transfer from $C 1$ to $C 3$ and $N$ to $C 3\left(R^{2} \neq R^{3}\right)$ in $[2,3]-$ sigmatropic rearrangements of ammonium ylides (only the endo-TS is considered).

\footnotetext{
${ }^{45} \mathrm{~A}$ recent review including asymmetric [2,3]-sigmatropic rearrangements of ylides: Li, A.-H.; L.-X., D.; Aggarwal, V. K. Chem. Rev. 1997, 97, 2341-2372.

${ }^{46}$ An interesting asymmetric [2,3]-sigmatropic rearrangement of a sulfonium ylide was published by Trost et al., in which the chiral induction was provided by a chiral base in chiral solvents: Trost, B. M.; Biddlecom, W. G. J. Org. Chem. 1973, 38, 3438-3439.
} 
Hill nicely demonstrated the efficiency of this process by rearranging ammonium ylide 10 (Scheme 13). The absolute configuration was retained during the rearrangement and gave ketone $\mathbf{1 1}$ in high enantiomeric excess after removal of the amino moiety. ${ }^{47}$

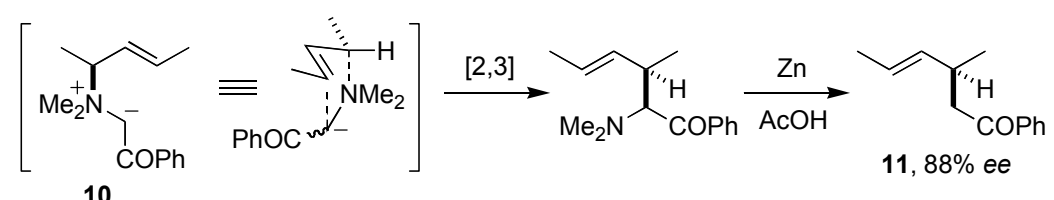

Scheme 13. Chirality transfer in the rearrangement of ammonium ylide $\mathbf{1 0}$.

An important example of chirality transfer was reported by Gawley, who achieved a highly enantioselective rearrangement of the enantiomerically enriched pyrrolidinium salt 12 (Scheme 14). ${ }^{48}$ It was shown that the rearrangement proceeded with $97-100 \%$ inversion of configuration at the lithium bearing carbon atom, which is in agreement with the concerted suprafacial nature of the $[2,3]$-sigmatropic rearrangement. ${ }^{37}$

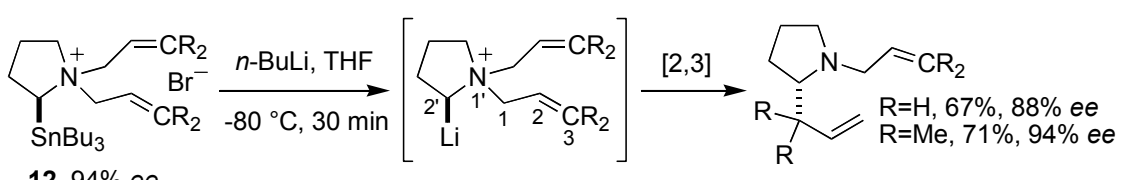

Scheme 14. Inversion of configuration at the lithium bearing carbon atom.

West presented an enantioselective rearrangement of ammonium salt $\mathbf{1 3}$ via chirality transfer from the quaternized stereogenic nitrogen atom to the newly formed carbon stereogenic center (Scheme 15). ${ }^{49,50,51}$ The process involved diastereoselective alkylation of proline derivative 14, subsequent deprotonation, in which the original stereogenic center is destroyed, and rearrangement to restore the carbon stereogenic center with inverted absolute configuration. Since rearrangement can only occur on one side of the pyrrolidine ring, the enantiomeric excess is determined in the alkylation step.

${ }^{47}$ Hill, R. K. In Asymmetric Synthesis; Morrison, J. D., Ed.; Academic Press: New York, 1984; Vol. 3, part B, pp 503-572. A similar type of chirality transfer was recently reported by Aggarwal, see reference 31 .

${ }^{48}$ Gawley, R. E.; Zhang, Q.; Campagna, S. J. Am. Chem. Soc. 1995, 117, 11817-11818.

${ }^{49}$ Glaeske, K. W.; West, F. G. Org. Lett. 1999, 1, 31-33.

${ }^{50}$ Two reports that employ a similar strategy: (a) Hiroi, K.; Nakazawa, K. Chem. Lett. 1980, 1077-1080; (b) Arboré, A. P. A.; Cane-Honeysett, D. J.; Coldham, I.; Middleton, M. L. Synlett 2000, 236-238.

${ }^{51} \mathrm{~A}$ chirality transfer from an optically pure allyl sulfide, in which the chirality resided in the heteroatom, was reported by Trost: Trost, B. M.; Hammen, R. F. J. Am. Chem. Soc. 1973, 95, 962-964. 

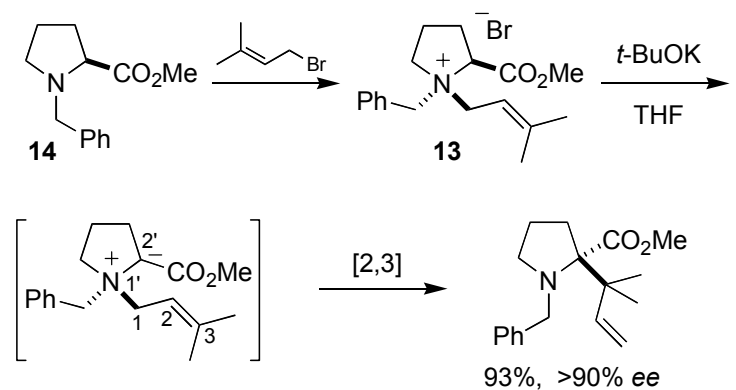

Scheme 15. Asymmetric rearrangement of the proline-derived allylic ammonium salt 13.

A similar type of rearrangement was utilized to synthesize the bicyclic amine 15. They treated a diazo ketone, derived from optically pure prolinol, with $\mathrm{Cu}(\mathrm{acac})_{2}$ to form a spiro-fused bicyclic ammonium ylide in situ (Scheme 16). This ylide subsequently ring-expanded into an eight-membered heterocycle via a $[2,3]$-sigmatropic rearrangement. ${ }^{52,53}$ After reduction of the carbonyl with L-selectride the desired bicyclic amino alcohol was obtained in $>98 \%$ optical purity.

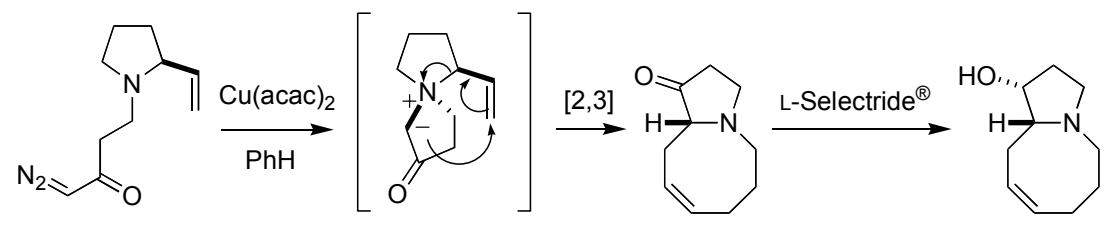

15

Scheme 16. Ring-expansion from a five- to an eight-membered heterocycle via a $[2,3]$-sigmatropic rearrangement.

\subsubsection{Asymmetric rearrangement via induction by remote stereogenic centers}

Kaiser and Baldwin applied a substrate-controlled asymmetric rearrangement to convert 16 into 17 (Scheme 17).54 The achievement was accomplished via quaternization of amine $\mathbf{1 6}$ with allyl bromide and subsequent treatment with $\mathrm{NaH}$, to provide $\mathbf{1 7}$ as the only isomer in $75 \%$ yield. It was reasoned that the obtained stereoselectivity at the newly formed stereogenic center was established by rearrangement via the sterically more accessible $\mathrm{Si}$-face of the enolate.

${ }^{52}$ Clark, J. S.; Hodgson, P. B. Tetrahedron Lett. 1995, 36, 2519-2522.

${ }^{53} \mathrm{~A}$ couple of very interesting ring-expansion reactions via [2,3]-sigmatropic rearrangements of ammonium ylides have been published: (a) Vedejs, E.; Arco, M. J.; Renga, J. M. Tetrahedron Lett. 1978, 523-526; (b) Vedejs, E.; Hagen, J. P.; Roach, B. L.; Spear, K. L. J. Org. Chem. 1978, 43, 1185-1190; (c) Vedejs, E.; Arco, M. J.; Powell, D. W.; Renga, J. M.; Singer, S. P. J. Org. Chem. 1978, 43, 4831-4837; (d) Wright, D. L.; Weekly, R. M.; Groff, R.; McMills, M. C. Tetrahedron Lett. 1996, 37, 2165-2168.

${ }^{54}$ Kaiser, G. V.; Ashbrook, C. W.; Baldwin, J. E. J. Am. Chem. Soc. 1971, 93, 2342-2344. 
<smiles>CNC1C(=O)N2[C@@H](C(=O)OC)C(C)(C)S[C@H]12</smiles><smiles>C=C[C@H](Br)[C@H](C)N</smiles>

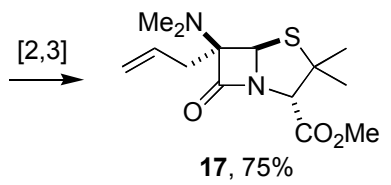

Scheme 17. Conversion of 16 into 17 using a [2,3]-sigmatropic rearrangement.

The most notable asymmetric [2,3]-sigmatropic rearrangement of acyclic ammonium ylides was accomplished by Sweeney and co-workers. They elegantly utilized various $N$-allyl glycine salts bearing a camphorsultam auxiliary to obtain $\alpha$-allylic glycines in high yields and diastereomeric excesses (Table 2). ${ }^{55}$

Table 2. Asymmetric [2,3]-sigmatropic rearrangement of various ammonium ylids.

\begin{tabular}{lllll} 
& & \\
\hline $\mathrm{R}^{1}$ & $\mathrm{R}^{2}$ & Yield & Anti:syn & De \\
\hline $\mathrm{H}$ & $\mathrm{H}$ & 99 & - & $96^{\mathrm{a}}$ \\
$\mathrm{Me}$ & $\mathrm{H}$ & 86 & $>99: 1$ & $92^{\mathrm{b}}$ \\
$\mathrm{Me}$ & $\mathrm{Me}$ & 70 & - & $94^{\mathrm{b}}$ \\
$\mathrm{MeO}_{2} \mathrm{C}$ & $\mathrm{H}$ & 64 & $>99: 1$ & $>98^{\mathrm{b}}$ \\
\hline
\end{tabular}

${ }^{\mathrm{a}} \mathrm{R}_{\mathrm{c}}=(2 R)$-Camphorsultam. ${ }^{\mathrm{b}} \mathrm{R}_{\mathrm{c}}=(2 S)$-Camphorsultam.

\footnotetext{
${ }^{55}$ Workman, J. A.; Garrido, N. P.; Sancon, J.; Roberts, E.; Wessel, H. P.; Sweeney, J. B. J. Am. Chem. Soc. 2005, 127, 1066-1067. A similar example of an asymmetric rearrangement employed a chiral dimenthoxyphosphonyl auxiliary, but afforded a low diasteroselectivity of the rearranged amine: see reference 40 .
} 


\subsection{Aim of the project}

[2,3]-Sigmatropic rearrangements of ammonium ylides proceed in high yields and create new carbon-carbon bonds with good diastereo- and enantioselectivities. As the reaction exhibits interesting and valuable characteristics, it is peculiar that it has received such little attention, especially in total synthesis. One reason might be that the rearrangement product is a tertiary amine and is not amenable for further derivatization unless appropriate protecting groups are employed.

The aim of this project was to develop a different entry to [2,3]-sigmatropic rearrangements of ammonium ylides, in which allylic tertiary amines are complexed to a Lewis acid. The subsequently formed ammonium salt would then be deprotonated to form an ammonium ylide, which is expected to [2,3]-rearrange to yield, after hydrolysis, a homoallylic secondary amine (Scheme 18). The choice of Lewis acid is of special interest, as it most likely influences the stereochemistry and reactivity of the intermediate ylide. As an extension of this study, an asymmetric version of the [2,3]-sigmatropic rearrangement was planned by employing chiral Lewis acids.

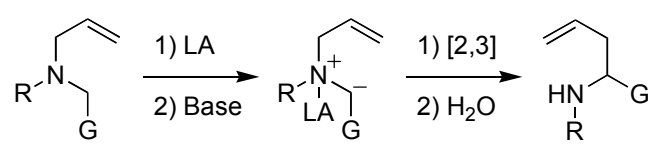

Scheme 18. Quaternization of allylic amines by Lewis acids (LAs) and subsequent [2,3]-sigmatropic rearrangement.

The ultimate goal would be to utilize the developed asymmetric $[2,3]$ sigmatropic rearrangement as a key step in the synthesis of natural products. For instance, (-)-stemoamide could be one such target (Scheme 19). By employment of the appropriate allylic amine in the asymmetric [2,3]-sigmatropic rearrangement, the corresponding homoallylic amine with the correct stereochemistry at two of the stereogenic carbons could be obtained.
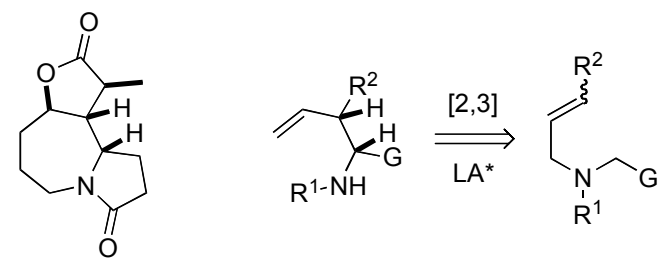

(-)-stemoamide

Scheme 19. The asymmetric [2,3]-sigmatropic rearrangement as a key step in the synthesis of $(-)$-stemoamide $\left(\mathrm{LA}^{*}=\right.$ chiral Lewis acid). 


\section{Lewis acid-mediated [2,3]- sigmatropic rearrangement of allylic ammonium ylides}

(Papers I and II)

\subsection{Background}

In 1990 Nakai realized the first Lewis acid-mediated [2,3]-sigmatropic rearrangement of an ammonium ylide by treating $N$-methyl amino ester 18 with TMSOTf/Et ${ }_{3} \mathrm{~N}$, affording 19 in good yield and with good syn-diastereoselectivity (Scheme 20). ${ }^{56}$

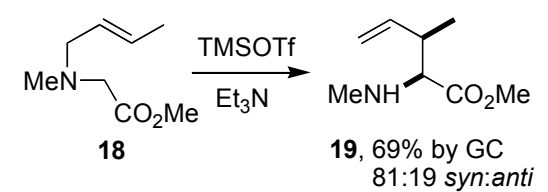

Scheme 20. TMSOTf-mediated [2,3]-sigmatropic rearrangement of $\mathbf{1 8}$.

This was followed up by a similar transformation in 1995 by Kessar, who examined the anionic rearrangement of the complex between $\mathbf{2 0}$ and $\mathrm{BF}_{3} \cdot \mathrm{OEt}_{2}$ (Scheme 21). ${ }^{57}$ This reaction proceeded in good yield, demonstrating that Lewis acids can activate tertiary amines towards [2,3]-sigmatropic rearrangements. Although the regioselectivity was excellent, the diastereoselectivity of the reaction was not reported.

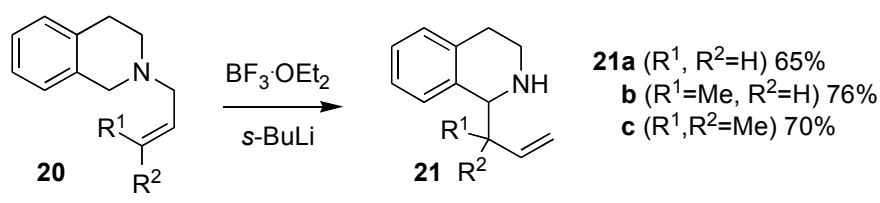

Scheme 21. [2,3]-Sigmatropic rearrangement of $\mathrm{BF}_{3}$-complexed 20.

Recently, Coldham presented a survey of the [2,3]-sigmatropic rearrangement of amines 22 mediated by a number of Lewis acids (Scheme 22). ${ }^{58}$ The efficacy of the Lewis acids in promoting the rearrangement was low, affording poor yields and mediocre diastereoselectivities of the resultant secondary amines. A selection of the results is collected in Scheme 22.

${ }^{56}$ Murata, Y.; Nakai, K. Chem. Lett. 1990, 2069-2072.

${ }^{57}$ Kessar, S. V.; Singh, P.; Kaul, V. K.; Kumar, G. Tetrahedron Lett. 1995, 36, 8481-8484.

${ }^{58}$ Coldham, I.; Middleton, M. L.; Taylor, P. L. J. Chem. Soc., Perkin Trans. 1 1998, 28172821. 


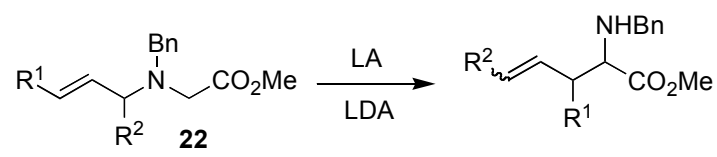

$$
\begin{array}{ll}
\mathrm{R}^{1}=\mathrm{Me}, \mathrm{R}^{2}=\mathrm{H} & \mathrm{LA}=\mathrm{Bu}_{2} \mathrm{BOTf} 22 \%, d r 3: 2 \\
\mathrm{R}^{1}=\mathrm{H}, \mathrm{R}^{2}=\mathrm{H} & \mathrm{Bu}_{2} \text { BOTf } 28 \%, d r 3: 2 \\
\mathrm{R}^{1}=\mathrm{H}, \mathrm{R}^{2}=\mathrm{Me} & \mathrm{Bu}_{2} \text { BOTf } 20-22 \%,(E):(Z) 10: 1
\end{array}
$$

Scheme 22. Lewis acid-mediated [2,3]-sigmatropic rearrangement of ammonium ylides.

In view of these few reported investigations, it is clear that the chemistry involving Lewis acid-mediated [2,3]-sigmatropic rearrangements of ammonium ylides remains unexplored. Although these studies clearly reveal the difficulty in promoting the rearrangement by use of Lewis acids, a more thorough investigation could give some insight into the role of the Lewis acid in the reaction. This in turn could provide information regarding the design of both the substrates and Lewis acids in order to achieve a more reactive and stereoselective [2,3]-sigmatropic rearrangement of ammonium ylides.

This part of the thesis describes an investigation of the role of the Lewis acid in the [2,3]-sigmatropic rearrangement of allylic amines. Initially, the focus was to develop suitable reaction conditions with a defined Lewis acid. Subsequently a range of Lewis acids was screened, and finally the stereoselectivity and scope of the [2,3]-rearrangement were investigated on various allylic amines to verify the suitability of the Lewis acids. The interaction between the Lewis acid and the substrate was also studied by using DFT-calculations and NMR spectroscopy.

\subsection{Screening of Brønsted bases}

Since Lewis acid-mediated [2,3]-sigmatropic rearrangement of allylic $\alpha$-amino esters had earlier been shown to provide low yields (vide infra), the focus was instead turned towards $\alpha$-amino amides. The idea was that amides would produce less stable enolates than esters and thus exhibit higher reactivity towards rearrangement. Consequently, allylic amine 23a was chosen as test substrate for the optimization and was easily prepared through standard transformations. ${ }^{59}$

Before surveying different Brønsted bases, a suitable Lewis acid to form the ammonium salt had to be chosen. $\mathrm{As} \mathrm{BF}_{3} \cdot \mathrm{OEt}_{2}$ is easy to handle and readily forms complexes with amines, it was deemed an appropriate candidate. ${ }^{60}$

The first objective was to promote the [2,3]-sigmatropic rearrangement by deprotonation of the $\mathbf{2 3} \mathbf{a} \cdot \mathrm{BF}_{3}$-complex with strong anionic bases. Hence, 23a was treated with $\mathrm{BF}_{3} \cdot \mathrm{OEt}_{2}$ and subjected to LDA or KHMDS under various conditions. Several approaches were tried and some of the selected results are

${ }^{59}$ For the preparation of 23a, see Supporting Information of Paper II.

${ }^{60}$ (a) Rothgery, E. F.; Hohnstedt, L. F. Inorganic Chemistry 1971, 10, 181-185; (b) Vedejs, E.; Lee, N. J. Am. Chem. Soc. 1995, 117, 891-900; (c) Kessar, S. V.; Singh, P. Chem. Rev. 1997, 97, 721-737. 
presented in Table 3. Unfortunately, no or low yield of the rearranged product 24a was obtained and starting material 23a was recovered in various amounts. ${ }^{61}$ In some cases $N$-allyl benzylamine was formed as a by-product, the reason for which is unclear.

Table 3. Screening of anionic Brønstedt bases. ${ }^{\text {a }}$

\begin{tabular}{|c|c|c|c|c|c|}
\hline & & $3 a$ & 24 & & \\
\hline Entry & $\begin{array}{l}\mathrm{BF}_{3} \cdot \mathrm{OEt}_{2} \\
\text { (equiv.) }\end{array}$ & $\begin{array}{l}\text { Base / } \\
\text { (equiv.) }\end{array}$ & $\begin{array}{l}\mathrm{T}\left({ }^{\circ} \mathrm{C}\right) / \\
\mathrm{t}(\mathrm{h})\end{array}$ & $\begin{array}{l}\text { Yield of } \\
\mathbf{2 4 a} \\
(\%)^{b}\end{array}$ & $\begin{array}{l}\text { Rec. } \\
\text { 23a } \\
(\%)^{b}\end{array}$ \\
\hline 1 & 1.5 & $\mathrm{LDA} / 1.5$ & $-78 \rightarrow \mathrm{rt} / 2.5$ & n.r. ${ }^{c}$ & n.d. \\
\hline 2 & 1.1 & $\mathrm{LDA} / 3.0$ & $\mathrm{rt} / 16$ & n.r..$^{\mathrm{c}}$ & n.d. \\
\hline 3 & 3.0 & KHMDS / 3.0 & $-20 / 23$ & 4 & 42 \\
\hline 4 & 1.2 & KHMDS / 1.2 & $-20 / 20$ & 7 & 60 \\
\hline 5 & 2.8 & KHMDS $/ 2.8^{\mathrm{d}}$ & $-20 / 19.5$ & 4 & 94 \\
\hline 6 & 1.2 & KHMDS $/ 1.2^{\mathrm{e}}$ & $-20 / 20$ & 12 & 63 \\
\hline
\end{tabular}

Both Nakai and Coldham had used non-ionic tertiary amines as bases in their [2,3]-sigmatropic rearrangements (see Chapter 2.1). Coldham actually obtained similar yields with $i$ - $\mathrm{Pr}_{2} \mathrm{NEt}$ as with LDA. ${ }^{58}$ To test if non-ionic bases could increase the conversion of the rearrangement, $i$ - $\mathrm{Pr}_{2} \mathrm{NEt}$ was probed. Treating a mixture of $\mathrm{BF}_{3} \cdot \mathrm{OEt}_{2}$ and $\mathbf{2 3 a}$ with the amine at room temperature did not promote the rearrangement, but at elevated temperature $\left(70{ }^{\circ} \mathrm{C}\right)$ some progress could be detected by TLC. Finally, in refluxing toluene 23a was converted to the rearranged product 24a in 57\% yield together with $15 \%$ recovered starting material (Table 4, entry 1). Based on the assumption that $i$ - $\operatorname{Pr}_{2} \mathrm{NEt}$ was a too weak base to deprotonate the Lewis acid-23a complex at lower temperatures, stronger neutral bases were explored. The Schwesinger phosphazene bases are readily available in various basicities and are easy to handle. Hence, the phosphazene bases 25-27 were chosen (Figure 6). ${ }^{62}$

\footnotetext{
${ }^{61}$ Yields were determined by adding a calibrated standard (phenethyl alcohol) to the crude product. An aliquot was then analyzed on a ZORBAX Rx-Sil $4.6 \mathrm{~mm} * 25 \mathrm{~cm}$ column (hexane: $i-\mathrm{PrOH}$ ).

${ }^{62}$ Schwesinger, R.; Schlemper, H.; Hasenfratz, C.; Willaredt, J.; Dambacher, T.; Breuer, T.; Ottaway, C.; Fletschinger, M.; Boele, J.; Fritz, H.; Putzas, D.; Rotter, H. W.; Bordwell, F. G.; Satish, A. V.; Ji, G. Z.; Peters, E. M.; Peters, K.; von Schnering, H. G.; Walz, L. Liebigs Ann./Recueil 1996, 1055-1081.
} 


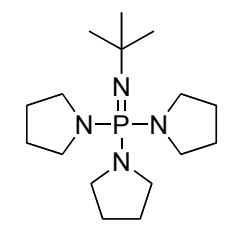

$\operatorname{BTPP}\left(\mathrm{pK}_{\left.\mathrm{BH}^{+}=\sim 26\right)}\right.$

25

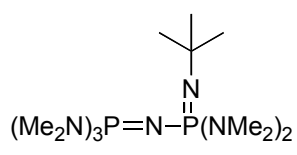

$\mathrm{P}_{2}-\mathrm{t}-\mathrm{Bu}\left(\mathrm{pK}_{\left.\mathrm{BH}^{+}=\sim 33\right)}\right.$

26<smiles>CN=PN(P=NP)[PH](N=PN)(N=PN)NC(C)(C)C</smiles>

$\mathrm{P}_{4}-\mathrm{t}-\mathrm{Bu}\left(\mathrm{pK}_{\left.\mathrm{BH}^{+}=\sim 42\right)}\right.$

27

Figure 6. The Schwesinger phosphazene bases.

A mixture of 23a and $\mathrm{BF}_{3} \cdot \mathrm{OEt}_{2}$ was treated with phosphazene bases 25-27 and a trend could be discerned from the results. Stronger bases increased the yield of 24a (Table 4). The weaker phosphazene bases 25 and 26 gave at $-20{ }^{\circ} \mathrm{C}$ yields around $10 \%$ and at room temperature slightly higher yields of 24a (entries 2-5). Compared to the rearrangement promoted by KHMDS, these bases gave only slightly higher yields at $-20{ }^{\circ} \mathrm{C}$ (compare Table 3 , entry 6). However, the stronger phosphazene base 27 gave a notable increase in yield: $36 \%$ at $-20{ }^{\circ} \mathrm{C}$ and at room temperature $42 \%$ (entries 6 and 7). Although considerable amounts of starting material was still recovered, the rearrangement could be run at lower temperatures than when using $i$ - $\mathrm{Pr}_{2} \mathrm{NEt}$ as a base (entry 1 ).

Table 4. Screening of non-ionic Brønstedt bases. ${ }^{\text {a }}$

\begin{tabular}{|c|c|c|c|c|}
\hline & $23 a$ & & 24 & \\
\hline Entry & Base & $\begin{array}{l}\mathrm{T}\left({ }^{\circ} \mathrm{C}\right) / \\
\mathrm{t}(\mathrm{h})\end{array}$ & $\begin{array}{l}\text { Yield of } \\
\mathbf{2 4 a}(\%)^{b}\end{array}$ & $\begin{array}{l}\text { Rec. 23a } \\
(\%)^{b}\end{array}$ \\
\hline 1 & $i-\mathrm{Pr}_{2} \mathrm{NEt}$ & reflux / 13 & 57 & 15 \\
\hline 2 & 25 & $\mathrm{rt} / 20$ & 24 & 61 \\
\hline 3 & 25 & $-20 / 20$ & 11 & 62 \\
\hline 4 & 26 & $\mathrm{rt} / 19$ & 31 & 68 \\
\hline 5 & 26 & $-20 / 19$ & 12 & 78 \\
\hline 6 & 27 & $\mathrm{rt} / 20$ & 42 & 50 \\
\hline 7 & 27 & $-20 / 20$ & 36 & 64 \\
\hline
\end{tabular}

\subsection{Screening of Lewis acids}

With promising reaction conditions for the rearrangement at hand, a survey involving various Lewis acids was initiated. Different boron trihalides were initially screened to see whether stronger Lewis acids could increase the 
conversion of the rearrangement. Indeed, the stronger boron Lewis acids $\mathrm{BCl}_{3}$ and $\mathrm{BBr}_{3}$ increased the yield, ${ }^{63,64}$ affording $24 \mathrm{a}$ in $46 \%$ and $66 \%$, respectively (Table 5, entries 2 and 3). On the other hand, dibutylboron triflate did not promote the rearrangement and only starting material was recovered (entry 4), probably due to the weaker Lewis acidity compared to the boron trihalides.

Table 5. Screening various Lewis acids. ${ }^{\text {a }}$

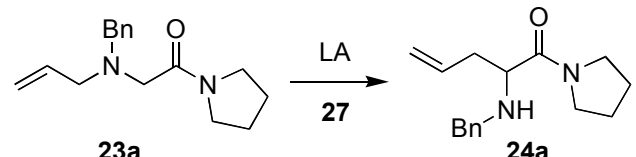

\begin{tabular}{lllll}
\hline Entry & $\begin{array}{l}\text { Lewis acid } \\
\text { (equiv.) }\end{array}$ & $\mathrm{T}\left({ }^{\circ} \mathrm{C}\right)$ & $\begin{array}{l}\text { Yield of } \\
\mathbf{2 4 a}(\%)\end{array}$ & $\begin{array}{l}\text { Rec. 23a } \\
(\%)^{\mathrm{b}}\end{array}$ \\
\hline 1 & $\mathrm{BF}_{3}$ & -20 & 36 & 64 \\
2 & $\mathrm{BCl}_{3}$ & -20 & 46 & 40 \\
3 & $\mathrm{BBr}_{3}$ & -20 & 66 & 22 \\
4 & $\mathrm{Bu}_{2} \mathrm{BOTf}$ & $\mathrm{rt}$ & 0 & 93 \\
5 & $\mathrm{InCl}_{3}$ & $\mathrm{rt}$ & 14 & 63 \\
6 & $\mathrm{ZnCl}_{2}$ & $\mathrm{rt}$ & 23 & 68 \\
7 & $\mathrm{CuCl}_{8}$ & -20 & 0 & 64 \\
8 & $\mathrm{CuCl}_{2}$ & -20 & 0 & 96 \\
9 & $\mathrm{TiCl}_{4}$ & -20 & 0 & 79 \\
10 & ${\mathrm{Yb}(\mathrm{OTf})_{3}}$ & -20 & 0 & 38 \\
11 & $\mathrm{FeCl}_{3}$ & $\mathrm{rt}$ & 0 & 71 \\
12 & $\mathrm{ZrCl}_{2} \mathrm{Cp}$ & $\mathrm{rt}$ & 0 & 75 \\
13 & $\mathrm{ScCl}_{3}$ & $\mathrm{rt}$ & 0 & 77 \\
14 & - & $\mathrm{rt}$ & 0 & 91 \\
\hline
\end{tabular}

${ }^{a}$ Reaction conditions: To 23a (1.0 equiv.) in PhMe was added Lewis acid (1.1-1.3 equiv.) and 27 (1.1 equiv.). The reaction mixture was stirred overnight $(16-20 \mathrm{~h})$ at $-20{ }^{\circ} \mathrm{C}$ or $\mathrm{rt} .{ }^{\mathrm{b}}$ Yields determined by HPLC. Rec. $=$ recovered

Attempts to promote the rearrangement with other Lewis acids were unfortunately unsuccessful. Apart from $\mathrm{InCl}_{3}$ and $\mathrm{ZnCl}_{2}$, which afforded 14 and $23 \%$ yield, respectively (entries 5 and 6), no other investigated Lewis acid promoted the rearrangement (entries 7-13). Interestingly, the low yield of recovered starting material when employing $\mathrm{Yb}(\mathrm{OTf})_{3}$ was due to formation of $N$-allyl benzyl-amine (entry 10). This side reaction had been encountered earlier using $\mathrm{BF}_{3} \cdot \mathrm{OEt}_{2}$ and $\mathrm{KHMDS}$ (Table 3, entries 3-6), but not to this extent.

\footnotetext{
${ }^{63}$ Nöth, H.; Wrackmeyer, B. Nuclear Magnetic Resonance Spectroscopy of Boron Compounds; Springer-Verlag: New York, 1978.

${ }^{64}$ Ishihara, K. In Lewis Acids in Organic Synthesis; Yamamoto, H., Ed.; Wiley-VCH: Weinheim, 2000; Vol. 1, pp. 89-133.
} 
Efforts to promote full conversion by addition of two equivalents of the base 27 or extending the reaction time met with no success. Actually, further experimentation with $\mathrm{BBr}_{3}$ and 27 indicated that the rearrangement probably was finished within an hour, but since the starting material was not fully consumed during that time the reactions were run at least overnight.

By treating 23a with the phosphazene base 27 in the absence of a Lewis acid, it was shown that the base alone could not promote the rearrangement (entry 14).

\subsection{Stereoselectivity of the Lewis acid-mediated rearrangement}

With optimal reaction conditions at hand a series of substrates was prepared to examine the diastereoselectivity of the reaction and the reactivity of different olefin moieties. Hence, the allylic amines 23b-e were synthesized as shown in Scheme $23 .{ }^{65}$

$$
\begin{aligned}
& \text { (c) } \\
& \begin{array}{ll}
\mathrm{K}_{2} \mathrm{CO}_{3}, \mathrm{MeCN}, \mathrm{rt} \\
88-100 \% & \mathrm{R}^{2}
\end{array}
\end{aligned}
$$

Scheme 23. The syntheses of allylic amines 24 .

The (E)- and (Z)-crotyl derivatives 23b and 23c would give valuable stereochemical information about the transition state of the rearrangement. By preparing the $(E)$-cinnamyl olefin 23d, an allyl substituent with different electronic properties than those of $\mathbf{2 3 b}$ and $\mathbf{2 3 c}$ could be evaluated. Finally, the triubstituted olefin 23e would give information about the sensitivity to steric hindrance, as the anionic carbon of the ylide develops a bond with the terminus of the allylic moiety.

Gratifyingly, the di- and trisubstituted olefins 23b-e exhibited similar reactivity as the monosubstituted 23a (Table 6, entries 1-4). Furthermore, both the $(E)$-crotyl amine $\mathbf{2 3 b}$ and $(E)$-cinnamyl amine $\mathbf{2 3 d}$ rearranged with high syndiastereoselectivity, giving syn-24b (71\%, >95:5 syn:anti) and syn-24d (62\%, 92:8 syn:anti), respectively (entries 1 and 3). ${ }^{6}$ Although the exo-transition state seemed to be the least sterically congested, $(E)$-olefins $\mathbf{2 3 b}$ and $\mathbf{2 3 d}$ preferred an

${ }^{65}$ For the experimental details and characterization of $\mathbf{2 3 b}-\mathbf{e}$, see Supporting Information of Paper II.

${ }^{66}$ For the determination of the relative stereochemistry, see chapter 2.5 . 
endo-transition state (Figure 7). Intriguingly, this is the opposite preference compared to the "normal" [2,3]-sigmatropic rearrangement of ammonium ylides (see Chapter 1.4.2). On the other hand, an endo-transition state seemed to be sterically favorable for the $(Z$ )-olefin 23c (Figure 7). It was therefore surprising that $23 \mathbf{c}$ afforded a 55:45 syn:anti mixture of the rearranged product $24 \mathbf{c}(=\mathbf{2 4 b})$ in $56 \%$ yield (entry 2). The sterically demanding trisubstituted olefin $23 \mathbf{e}$ rearranged smoothly, affording $24 \mathrm{e}$ in $60 \%$ yield (entry 4 ).

Table 6. [2,3]-Sigmatropic rearrangement of 23b-e. ${ }^{\text {a }}$

\begin{tabular}{|c|c|c|c|c|c|c|c|}
\hline Entry & Amine & $\mathrm{R}^{1}$ & $\mathrm{R}^{2}$ & $\begin{array}{l}\text { Lewis acid/ } \\
\text { (equiv.) }\end{array}$ & $\begin{array}{l}\text { Yield of } \\
\mathbf{2 4}(\%)^{\mathrm{b}}\end{array}$ & Syn:anti & $\begin{array}{l}\text { Rec. 23a } \\
(\%)^{b}\end{array}$ \\
\hline 1 & $23 b$ & $\mathrm{Me}$ & $\mathrm{H}$ & $\mathrm{BBr}_{3} / 1.1$ & 71 & $>95: 5$ & 20 \\
\hline 2 & $23 c$ & $\mathrm{H}$ & $\mathrm{Me}$ & $\mathrm{BBr}_{3} / 1.1$ & 56 & $55: 45$ & 33 \\
\hline 3 & 23d & $\mathrm{Ph}$ & $\mathrm{H}$ & $\mathrm{BBr}_{3} / 1.1$ & 62 & $92: 8$ & 32 \\
\hline 4 & $23 e$ & $\mathrm{Me}$ & $\mathrm{Me}$ & $\mathrm{BBr}_{3} / 1.1$ & 60 & - & 31 \\
\hline 5 & $23 b$ & $\mathrm{Me}$ & $\mathrm{H}$ & $\mathrm{BF}_{3} / 1.1$ & 14 & $>97: 3$ & 48 \\
\hline 6 & $23 c$ & $\mathrm{H}$ & $\mathrm{Me}$ & $\mathrm{BF}_{3} / 1.1$ & 2 & $75: 25$ & 56 \\
\hline 7 & $23 b$ & $\mathrm{Me}$ & $\mathrm{H}$ & $\mathrm{BF}_{3} / 2.0$ & 55 & $>97: 3$ & 22 \\
\hline 8 & $23 c$ & $\mathrm{H}$ & $\mathrm{Me}$ & $\mathrm{BF}_{3} / 2.0$ & 3 & $67: 33$ & 72 \\
\hline 9 & 23d & $\mathrm{Ph}$ & $\mathrm{H}$ & $\mathrm{BF}_{3} / 2.0$ & 52 & $>97: 3^{\mathrm{d}}$ & 35 \\
\hline 10 & $23 b$ & $\mathrm{Me}$ & $\mathrm{H}$ & $\mathrm{BBr}_{3} / 2.0$ & 78 & $>95: 5$ & 10 \\
\hline 11 & $23 c$ & $\mathrm{H}$ & $\mathrm{Me}$ & $\mathrm{BBr}_{3} / 2.0$ & 49 & $57: 43$ & 22 \\
\hline
\end{tabular}

${ }^{\mathrm{a}}$ Reaction conditions: To an amine (1.0 equiv.) in PhMe was added Lewis acid (1.1 equiv.) and 27 (1.0 equiv.). Stirred overnight $(18-20 \mathrm{~h})$ at $-20{ }^{\circ} \mathrm{C} .{ }^{\mathrm{b}}$ Yields determined by HPLC. Rec. $=$ recovered. ${ }^{\mathrm{c}}$ Ratio determined by ${ }^{1} \mathrm{H}$ NMR, see also chapter 2.5 . ${ }^{\mathrm{d}}$ Only one diastereomer was visible on ${ }^{1} \mathrm{H}$ NMR.

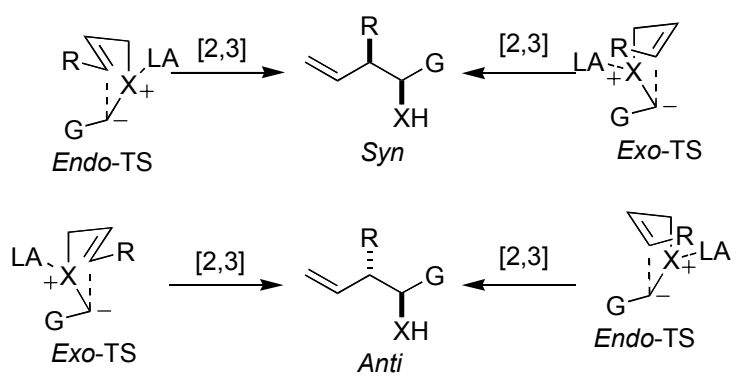

Figure 7. Plausible transition states for the [2,3]-sigmatropic rearrangement $\left(\mathrm{X}=\mathrm{NBn} ; \mathrm{R}=\mathrm{Me}, \mathrm{Ph} ; \mathrm{G}=\mathrm{CON}\left(\mathrm{CH}_{2}\right)_{4}\right)$. The preferred conformation of the Lewis acid is not considered. 
At this point we wanted to compare the observed diastereoselectivities of $\mathbf{2 3 b}$ and 23c from the $\mathrm{BBr}_{3}$-mediated rearrangement with those from the $\mathrm{BF}_{3}$-mediated process. Applying the base 27 to the mixture of $\mathrm{BF}_{3} \cdot \mathrm{OEt}_{2}$ and $\mathbf{2 3} \mathbf{b}$ revealed an even higher syn-selectivity ( $>97: 3$ syn:anti) than when using $\mathrm{BBr}_{3}$ (entry 5 vs. entry 1). As expected from earlier experiments the yield was much lower (see Table 5, entries 1 and 3). When the (Z)-olefin 23c was subjected to $\mathrm{BF}_{3}$ and treated with $\mathbf{2 7 , 2 4 c}$ was obtained in poor yield (entry 6).

During this investigation, the amines $\mathbf{2 3 b}, \mathbf{2 3 c}$ and 23d were subjected to 1.1 equivalents of $\mathrm{BF}_{3} \cdot \mathrm{OEt}_{2}$ or $\mathrm{BBr}_{3}$. Since the allylic amines 23 have two Lewis basic sites (the amine nitrogen atom and the carbonyl oxygen atom) it is plausible that both have to be coordinated to the Lewis acid for the rearrangement to proceed, thus explaining the low yield obtained when with 1.1 equivalents of $\mathrm{BF}_{3} \cdot \mathrm{OEt}_{2}$. Consequently, the rearrangements were repeated with two equivalents of $\mathrm{BF}_{3} \cdot \mathrm{OEt}_{2}$. Rather unexpectedly, the yield increased from $14 \%$ to $55 \%$ for the $(E)$-olefin $\mathbf{2 3 b}$ and at the same time maintaining the excellent diastereoselectivity (entry 7). In contrast, even with two equivalents of $\mathrm{BF}_{3} \cdot \mathrm{OEt}_{2}$ the $(Z)$-olefin $23 \mathbf{c}$ was still found to be unreactive towards rearrangement (entry $8)$. The $(E)$-cinnamyl amine $\mathbf{2 3 d}$ rearranged to give $s y n-\mathbf{2 4 d}$ in $52 \%$ yield as the only detectable diastereomer (entry 9). The $\mathrm{BBr}_{3}$-mediated rearrangement, on the other hand, was unaffected when the amount of Lewis acid was increased (entries 10 and 11).

All the results clearly show that the $\mathrm{BBr}_{3}$ and $\mathrm{BF}_{3}$-mediated rearrangements proceed via a $[2,3]$-sigmatropic path, as no products arising from the competing radical $[1,2]$ or concerted [3,3]-sigmatropic rearrangements were found (Scheme 24).

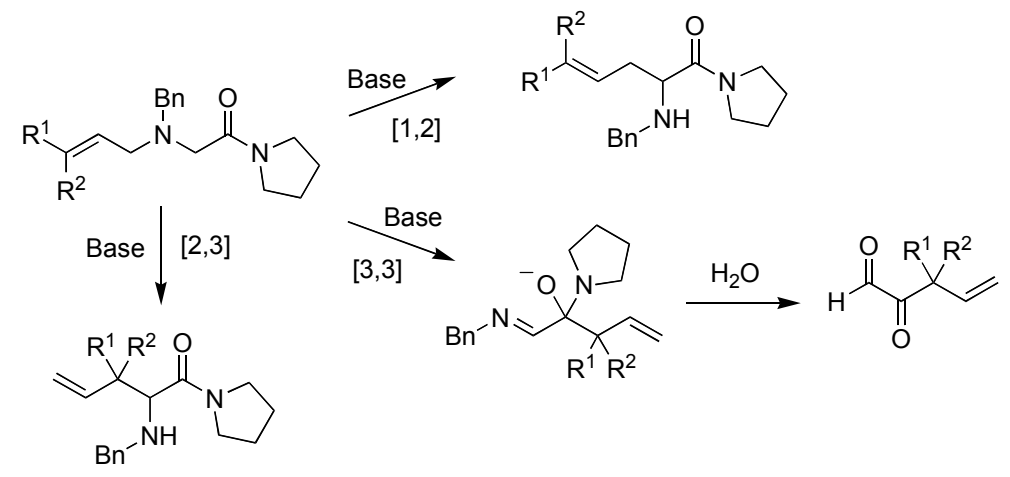

Scheme 24. Possible competing [1,2] and [3,3]-sigmatropic rearrangements.

To further extend the scope of the reaction, we wanted to investigate whether substrates with alternative anion-stabilizing groups could participate in the $\mathrm{BBr}_{3}$-mediated rearrangement. The propargylic amine $\mathbf{2 8}$ and the aminoester $\mathbf{2 9}$ were thus prepared through standard transformations and subjected to the optimal rearrangement conditions (Figure 8) ${ }^{67}$ Unfortunately, the propargylic

${ }^{67}$ For the preparation of $\mathbf{2 8}$ and $\mathbf{2 9}$, see Supporting Information of Paper II. 
amine 28 was unreactive and gave only recovered starting material, while the glycine derivative $\mathbf{2 9}$ probably hydrolyzed during work-up to the corresponding acid, since only small amounts of starting material could be recovered. Although an amino acid-Lewis acid complex probably formed (compare with Figure 10, page 28), no corresponding rearranged product could be isolated.

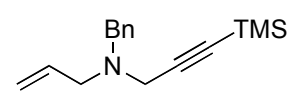

28

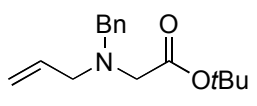

29

Figure 8. Allylic amines with various anion-stabilizing groups.

\subsection{Determination of the relative stereochemistry of $\mathbf{2 4}$}

To determine the relative stereochemistry (syn/anti) of the rearranged compounds $\mathbf{2 4}, \mathrm{a} \mathrm{Hg}^{2+}$-mediated cyclization to the corresponding pyrrolidines $\mathbf{3 0}$ was envisioned (Scheme 25). ${ }^{68}$ Hence, $s y n-\mathbf{2 4} \mathbf{b}$ and anti-24c were treated with $\mathrm{Hg}\left(\mathrm{CF}_{3} \mathrm{CO}_{2}\right)_{2}$ in refluxing THF and subsequently demercurized by $\mathrm{NaBH}_{4}$ affording the pyrrolidines 30a and 30b in modest yields. Application of the same cyclization conditions to the secondary amine syn-24d did not work as efficiently. Apart from $49 \%$ of recovered starting material, a mixture of two products was obtained. Although they have not yet been fully characterized, 2D NOESY as well as 2D COSY indicated the two compounds 30c and 31. The hydroxyl group in compound $\mathbf{3 1}$ was probably incorporated via a radical entrapment of oxygen during the reduction of the formed intermediate alkylmercury salt. ${ }^{69}$ Interestingly, only one diastereomer of compound $\mathbf{3 1}$ was formed.

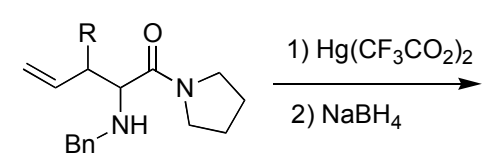

$$
\text { syn-24b }(\mathrm{R}=\mathrm{Me})
$$
anti-24c $(\mathrm{R}=\mathrm{Me})$
syn-24d $(\mathrm{R}=\mathrm{Ph})$

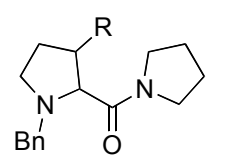

$30 \mathrm{a}(\mathrm{R}=s y n-\mathrm{Me}) ; 60 \%$ 30b (R=anti-Me); $40 \%$ 30c $(\mathrm{R}=$ syn- $\mathrm{Ph}) ; 10 \%$

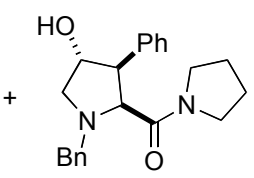

$31 ; 23 \%$

Scheme 25. $\mathrm{Hg}^{2+}$-mediated cyclization of the secondary amines 24 .

The relative stereochemistry of syn-24b and anti-24c could be determined by the NOE enhancement between the two methine protons in the corresponding pyrrolidines 30 (Figure 9). Likewise, the stereochemistry of syn-24d was determined by measuring the NOE enhancements in the pyrrolidine $\mathbf{3 1}$.

\footnotetext{
${ }^{68}$ Wilson, S. R.; Sawicki, R. A. J. Org. Chem. 1979, 44, 287-291.

${ }^{69}$ Giese, B. Radicals in Organic Synthesis: Formation of Carbon-Carbon Bonds; Pergamon: Oxford, 1986.
} 


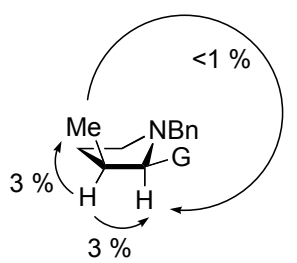

$30 a$

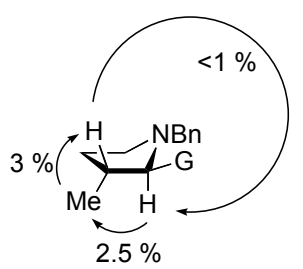

$30 \mathrm{~b}$

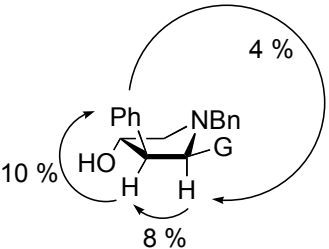

31

Figure 9. NOE enhancement measurements of amines 30a, 30b and 31. Mixing times were $700(\mathrm{~T} 1=1.1 \mathrm{~s}), 600(\mathrm{~T} 1=0.9 \mathrm{~s})$ and $1250 \mathrm{~ms}(\mathrm{~T} 1=1.9 \mathrm{~s})$ for $\mathbf{3 0 a}, \mathbf{3 0 b}$ and 31, respectively. $\mathrm{G}=\mathrm{CON}\left(\mathrm{CH}_{2}\right)_{4}$.

\subsection{Proposed mechanism of the rearrangement}

To be able to explain the observed diastereoselectivities and experimental results described in Chapter 2.4, a better understanding of the reaction mechanism and the structure of the Lewis acid complex has to be acquired. Of special interest is the role of the Lewis acid in promoting the rearrangement, since it could facilitate the design of more reactive Lewis acids and chiral auxiliaries.

\subsubsection{Density functional calculations}

From the results in Table 6, it seemed that $\mathrm{BBr}_{3}$ and $\mathrm{BF}_{3}$ behaved differently during the rearrangement. While one equivalent $\mathrm{BBr}_{3}$ was enough to promote the rearrangement, one equivalent $\mathrm{BF}_{3}$ gave poor conversion. With two equivalents of $\mathrm{BF}_{3}$ the yield was increased to a level near that of the $\mathrm{BBr}_{3}$-promoted rearrangement. As an initial hypothesis, two different coordination modes were investigated. First, the coordination of one $\mathrm{BX}_{3}$ to the deprotonated $\alpha$-amino amide, and secondly the coordination of one $\mathrm{BX}_{3}$ to the carbonyl oxygen and one to the tertiary amine (Table 7).<smiles>CC=CCN(C)CC(=O)N(C)C</smiles>

To reduce the number of possible conformations, we used the model system 32, where a methyl group replaced the $\mathrm{N}$-benzyl group of substrate $\mathbf{2 3}$ and the pyrrolidine was replaced by a dimetylamine. All geometry optimizations together with final gas phase energy determinations were performed using the B3LYP ${ }^{70}$ hybrid density functional theory. ${ }^{71}$

${ }^{70}$ (a) Becke, A. D. J. Chem. Phys. 1993, 98, 5648; (b) Lee, C.; Yang, W.; Parr, R. G. Phys. Rev. B 1988, 37, 785 .

${ }^{71}$ For references of the different basis-sets used, see Paper II. 
Table 7. Activation free energies $\left(\mathrm{kcal} \mathrm{mol}^{-1}\right)$ for the anionic reaction paths $(\mathrm{X}=\mathrm{F}$ or $\mathrm{Br})$.

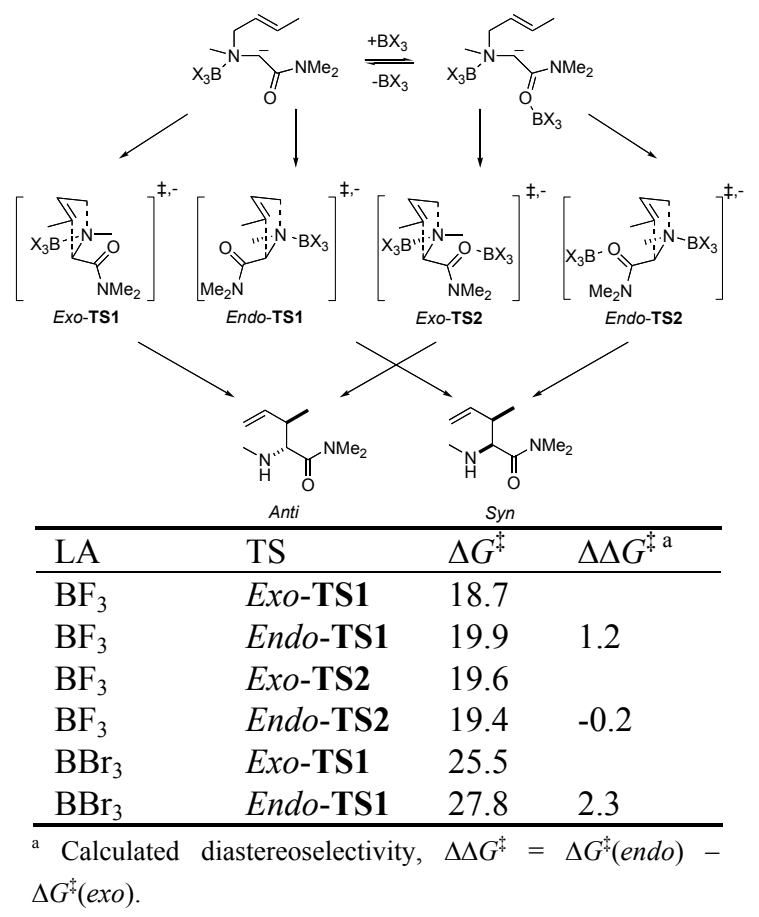

The results given showed reasonable activation energies for the $\mathrm{BF}_{3}$-promoted rearrangement but the calculated diastereoselectivities were not in accordance with the experimental result (Table 7). In the case of the $\mathrm{BBr}_{3}$-promoted reaction, the calculated activation energies were well above the barriers suggested by the time of the experimental reaction. Again, the predicted diastereoselectivity was not in accordance with the experimental result. The high activation energy in case of $\mathrm{BBr}_{3}$ is due to a very strong coordination of this Lewis acid to the amide oxygen. Calculations showed that also $\mathrm{BF}_{3}$ preferentially coordinated to the amide oxygen after deprotonation.

At this point, alternative reaction mechanisms were explored. It has previously been established that boron Lewis acids, such as $\mathrm{ArBF}_{2}$ and $\mathrm{BF}_{3}$, can form cyclic complexes with $N, N$-dialkyl amino acids by displacing a fluoride ion (Figure 10). ${ }^{72,73}$ It was assumed that similar cyclic boron complexes could be formed between $\mathrm{BF}_{3}$ or $\mathrm{BBr}_{3}$ and substrate 23a.

\footnotetext{
${ }^{72}$ Halstrøm, J.; Nebelin, E.; Pedersen, E. J. J. Chem. Res. 1978, 80-81.

${ }^{73}$ Vedejs, E.; Fields, S. C.; Lin, S.; Schrimpf, M. R. J. Org. Chem. 1995, 60, 3028-3034.
} 

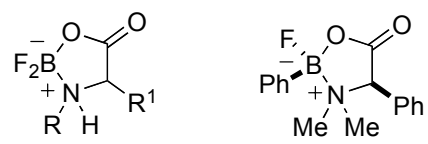

Figure 10. Boron-amino acid complexes.

The energies of the reaction when one halide in $\mathrm{BX}_{3}$ is displaced by the bidentate substrate were first investigated. Forming the bidentate complex $\mathbf{3 3}$ by displacing one fluoride ion from $\mathrm{BF}_{3}$ was shown to be endergonic by $12.4 \mathrm{kcal}$ $\mathrm{mol}^{-1}$ (Figure 11). If one additional $\mathrm{BF}_{3}$ was used to take care of the relieved fluoride ion to form the complex 34, the reaction instead became exergonic by $14.9 \mathrm{kcal} \mathrm{mol}^{-1}$. This mode of action fits well with the experimental observations (Table 6, compare entries 5 and 7). Analogous displacement of one bromide ion from $\mathrm{BBr}_{3}$ to form 35 was favorable by $-13.7 \mathrm{kcal} \mathrm{mol}^{-1}$ in free energy and introduction of an additional $\mathrm{BBr}_{3}$ decreased the free energy to $-32.6 \mathrm{kcal} \mathrm{mol}^{-1}$. To conclude, two equivalents of $\mathrm{BF}_{3}$ were needed to form the complex 34, whereas probably only one equivalent of $\mathrm{BBr}_{3}$ was needed to form $\mathbf{3 5}$. Both conclusions were in agreement with the experimental results (see section 2.4).

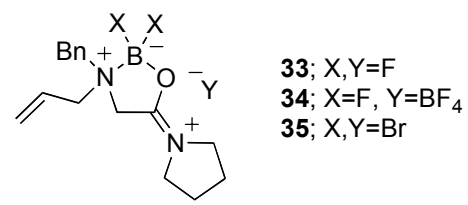

Figure 11. Cyclic boron complexes.

With these conclusions at hand, calculations were undertaken to predict the transition states of the deprotonated complexes of $\mathbf{3 4}$ and $\mathbf{3 5}$. Figure 12 shows the two possible diastereomeric transition states possible for the $\mathrm{BF}_{2}^{+}$-mediated $[2,3]$-sigmatropic rearrangement. The calculated activation energies for both $\mathrm{BX}_{2}{ }^{+}$-mediated rearrangements were well within the acceptable rates of reaction (Table 8). Although the calculations correctly estimated the diastereoselectivities, no apparent conformational rationale for the selectivity was revealed by the transition state structures shown in Figure 12. 

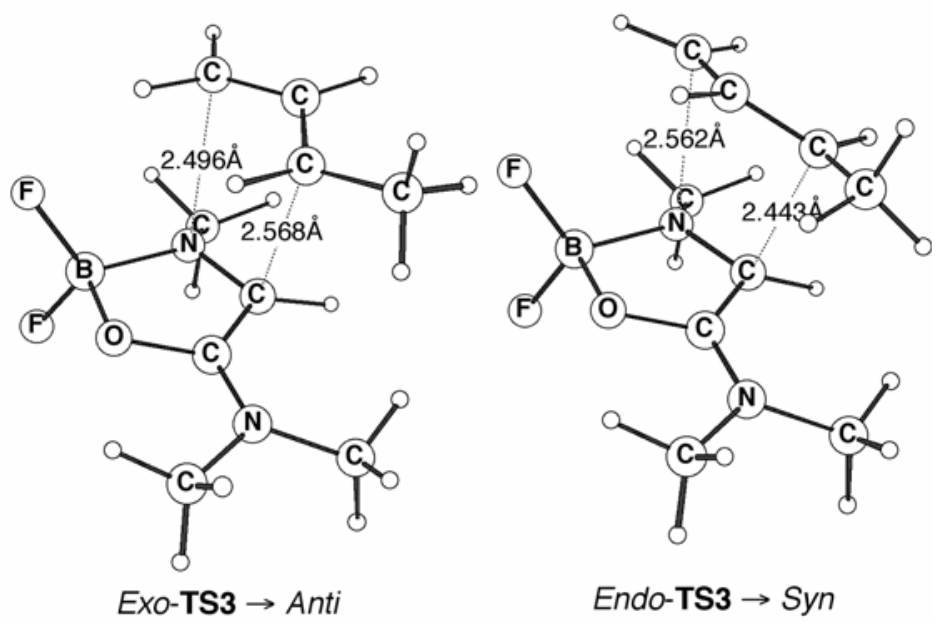

Figure 12. Diastereomeric transition states for the neutral $\mathrm{BF}_{2}{ }^{+}$-mediated $[2,3]$ sigmatropic rearrangement of the model amine.

Table 8. Activation free energies $\left(\mathrm{kcal} \mathrm{mol}^{-1}\right.$ ) for the neutral mechanism with the model amine (Figure 12).

\begin{tabular}{llllll}
\hline $\mathrm{LA}$ & Substrate & TS & $\Delta G^{\ddagger}$ & $\Delta \Delta G^{\sharp \mathrm{a}}$ & $\Delta \Delta G^{\sharp}(\mathrm{exp})^{\mathrm{b}}$ \\
\hline $\mathrm{BF}_{2}{ }^{+}$ & $(E)-\mathbf{3 2}$ & Exo-TS3 & 22.3 & & \\
& $(E)-\mathbf{3 2}$ & Endo-TS3 & 21.0 & -1.3 & $<-1.7$ \\
$\mathrm{BBr}_{2}{ }^{+}$ & $(E)-\mathbf{3 2}$ & Exo-TS3 & 17.4 & & \\
& $(E)-32$ & Endo-TS3 & 15.8 & -1.6 & $<-1.5$ \\
$\mathrm{BBr}_{2}^{+}$ & $(Z)-32$ & Exo-TS3 & 17.2 & & \\
& $(Z)-32$ & Endo-TS3 & 17.4 & 0.2 & $\approx-0.1$ \\
\hline
\end{tabular}

${ }^{a}$ Calculated diastereoselectivity, $\Delta \Delta G^{\ddagger}=\Delta G^{\ddagger}($ endo $)-\Delta G^{\ddagger}($ exo $) .{ }^{\mathrm{b}}$ Calculated from the experimentally determined diastereomeric ratio.

Houk has made calculations on the [2,3]-Wittig rearrangement of allylic ethers with a formyl group as an anion-stabilizing group. ${ }^{37,74}$ He explained the calculated and experimentally substantiated endo preference by an electrostatic interaction between the negatively charged allylic $\mathrm{C} 2$-carbon and the positively charged formyl group (good $\pi$-acceptor). The calculations provided by us suggested that this could also be the case in our system.

During the development of the asymmetric rearrangement described in the following chapter, five additional allylic amines were synthesized, providing a total of four different $(E) /(Z)$-olefinic pairs. Although some of the corresponding rearranged amines were not isolated, the diastereoselectivities of the rearranged olefinic pairs were readily available from ${ }^{1} \mathrm{H}$ NMR. From the collected diastereoselectivities an endo preference was revealed (Table 9), rationalized by

${ }^{74}$ Wu, Y.-D.; Houk, K. N.; Marshall, J. A. J. Org. Chem. 1990, 55, 1421-1423. 
electrostatic interactions between the allylic moiety and the five-membered oxazaborocycle in analogy with the interactions described by Houk. The only exceptions were the $(E)$-silyl olefin, which could be explained by non-bonding interactions in the endo-transition state, and the $(Z)$-methyl olefin, which gave virtually no diastereoselectivity. No explanation for the low selectivity in the rearrangement of the $(Z)$-methyl olefin could be provided, in fact, with the present transition state model the electrostatic interaction and the sterically preferential position of the methyl group should give a very selective rearrangement (Scheme 26). According to the transition state model, the $(Z)$ olefins should provide better diastereoselectivities than the $(E)$-olefins, but the latter olefins seemed generally to afford somewhat higher diastereoselectivities. Evidently there must be additional rationalizations of the observed diastereoselectivities.

Table 9. Diasteroselectivities of the $\mathrm{BBr}_{3}$-mediated rearrangement

\begin{tabular}{|c|c|c|c|c|c|}
\hline $\mathrm{R}$ & Syn:anti & $\mathrm{TS}$ & $\mathrm{R}$ & Syn:antib & $\mathrm{TS}$ \\
\hline$(E)-\mathrm{Me}^{\mathrm{d}}$ & $>95: 5$ & endo & $(Z)-\mathrm{Me}^{\mathrm{d}}$ & $55: 45$ & - \\
\hline$(E)-\mathrm{Ph}^{\mathrm{d}}$ & $92: 8$ & endo & $(Z)-\mathrm{Ph}^{\mathrm{e}}$ & $25: 75$ & endo \\
\hline$(E)-\mathrm{CH}_{2} \mathrm{OBn}^{\mathrm{e}}$ & $95: 5^{\mathrm{f}}$ & endo & $(Z)-\mathrm{CH}_{2} \mathrm{OBn}^{\mathrm{e}}$ & $14: 86^{\mathrm{f}}$ & endo \\
\hline$(E)-\mathrm{SiMe}_{2} \mathrm{Ph}^{\mathrm{e}}$ & $7: 83$ & exo & (Z)- $\mathrm{SiMe}_{2} \mathrm{Ph}^{\mathrm{e}}$ & $6: 94^{g}$ & endo \\
\hline
\end{tabular}

${ }^{a}$ Reaction conditions: To 23 (1.0 equiv.) in $\mathrm{PhMe}_{\text {or }} \mathrm{CH}_{2} \mathrm{Cl}_{2}$ was added $\mathrm{BBr}_{3}$ (1.1 equiv.) and 27 (1.0 equiv.) or $\mathrm{Et}_{3} \mathrm{~N}$ (5.0 equiv.). Stirred overnight $\left(18-20 \mathrm{~h}\right.$ ) at $-20{ }^{\circ} \mathrm{C}$. ${ }^{\mathrm{b}}$ Ratio determined by ${ }^{1} \mathrm{H}$ NMR. ${ }^{\mathrm{d}} \mathrm{PhMe}$ and 27. ${ }^{\mathrm{e}} \mathrm{CH}_{2} \mathrm{Cl}_{2}$ and $\mathrm{Et}_{3} \mathrm{~N}$. ${ }^{\mathrm{f}}$ Approximately $25 \%$ of the rearranged product was deprotected to the corresponding alcohol according to ${ }^{1} \mathrm{H}$ NMR. ${ }^{\mathrm{g}}$ Approximately $25 \%$ of the starting material was converted to the corresponding [1,2]-rearranged product according to ${ }^{1} \mathrm{H} \mathrm{NMR}$, see Chapter 3.5. 


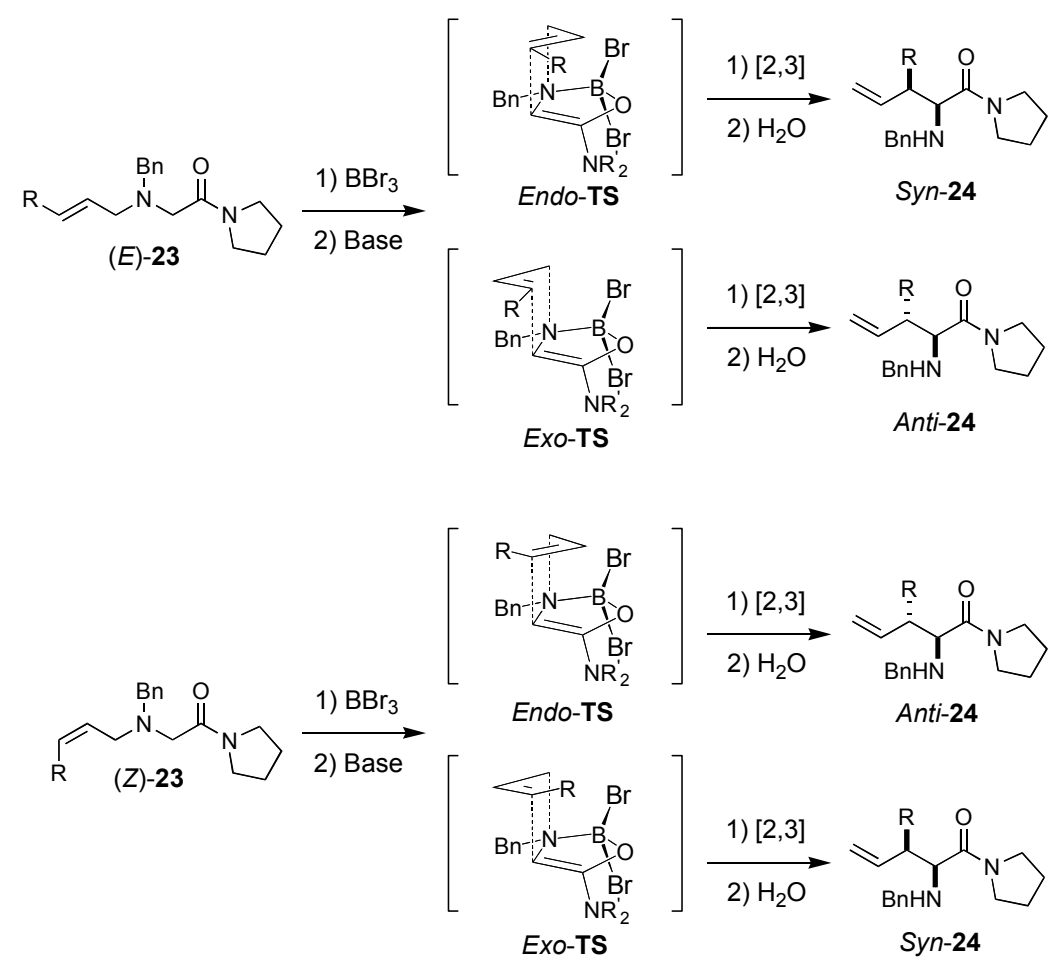

Scheme 26. Possible transition states for the $\mathrm{BBr}_{3}$-mediated [2,3]-sigmatropic rearrangement of $(E)$ - and $(Z)-23\left(\mathrm{R}^{\prime}=\mathrm{N}\left(\mathrm{CH}_{2}\right)_{4}\right)$.

To conclude, both experimental results and DFT calculations predict $(E)$-olefins to preferentially rearrange via an endo-transition state, though this preference can be reversed by steric interaction. The isomeric ( $Z$ )-olefins displayed somewhat lower diastereoselectivities. The reason for this behavior could not be explained.

\subsubsection{NMR-investigation of the Lewis acid complex 34 and $\mathbf{3 5}$}

To determine the structures of the proposed Lewis acid complexes $\mathbf{3 4}$ and $\mathbf{3 5}$, an NMR investigation was conducted. Similar complexes had been investigated by ${ }^{11} \mathrm{~B}$ and ${ }^{19} \mathrm{~F}$ NMR and it seemed reasonable that they should exhibit comparable spectroscopic properties as complexes $\mathbf{3 4}$ and 35 (compare Figure 10 and 11). ${ }^{72,73}$ Together with ${ }^{1} \mathrm{H}$ and ${ }^{13} \mathrm{C} \mathrm{NMR}$, adequate spectroscopic information to characterize the complexes should be provided.

Consequently, addition of one equivalent of $\mathrm{BF}_{3} \cdot \mathrm{OEt}_{2}$ to $23 \mathbf{a}$ afforded, according to ${ }^{1} \mathrm{H} \mathrm{NMR}$, an approximately 3:2 mixture of 23a and the anticipated complex 34 (see Appendix B). A second equivalent of $\mathrm{BF}_{3}$ transformed the remaining 23a into a single complexed species. These observations were in agreement with the DFT-calculations.

Examination of the ${ }^{11} \mathrm{~B}$ NMR spectrum of complex 34 revealed one triplet at 
$4.9 \mathrm{ppm}\left({ }^{1} J_{\mathrm{B}, \mathrm{F}}=15 \mathrm{~Hz}\right)$ and one singlet at $-0.7 \mathrm{ppm} \cdot{ }^{75}$ The triplet signal indicated a boron atom with two fluorine substituents and $\mathrm{a}^{11} \mathrm{~B}$ chemical shift that was in good agreement with those of related compounds. ${ }^{72,73}$ Evidently, half of the $\mathrm{BF}_{3}$ took care of the displaced fluoride ions and formed $\mathrm{BF}_{4}^{-}$, which corresponded to the ${ }^{11} \mathrm{~B}$ signal at $-0.7 \mathrm{ppm} .{ }^{63,76}$ Furthermore, ${ }^{19} \mathrm{~F}$ NMR supported structure 34 giving two multiplet signals at -85.7 and $-88.5 \mathrm{ppm},{ }^{77}$ corresponding to the diastereotopic fluorine atoms and a singlet at $-88.6 \mathrm{ppm}$ from the $\mathrm{BF}_{4}{ }^{-}$anion. ${ }^{78}$

When equimolar amounts of $\mathrm{BBr}_{3}$ and $\mathbf{2 3 a}$ were mixed, ${ }^{1} \mathrm{H}$ NMR revealed the formation of two distinct complexes in a 5:2 ratio. When the relative amount of $\mathrm{BBr}_{3}$ was stepwise increased, the ratio of the two complexes changed to $5: 1$ (2 equiv.) and 8:1 (3 equiv.) (see Appendix B). The appearance of the two complexes on ${ }^{1} \mathrm{H}$ NMR changed on going from one to two equivalents of $\mathrm{BBr}_{3}$, but was unchanged with a further increase to three equivalents

Examination of the ${ }^{11} \mathrm{~B}$ NMR spectrum revealed one major peak at $5.7 \mathrm{ppm}$ on going from one to three equivalents of $\mathrm{BBr}_{3}$. At one equivalent of $\mathrm{BBr}_{3}$ the major peak was accompanied by an additional signal at $-24.3 \mathrm{ppm}$. Actually, this chemical shift fits well with the $\mathrm{BBr}_{4}{ }^{-}$anion. ${ }^{63}$ Addition of an additional equivalent of $\mathrm{BBr}_{3}$ made the signal at -24.3 ppm disappear and instead a very small peak at $-11.8 \mathrm{ppm}$ together with a broad signal at $-21.4 \mathrm{ppm}$ emerged.

By comparing the ${ }^{11} \mathrm{~B}$ chemical shift of $5.7 \mathrm{ppm}$ with the chemical shift of the $\mathrm{BF}_{2}^{+}$-complex 34 and looking at the matching appearance of the ${ }^{1} \mathrm{H}$ NMR spectra, the major species was suggested to be the complex 35. The remaining ${ }^{11} \mathrm{~B}$ peaks could not be elucidated and the structure of the minor complex could not be unravelled. The ratio of the major and minor complex at 1 equivalent of $\mathrm{BBr}_{3}(5: 2)$ was similar to the ratio between the rearranged product 24a and starting material 23a (3:1, Table 5, entry 3$)$, suggesting that the minor complex perhaps does not participate in the rearrangement. That no rearrangement had occurred during or after complexation was confirmed by COSY as well as ${ }^{13} \mathrm{C}$ DEPT.

If the amine 23a had been quaternized by $\mathrm{BBr}_{3}$ to form the anticipated rigid complex 35, the benzyl and allyl moieties would be on different sides of the molecular plane and, therefore, be closer in space to either of the methylene protons $\mathrm{H}^{1}$ or $\mathrm{H}^{2}$ (Table 10). This fact was unambiguously proven by NOESY, as can be gathered from the important NOE interactions in Table 10. Furthermore, the two methylene protons $\mathrm{H}^{6}$ and $\mathrm{H}^{7}$ on the pyrrolidine ring displayed similar NOE interactions as the benzyl and allyl moieties, further substantiating the proposed structure and the rigidity of complex 35 (entries 4-7). Similar NOE interactions could be found when examining complex $\mathbf{3 4}$.

${ }^{75}{ }^{11} \mathrm{~B}$ chemical shifts were referenced to $\mathrm{BF}_{3} \cdot \mathrm{OEt}_{2}$ (as external standard).

$76{ }^{1} \mathrm{~J}_{\mathrm{B}, \mathrm{F}}=\sim 1 \mathrm{~Hz}$ gives an apparent singlet.

${ }^{77}{ }^{19} \mathrm{~F}$ chemical shifts were referenced to $\mathrm{CF}_{3} \mathrm{C}_{6} \mathrm{H}_{5}$ (as external standard).

${ }^{78}$ (a) Harris, R. K.; Mann, B. E. NMR and the Periodic Table; Academic Press: London, 1978; (b) Vedejs, E.; Chapman, R. W.; Fields, S. C.; Lin, S.; Schrimpf, M. R. J. Org. Chem. 1995, 60, 3020-3027. 
Table 10. Important NOE enhancement measurements of complex 35.

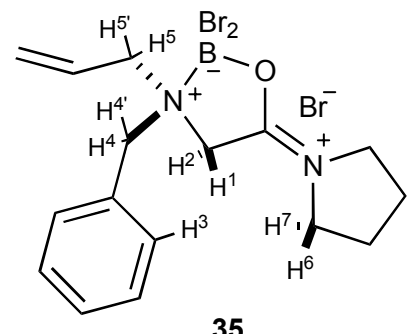

\begin{tabular}{lll}
\hline Entry & $\begin{array}{l}\text { NOE } \\
\text { interaction }\end{array}$ & $\begin{array}{l}\text { NOE } \\
\text { enhancement }\end{array}$ \\
\hline 1 & $\mathrm{H}^{1} \rightarrow \mathrm{H}^{3}$ & $6 \%$ \\
2 & $\mathrm{H}^{1} \rightarrow \mathrm{H}^{4}$ & $5 \%$ \\
3 & $\mathrm{H}^{5} \rightarrow \mathrm{H}^{2}$ & $6 \%$ \\
4 & $\mathrm{H}^{6} \rightarrow \mathrm{H}^{1}$ & $4 \%$ \\
5 & $\mathrm{H}^{6} \rightarrow \mathrm{H}^{2}$ & $<1 \%$ \\
6 & $\mathrm{H}^{7} \rightarrow \mathrm{H}^{2}$ & $5 \%$ \\
7 & $\mathrm{H}^{7} \rightarrow \mathrm{H}^{1}$ & $<1 \%$ \\
\hline
\end{tabular}

${ }^{a}$ Mixing time was $800 \mathrm{~ms}(\mathrm{~T} 1=1.2 \mathrm{~s})$.

To conclude, the NMR studies and DFT calculations presented in the previous chapter mutually confirm the proposed cyclic boron complexes 34 and 35 .

The lack of reactivity of the $\left(Z\right.$ )-olefin $23 \mathrm{c}$ in the $\mathrm{BF}_{3}$-mediated rearrangement was still puzzling. By subjecting the olefin to the same NMR investigation as for 23a, it was confirmed that a similar cyclic $\mathrm{BF}_{2}{ }^{+}$-complex had been formed. The ${ }^{11} \mathrm{~B}$ NMR was in agreement with previous results, presenting one triplet at 4.9 ppm and one singlet at $-0.7 \mathrm{ppm} .{ }^{19} \mathrm{~F}$ NMR further supported the formed complex, giving two diastereotopic multiplets at -86.3 and $-87.5 \mathrm{ppm}$, respectively, together with the signal for $\mathrm{BF}_{4}{ }^{-}$at $-88.6 \mathrm{ppm}$. Although the active $\mathrm{BF}_{2}^{+}$-complex apparently had formed, the reactivity of the $(Z)$-olefin $23 \mathbf{c}$ was negligible (Table 6, entry 8).

\subsection{Acidity of complex 35}

Earlier studies made on cyclic boron complexes had established that the acidity of the $\alpha$-carbonyl protons in $N, N$-dialkyl amino acids increased upon complexation with boron Lewis acids. ${ }^{72,79}$ For instance, the cyclic complex 36 was sufficiently acidic to undergo rapid exchange with $\mathrm{D}_{2} \mathrm{O}$ under mildly basic conditions (aqueous $\mathrm{Et}_{3} \mathrm{~N}$ ). The complexes also exhibited a remarkable stability towards hydrolysis and some of them were even shelf-stable for several months. $^{79}$

${ }^{79}$ Miller, N. E. Inorg. Chem. 1974, 13, 1459-1467. 


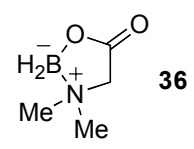

In view of these results an investigation, to establish whether complex $\mathbf{3 5}$ could be rearranged with weaker bases was initiated. Indeed, yields similar to those obtained using the phosphazene base 27 were achieved by employing the weaker phosphazene bases 25 and 26 (compare entries 1-3, Table 11). In fact, complex 35 was sufficiently acidic to be deprotonated and undergo rearrangement by employing an excess of $\mathrm{Et}_{3} \mathrm{~N}$ (entry 4). It seemed important to use an excess of $\mathrm{Et}_{3} \mathrm{~N}$, as treatment with one equivalent gave no indication of rearranged product according to TLC (compare with entry 1, Table 4). A significant resistance towards hydrolysis was also experienced, when $\mathbf{3 5}$ was treated with $2 \mathrm{M} \mathrm{NaOH}$ (entry 5). Evidently, deprotonation and rearrangement of complex 35 were faster than the hydrolysis. Surprisingly, saturated $\mathrm{NaHCO}_{3}$, buffered aqueous solution and water also promoted the rearrangement, albeit to a lower extent (entries 6-8).

Table 11. Investigation of the acidity of complex $35 .{ }^{\text {a }}$

\begin{tabular}{lllll}
\hline Entry & $\begin{array}{l}\text { Additive/ } \\
\text { (equiv.) }\end{array}$ & $\begin{array}{l}\mathrm{T}\left({ }^{\circ} \mathrm{C}\right) / \\
\mathrm{t}(\mathrm{h})\end{array}$ & $\begin{array}{l}\text { Yield of } \\
\mathbf{2 4 a}(\%)^{\mathrm{b}}\end{array}$ & $\begin{array}{l}\text { Rec. 23a } \\
(\%)^{\mathrm{b}}\end{array}$ \\
\hline 1 & $\mathbf{2 7} / 1.1$ & $-20 / 16$ & 66 & 22 \\
2 & $\mathbf{2 6} / 1.1$ & $-20 / 18$ & 64 & 15 \\
3 & $\mathbf{2 5} / 1.1$ & $-20 / 18$ & 71 & 15 \\
4 & $\mathrm{Et}_{3} \mathrm{~N} / 4.2$ & $-20 / 18$ & 67 & 13 \\
5 & $2 \mathrm{M} \mathrm{NaOH} /-$ & $\mathrm{rt}$ & 65 & 27 \\
6 & $\mathrm{NaHCO}_{3}($ saturated) $/-$ & $\mathrm{rt}$ & 33 & 46 \\
7 & $\mathrm{Phosphate-buffer}(\mathrm{pH} 7) /-^{\mathrm{rt}}$ & $\sim 30^{\mathrm{c}}$ & - \\
8 & $\mathrm{H}_{2} \mathrm{O} /-$ & $\mathrm{rt}$ & 29 & 51 \\
\hline
\end{tabular}

${ }^{a}$ Reaction conditions: To 23a (1.0 equiv.) in $\mathrm{PhMe}$ at $-20^{\circ} \mathrm{C}$ to rt was added $\mathrm{BBr}_{3}$ (1.1 equiv.) and base. ${ }^{\mathrm{b}}$ Yield determined by HPLC. Rec. $=$ recovered. ${ }^{\mathrm{c}}$ Conversion estimated from ${ }^{1} \mathrm{H}$ NMR.

Whether the complex $\mathbf{3 5}$ actually was deprotonated by the aqueous solutions and then rearranged or whether the reaction followed a different mechanism has not yet been established. Nonetheless, in agreement with earlier published results, ${ }^{72,79}$ complex 35 most likely exhibited a significantly enhanced acidity compared to the parent amino amide 23a due to the complexation with $\mathrm{BBr}_{3}$.

The complexes formed by mixing $\mathrm{BBr}_{3}$ and $\mathbf{2 3 b}$ or $\mathbf{2 3} \mathbf{c}$ were also treated with $2 \mathrm{M} \mathrm{NaOH}$ and afforded identical diastereoselectivities as those obtained by the rearrangements promoted by 27 (Scheme 27, compare with entries 1 and 2, Table $6)$. 


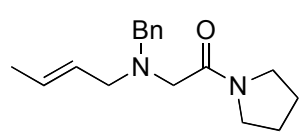

23b

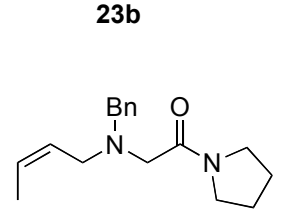

23c

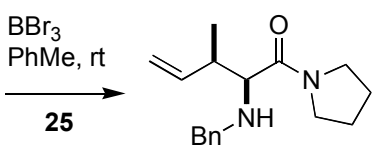

$47 \%$ 24b, $>95 \%$ syn

$28 \%$ recovered $\mathbf{2 3 b}$

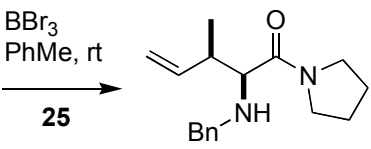

$46 \%$ 24b, $55 \%$ syn

$31 \%$ recovered $23 c$

Scheme 27. [2,3]-Sigmatropic rearrangements of $\mathbf{2 3 b}$ and $\mathbf{2 3 \mathbf { c }}$ promoted by aqueous $\mathrm{NaOH}$.

\section{8 $\mathrm{BBr}_{3}$-mediated rearrangement of a chiral allylic amine}

The chiral amine $(S)$-37 was prepared to evaluate the efficiency in the transfer of chirality from an adjacent stereogenic center to the quaternary nitrogen in the formed $\mathrm{BBr}_{3}-37$ ammonium salt (Scheme 28). ${ }^{80}$ Furthermore, this transformation had the propensity to create optically pure amino acid derivatives with a quaternary $\alpha$-carbon. However, treatment of 37 under optimized rearrangement conditions provided the [2,3]-rearranged $\mathbf{3 8}$ in modest yield and poor enantioselectivity together with $13 \%$ of racemic [1,2]-product $39 .{ }^{81}$ Interestingly, the starting material was recovered with a substantial decrease in optical purity.

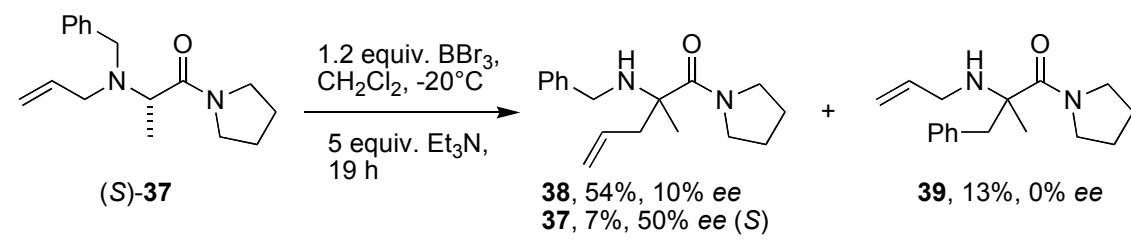

Scheme 28. $\mathrm{BBr}_{3}$-mediated rearrangement of the chiral $(S)-\mathbf{3 7}$.

\subsection{Conclusions}

Amines 23 can be [2,3]-rearranged in the presence of $\mathrm{BF}_{3}$ or $\mathrm{BBr}_{3}$ to give the corresponding products in good yields. Furthermore, the obtained diastereoselectivities in the rearrangement are good to excellent, with the exception of $(Z)$-olefin 23c, which rearranges to the corresponding homoallylic amine with virtually no diastereoselectivity. Taking into account that unreacted starting material can be recovered, the $\mathrm{BF}_{3}$ and $\mathrm{BBr}_{3}$-mediated rearrangements

${ }^{80}$ The experimental data of (S)-37 and $\mathbf{3 8}$ are provided in Supporting Information of Paper IV.

${ }^{81} \mathrm{CH}_{2} \mathrm{Cl}_{2}$ replaced $\mathrm{PhMe}$ in this reaction for reason given in chapter 3.3. 
are powerful carbon-carbon bond forming reactions with great potential for further optimization.

DFT calculations and NMR spectroscopic investigations have established the structure of the intermediate boron-allylic amine complexes and have given a plausible transition state for the rearrangement. This information is invaluable for the design of chiral Lewis acids and auxiliaries in the development of an asymmetric version of the reaction. 


\title{
3. Asymmetric [2,3]-sigmatropic rear- rangement of allylic ammonium ylides
}

\author{
(Papers III and IV)
}

\subsection{Background}

Few examples of $\mathrm{C}-\mathrm{C}$ bond forming [2,3]-sigmatropic rearrangements using chiral Lewis acids have been reported. Only two groups have published asymmetric [2,3]-sigmatropic rearrangements of allylic onium ylides, in which a chiral Lewis acid coordinates the heteroatom.

First, in the mid 1990s Nakai published an asymmetric [2,3]-sigmatropic rearrangement of allylic ethers involving chiral boron Lewis acids. ${ }^{82}$ The achieved diastereo- and enantioselectivities were excellent and the synthetic potential of the rearrangement was demonstrated by an enantioselective synthesis of the 4-epibrefeldin C intermediate 40 (Scheme 29).

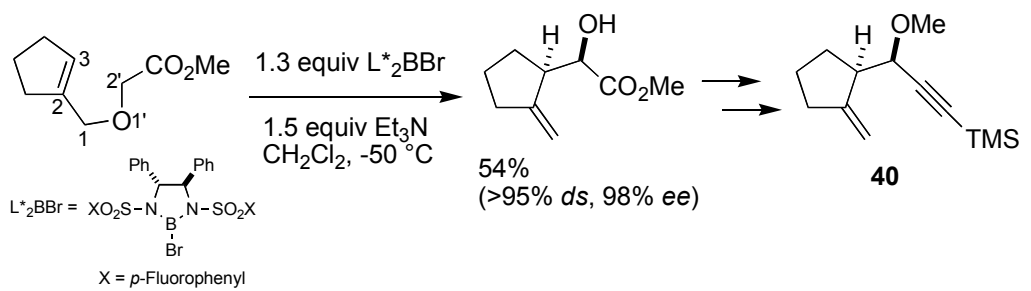

Scheme 29. Enantioselective [2,3]-sigmatropic rearrangement of an allylic ether.

Secondly, Gladysz and co-workers presented a highly enantioselective $[2,3]$-sigmatropic rearrangement of symmetrical diallylic sulfides by employing a chiral rhenium Lewis acid as a chiral auxiliary (Scheme 30$){ }^{83}$ Although the auxiliary had to be removed after the rearrangement, it could easily be cleaved and recycled without compromising the optical purity of either the sulfide or the Lewis acid.

\footnotetext{
${ }^{82}$ Fujimoto, K.; Matsuhashi, C.; Nakai, T. Heterocycles 1996, 42, 423-435; The same group has also presented an enantioselective [2,3]-Wittig rearrangement induced by asymmetric lithiation: Tomooka, K.; Komine, N.; Nakai, T. Tetrahedron Lett. 1998, 39, 5513-5516.

${ }^{83}$ (a) Cagle, P. C.; Arif, A. M.; Gladysz, J. A. J. Am. Chem. Soc. 1994, 116, 3655-3656; (b) Meyer, O.; Cagle, P. C.; Weickhardt, K.; Vichard, D.; Gladysz, J. A. Pure Appl. Chem. 1996, $68,79-88$.
} 


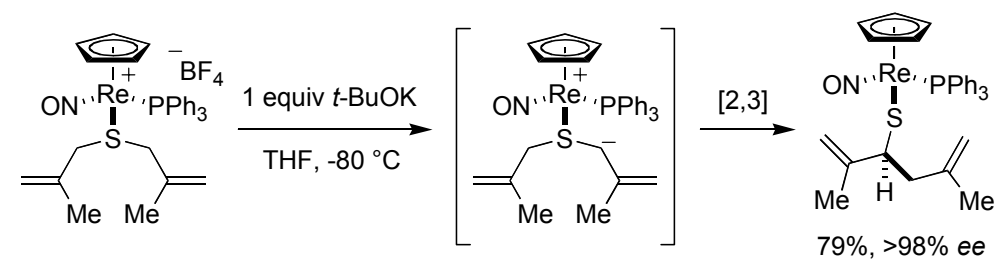

Scheme 30. Enantioselective [2,3]-sigmatropic rearrangement of a diallylic sulfonium ylide.

An alternative approach to implement asymmetry in the [2,3]-sigmatropic rearrangement is to use chiral transition metal catalysts, derived from $\mathrm{Rh}$ (II) or $\mathrm{Cu}(\mathrm{I})$, to promote ylide formation from allylic ethers or sulfides, ${ }^{84,85}$ and at the same time provide chiral induction in the subsequent [2,3]-sigmatropic rearrangement (Scheme 31). Common catalyst loadings are less than $10 \mathrm{~mol} \%$. For instance, Doyle presented a highly enantioselective rearrangement of (E)-cinnamyl methyl ether by employing only $1 \mathrm{~mol} \%$ of a chiral dirhodium(II)catalyst and 2 equivalents of ethyl diazoacetate (Scheme 31$).{ }^{84 \mathrm{c}}$

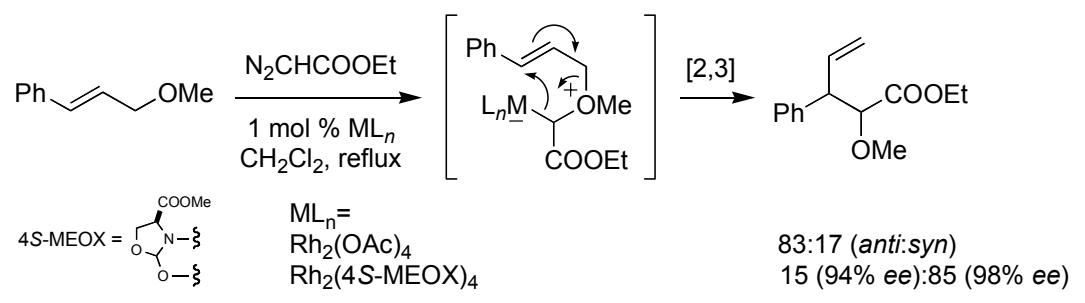

Scheme 31. Rhodium-catalyzed oxonium ylide formation and subsequent asymmetric [2,3]-sigmatropic rearrangement of $(E)$-cinnamyl methyl ether.

No general catalyst seems to exist and the level of enantioselectivity varies considerably depending on the substrates employed in the rearrangement. This is amply highlighted by a recent publication by Wang and co-workers, who utilized copper(I)-catalysts to rearrange various allylic sulfides in poor to moderate enantioselectivities (Scheme 32). ${ }^{85 e}$

\footnotetext{
${ }^{84}$ Selected references of asymmetric oxonium ylide rearrangements: (a) Pierson, N.; Fernandez-Garcia, C.; McKervey, M. A. Tetrahedron Lett. 1997, 38, 4705-4708; (b) Clark, J. S.; Fretwell, M.; Whitlock, G. A.; Burns, C. J.; Fox, D. N. A. Tetrahedron Lett. 1998, 39, 97100; (c) Doyle, M. P.; Forbes, D. C.; Vasbinder, M. M.; Peterson, C. S. J. Am. Chem. Soc. 1998, 120, 7653-7654; (d) Calter, M. A.; Sugathapala, P. M. Tetrahedron Lett. 1998, 39, 8813-8816; (e) Kitagaki, S.; Yanamoto, Y.; Tsutsui, H.; Anada, M.; Nakajima, M.; Hashimoto, S. Tetrahedron Lett. 2001, 42, 6361-6364 (Corrigendum 7715).

${ }^{85}$ Selected references of asymmetric sulfonium ylide rearrangements: (a) Nishibayashi, Y.; Ohe, K.; Uemura, S. Chem. Commun. 1995, 1245-1264; (b) Aggarwal, V. K.; Thompson, A.; Jones, R. V. H.; Standen, M. C. H. J. Org. Chem. 1996, 61, 8368-8369; (c) Fukuda, T.; Irie, R.; Katsuki, T. Tetrahedron 1999, 55, 649-664; (d) McMillen, D. W.; Varga, N.; Reed, B. A.; King, C. J. Org. Chem. 2000, 65, 2532-2536; (e) Zhang, X.; Qu, Z.; Ma, R.; Shi, W.; Jin, X.; Wang, J. J. Org. Chem. 2002, 67, 5621-5625.
} 


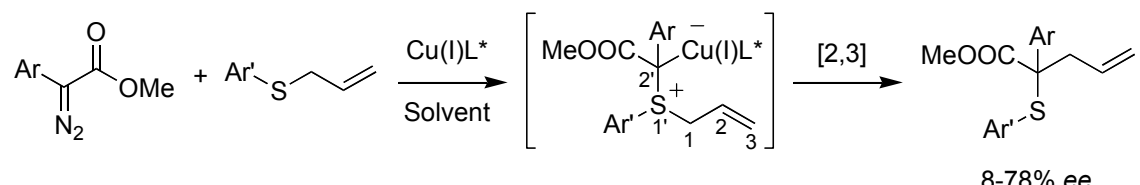

Scheme 32. Copper-catalyzed asymmetric [2,3]-rearrangement of various allylic sulfides.

Allylic ethers and sulfides are the most common rearrangement substrates, although also allylic iodides ${ }^{84 c}$ and selenides ${ }^{85 a}$ have been employed. Surprisingly, no [2,3]-sigmatropic rearrangements involving chiral transition metal catalysts have been conducted on allylic amines.

\subsection{Suitable chiral Lewis acids}

Based on the previous investigation (Chapter 2), chiral Lewis acids based on boron seemed to be the most profitable to explore. Two important characteristics for a successful Lewis acid-mediated [2,3]-sigmatropic rearrangement of allylic ammonium ylides emerged from that investigation:

- The boron-based Lewis acid must be able to form chelated complexes with amines 23, similar to those obtained when employing $\mathrm{BBr}_{3}$. Thus one of the substituents on boron must be readily displaced (Scheme 33).

- Electron withdrawing substituents are required on the boron atom to obtain a sufficiently reactive rearrangement precursor (41, compare also entries 3 and 4, Table 5).

Naturally, the Lewis acid should also be reasonably easy to obtain.

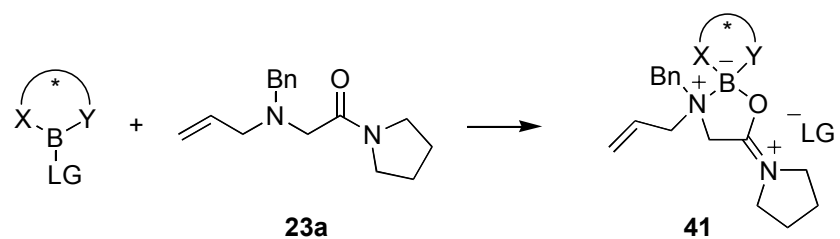

Scheme 33. Proposed complex 41, formed between amine 23a and a chiral Lewis acid (X, $\mathrm{Y}=$ electron-withdrawing groups).

The structure of Lewis acid complex 35 also revealed that a chiral, $C_{2}$-symmetric ligand on boron would probably give a stereochemical outcome that would be reasonably easy to rationalize. A $C_{1}$-symmetric ligand would form an additional stereogenic center at the boron atom. This could theoretically lead to four different diastereomeric complexes, while a $C_{2}$-symmetric ligand would theoretically give only two diastereomeric complexes (Figure 13). The number of different reaction paths is thus decreased by a factor of two. Consequently, the number of intermediates in the rearrangement is reduced, which could statistically improve the selectivity. 

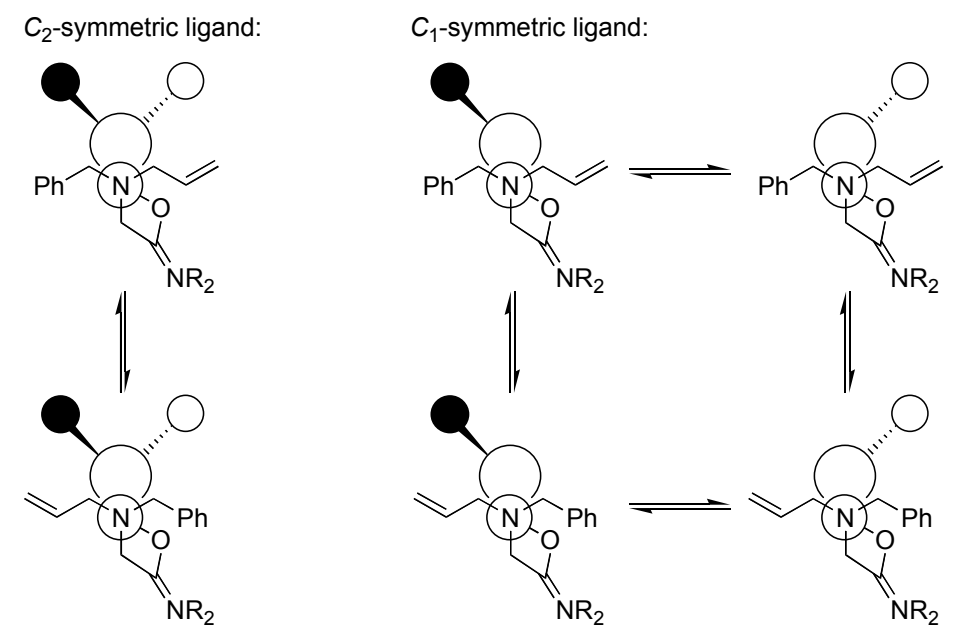

Figure 13. Rationalization of the stereochemical control provided by a $C_{2^{-}}$or $C_{1^{-}}$ symmetric ligand on the quaternary nitrogen atom, as viewed by Newman projections through B-N bond $\left(\mathrm{NR}_{2}=\mathrm{N}\left(\mathrm{CH}_{2}\right)_{4}\right)$. The positive charge on the complex and the counter anion are omitted for clarity.

The numbers of chiral boronic Lewis acids that meet the above-mentioned constraints are limited. A couple of potential Lewis acids are displayed in Figure 14. The cationic Lewis acid $\mathbf{4 2}$, which contains a $C_{2}$-symmetric pyrrolidine subunit, was recently developed by Corey as an efficient catalyst for enantioselective Diels-Alder reactions. ${ }^{86}$ The $C_{2}$-symmetric Lewis acid $\mathbf{4 3}$ was employed as a catalyst in the cycloaddition of $C, N$-diphenylnitrone to $t$-butyl vinyl ether, giving the corresponding cycloadducts with moderate enantioselectivities. ${ }^{87,88}$ The low enantioselectivities could possibly be explained by insufficient chiral induction of the Lewis acidic atom by the rather distant stereogenic centers. The diazaborolidines $\mathbf{4 4}$ have been utilized in various enantioselective transformations that have been successfully implemented in a number of total syntheses. ${ }^{82,8990}$ The high enantioselectivities usually associated

${ }^{86}$ Sprott, K. T.; Corey, E. J. Org. Lett. 2003, 5, 2465-2467.

${ }^{87}$ Bayón, P.; March, P.; Figueredo, M.; Font, J.; Medrano, J. Tetrahedron: Asymmetry 2000, 11, 4269-4278.

${ }^{88}$ A reported boron chloride with a racemic $\beta$-binaphthol ligand could also be a potential Lewis acid in the rearrangement: Thormeier, S.; Carboni, B.; Kaufmann, D. E. J. Organomet. Chem. 2002, 657, 136-145.

(a) Corey, E. J.; Imwinkelried, R.; Pikul, S.; Xiang, Y. B. J. Am. Chem. Soc. 1989, 111, 5493-5495; (b) Corey, E. J.; Kim, S. S. J. Am. Chem. Soc. 1990, 112, 4976-4977; (c) Corey, E. J.; Kim, S. S. Tetrahedron Lett. 1990, 31, 3715-3718; (d) Corey, E. J.; Lee, D.-H. J. Am. Chem. Soc. 1991, 113, 4026-4028; (e) Corey, E. J.; Choi, S. Tetrahedron Lett. 1991, 32, 2857-2860; (f) Corey, E. J.; Decicco, C. P.; Newbold, R. C. Tetrahedron Lett. 1991, 32, 5287-5290; (g) Corey, E. J.; Jones, G. B. Tetrahedron Lett. 1991, 32, 5713-5716; (h) Corey, E. J.; Kania, R. S. J. Am. Chem. Soc. 1996, 118, 1229-1230; (i) Ito, H.; Sato, A.; Taguchi, T. Tetrahedron Lett. 1997, 38, 4815-4818; (j) Ito, H.; Sato, A.; Kobayashi, T.; Taguchi, T. Chem. Commun. 1998, 2441-2442. 
with these diazaborolidines probably arise from efficient chirality transfer from the methine carbons, via the bulky sulfonyl groups that efficiently shield the proximal Lewis acidic boron nucleus, to the substrate.

$C_{1}$-symmetric Lewis acid:<smiles></smiles>

42
$C_{2}$-symmetric Lewis acids:<smiles>[CH2]CC1OB([O+])O[C@@H]1C[14CH3]</smiles>

43, $\mathrm{Ar}=2,4-(\mathrm{MeO})_{2} \mathrm{C}_{6} \mathrm{H}_{3}$<smiles>[X]O[N+]1=C([R])C([R])N(S(=O)(=O)O[Na])B1Br</smiles>

e.g. 44a, $\mathrm{R}=\mathrm{Ph}, \mathrm{X}=4-\left(\mathrm{CH}_{3}\right) \mathrm{C}_{6} \mathrm{H}_{4}$ or b, $\mathrm{R}=-\left(\mathrm{CH}_{2}\right)_{4^{-}}, \mathrm{X}=4-\left(\mathrm{CH}_{3}\right) \mathrm{C}_{6} \mathrm{H}_{4}$ or c, $\mathrm{R}=2,4-\left(\mathrm{CH}_{3}\right)_{2} \mathrm{C}_{6} \mathrm{H}_{3}, \mathrm{X}=\mathrm{CF}_{3}$

Figure 14. Selected potential Lewis acids for the asymmetric [2,3]-sigmatropic rearrangement of amines $\mathbf{2 3}$.

Based on the above-mentioned constraints, the diazaborolidine 44a seemed most promising, having the following features:

- A good leaving group $\left(\mathrm{Br}^{-}\right)$, which would enable the Lewis acid to form chelates with amines $\mathbf{2 3}$, similarly to those formed between $\mathbf{2 3}$ and $\mathrm{BBr}_{3}$.

- Electron withdrawing substituents on boron ( $N$-Ts), to make the boron atom Lewis acidic enough to obtain an active rearrangement precursor.

- Moreover, the diazaborolidine 44a is $C_{2}$-symmetric and efficiently induces asymmetry in various transformations. ${ }^{82,89,91,92}$

- 44a can be efficiently synthesized from the commercially available ligand 45a (Scheme 34) ${ }^{89 a, 93}$

\subsection{Initial experiments and optimization of the asymmetric rearrangement}

Lewis acid 44a was prepared in concurrence with earlier methods by treating the ligand 45a with $\mathrm{BBr}_{3}$ in $\mathrm{CH}_{2} \mathrm{Cl}_{2}$ at room temperature and evaporating the solvent under reduced pressure (Scheme 34). ${ }^{89}$ The resultant solid was subsequently

${ }^{90}$ (a) Corey, E. J.; Huang, H.-C. Tetrahedron Lett. 1989, 30, 5235-5238; (b) Corey, E. J.; Lee, D.-H.; Choi, S. Tetrahedron Lett. 1992, 33, 6735-6738; (c) Jacobi, P. A.; Li, Y. Org. Lett. 2003, 5, 701-704; (d) Williams, D. R.; Patnaik, S.; Plummer, S. V. Org. Lett. 2003, 5, 50355038 , and references therein.

${ }_{91}^{91}$ Corey, E. J.; Yu, C.; Kim, S. S. J. Am. Chem. Soc. 1989, 111, 5495-5496.

92 Kiyooka, S.-i.; Fujiyama, R.; Uddin, M. K.; Goh, K.; Nagano, Y.; Fujiob, M.; Tsunob, Y. Tetrahedron Lett. 2005, 46, 209-212.

${ }_{93}$ Selected references for syntheses of various chiral 1,2-diamines: (a) Shono, T.; Kise, N.; Oike, H.; Yoshimoto, M.; Okazaki, E. Tetrahedron Lett. 1992, 33, 5559-5562; (b) Bette, V.; Mortreux, A.; Ferioli, F.; Martelli, G.; Savoia, D.; Carpentier, J.-F. Eur. J. Org. Chem. 2004, 3040-3045. Some dialkyl-substituted diamines: (a) Nantz, M. H.; Lee, D. A.; Bender, D. M.; Roohi, A. H. J. Org. Chem. 1992, 57, 6653-6657; (b) Scheurer, A.; Mosset, P.; Saalfrank, R. W. Tetrahedron: Asymmetry 1999, 10, 3559-3570; (c) McNulty, J.; Mo, R.; Carpetta, A.; Frampton, C. S. Chem. Commun. 2001, 2384-2384. 
dissolved in $\mathrm{CH}_{2} \mathrm{Cl}_{2}$ and the solvent evaporated again. The latter procedure was performed twice in order to remove the formed $\mathrm{HBr}$.

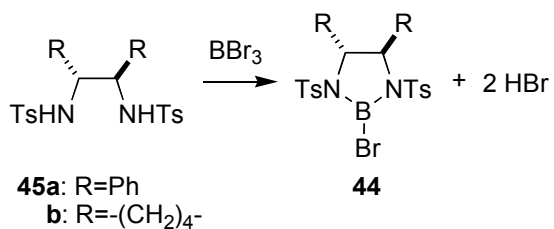

Scheme 34. Preparation of the chiral Lewis acids 44.

The initial asymmetric rearrangement attempts followed the procedure developed for the achiral rearrangement (Chapter 2). Thus, amine 23a in PhMe was added to the Lewis acid 44a at room temperature and stirred for 1-2 hours before the phosphazene base 27 was added at $-20{ }^{\circ} \mathrm{C}$ and the reaction allowed to stir overnight (Table 12, entry 1). Gratifyingly, the chiral Lewis acid promoted the [2,3]-sigmatropic rearrangement, even though homoallylic amine 24a was formed in only $16 \%$ yield and $51 \%$ ee along with $45 \%$ recovered starting material. Attempts to increase the enantiomeric excess and yield by preparing the complex at $-78^{\circ} \mathrm{C}$ or by increasing the amount of Lewis acid were made, but met with no success. Instead, the enantiomeric excess could be increased by adding 1.0 equivalent of the weaker phosphazene base $\mathbf{2 5}$ to a mixture of $\mathbf{2 3 a}$ and the Lewis acid (formed by mixing 2.0 equiv. 45a and 2.4 equiv. $\mathrm{BBr}_{3}$ ), affording $\mathbf{2 4 a}$ in $29 \%$ yield and $68 \%$ ee (entry 2 ). ${ }^{94}$

In the initial experiments an unidentified byproduct could be observed on ${ }^{1} \mathrm{H}$ NMR. This byproduct was rather similar to the $\mathrm{BBr}_{3}-\mathbf{2 3 a}$ complexes on ${ }^{1} \mathrm{H}$ NMR, but later proved to be the surprisingly stable complex between the residual Lewis acid and the rearranged product 24a (see Figure 16). By extending the time for quenching the reaction $(2 \mathrm{M} \mathrm{HCl}$ at $\mathrm{rt}$ ) from a couple of hours to more than 24 hours, the unidentified byproduct disappeared. After some experimentation, the most efficient quenching was achieved by using a concentrated $\mathrm{HCl}: \mathrm{MeOH}(1: 5)$ mixture for $1-2$ hours at $60^{\circ} \mathrm{C}$ or overnight at room temperature.

Although the Lewis acid 44a was soluble in PhMe, a precipitate formed as soon as amine 23a was added and prevented efficient stirring. This could be avoided by changing solvents to $\mathrm{CH}_{2} \mathrm{Cl}_{2}$, which gave a homogenous solution throughout the reaction. Employment of 1.2 equivalents of $45 \mathbf{a}$ and 1.4 equivalents of $\mathrm{BBr}_{3}$ in $\mathrm{CH}_{2} \mathrm{Cl}_{2}$ increased the enantiomeric excess to $85 \%$, although the yield was still low (entry 3 ). Using 1.0 equivalent $\mathrm{Et}_{3} \mathrm{~N}$ as a base gave a comparable yield, but a slight decrease in enantiomeric excess (entry 4). Instead an excess of $\mathrm{Et}_{3} \mathrm{~N}$ proved best, producing the rearranged 24a in $43 \%$ yield and with high enantiomeric excess (entry 5). The weaker bases $\mathrm{K}_{2} \mathrm{CO}_{3}$ and $\mathrm{NaHCO}_{3}$ did not promote the rearrangement (entries 6 and 7).

${ }^{94}$ The reactions were difficult to monitor by TLC. No product spot could be seen during the experiment, as the product was complexed to the residual Lewis acid, vide supra. 
Table 12. The asymmetric [2,3]-sigmatropic rearrangement of 23a. ${ }^{a}$

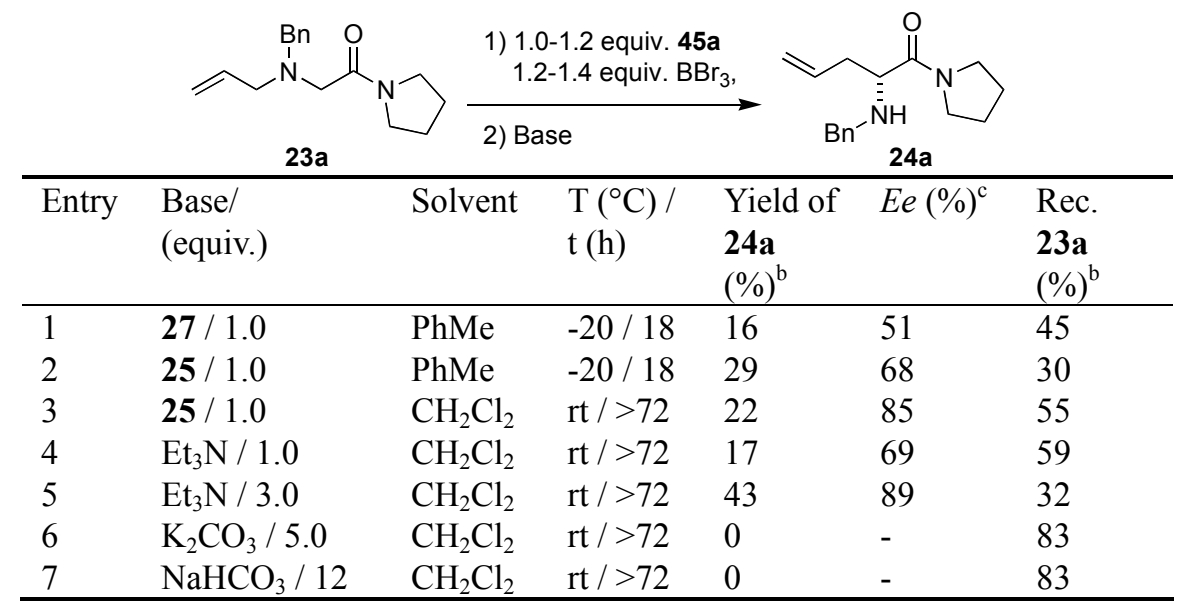

${ }^{a}$ Reaction conditions: To a premade solution of 44a at rt was added 23a (1 equiv.) and the resultant solution was stirred for $1 \mathrm{~h}$. The base was added and the reaction mixture was stirred for $18->72 \mathrm{~h}^{\mathrm{b}}$ Yield determined by HPLC. Rec. $=$ recovered. ${ }^{c}$ Determined by HPLC analysis of crude product on a Chiracel OJ column (hexane: $i-\mathrm{PrOH}$ ).

Unfortunately, the enantiomeric excesses obtained in the rearrangement were inconsistent, regardless of the amount or type of base employed. ${ }^{95}$ This irregularity was attributed to the slight excess of $\mathrm{BBr}_{3}$ when preparing the Lewis acid $44 a{ }^{96}$ The $\mathrm{BBr}_{3}$ is probably a stronger Lewis acid than $\mathbf{4 4 a}$, which makes amine 23a to preferentially complex to $\mathrm{BBr}_{3}$. Some of amine 23a will subsequently rearrange via the racemic complex 35 (see Chapter 2.6.1), thereby lowering the enantiomeric excess of 24a. Consequently, by introducing an equimolar amount of $\mathrm{BBr}_{3}$ an excellent enantiomeric excess was obtained, although the conversion was still moderate (Table 13, entry 1). Likewise, employment of a large excess of $\mathrm{BBr}_{3}$ significantly lowered the enantiomeric excess, although the conversion of 23a was complete (entry 2).

While the choice of ligand was approved concerning the selectivity of the rearrangement, the low conversion had to be addressed. This issue was simply solved by applying two equivalents of the Lewis acid 44a to $23 \mathbf{a}$ in $\mathrm{CH}_{2} \mathrm{Cl}_{2}$ at room temperature, adding two equivalents of base 25 and stirring the resultant solution overnight. These reaction conditions satisfactorily afforded $\mathbf{2 4 a}$ in $79 \%$ yield and with excellent enantiomeric excess (entry 3 ).

The rate of the reaction was considerably slower compared to the $\mathrm{BBr}_{3}$-mediated rearrangement, as was seen by the somewhat lower conversion when stopping the reaction after 3 hours (entry 4). ${ }^{97}$ The large phosphazene base $\mathbf{2 6}$ gave a considerably lower conversion than $\mathbf{2 5}$ during the same reaction time

${ }^{95}$ The rearrangements were repeated, but gave differing enantiomeric excesses.

${ }^{96}$ Excess $\mathrm{BBr}_{3}$ was trapped as $\mathrm{BBr}_{4}$-anions during preparation of the chiral Lewis acid.

${ }^{97}$ Compare with $\mathrm{BBr}_{3}$, page 22. 
(entry 5). It was clear that an excess of base was needed; applying one equivalent of base gave a poor conversion of 23a (entry 6). Moreover, employing $\mathrm{PhMe}$ as solvent with the optimized reaction conditions gave comparable results, but $\mathrm{Et}_{2} \mathrm{O}$ and THF gave lower yields and/or enantiomeric excess..$^{98}$

Table 13. Probing the influence of Lewis acids and bases in the rearrangement of 23a. ${ }^{\mathrm{a}}$

\begin{tabular}{lllllll}
\hline Entry & $\begin{array}{l}\text { Ligand/ } \\
\text { (equiv.) }\end{array}$ & $\begin{array}{l}\mathrm{BBr}_{3} / \\
\text { (equiv.) }\end{array}$ & $\begin{array}{l}\text { Base/ } \\
\text { (equiv.) }\end{array}$ & $\begin{array}{l}\text { Yield of } \\
\mathbf{2 4 a} \\
(\%)^{b}\end{array}$ & $\begin{array}{l}\text { bec. } \\
(\%)^{\mathrm{c}}\end{array}$ & $\begin{array}{l}\text { 23a } \\
(\%)^{b}\end{array}$ \\
\hline 1 & $\mathbf{4 5 a} / 1.2$ & 1.2 & $\mathbf{2 5} / 2.0$ & 39 & $97(R)$ & 59 \\
2 & $\mathbf{4 5 a} / 1.2$ & 2.0 & $\mathbf{2 5} / 2.0$ & 79 & $48(R)$ & 0 \\
3 & $\mathbf{4 5 a} / 2.0$ & 2.0 & $\mathbf{2 5} / 2.0$ & 79 & $96(R)$ & 0 \\
$4^{\mathrm{d}}$ & $\mathbf{4 5 a} / 2.0$ & 2.0 & $\mathbf{2 5} / 2.0$ & 71 & $97(R)$ & 11 \\
5 & $\mathbf{4 5 a} / 2.0$ & 2.0 & $\mathbf{2 6} / 2.0$ & 56 & $97(R)$ & 46 \\
6 & $\mathbf{4 5 a} / 2.0$ & 2.0 & $\mathbf{2 5} / 1.0$ & 18 & $97(R)$ & 78 \\
7 & $\mathbf{4 5 a} / 2.0$ & 2.0 & $\mathrm{Et}_{3} \mathrm{~N} / 5.0$ & 87 & $97(R)$ & 3 \\
8 & $\mathbf{4 5 b} / 2.0$ & 2.0 & $\mathrm{Et}_{3} \mathrm{~N} / 5.0$ & 84 & $25(S)$ & 0 \\
9 & $\mathbf{4 5 b} / 2.0$ & 2.0 & $\mathbf{2 5} / 2.0$ & 87 & $28(S)$ & $\mathrm{NA}$ \\
\hline
\end{tabular}

${ }^{\text {a }}$ Reaction conditions: To a premade solution of Lewis acid at rt was added 23a (1 equiv.) and the resultant solution stirred for $1 \mathrm{~h}$. The base was added and reaction mixture stirred for 18-22 h. ${ }^{\mathrm{b}}$ Yield determined by HPLC. Rec. $=$ recovered. ${ }^{c}$ Determined by HPLC analysis of crude product on a Chiracel OJ column (hexane:i-PrOH). Absolute configuration, see Supporting Information of Paper III. ${ }^{\mathrm{d}}$ Reaction run for $3 \mathrm{~h}$.

As anticipated from earlier results, an excess of $\mathrm{Et}_{3} \mathrm{~N}$ could be employed as base without compromising yield or enantiomeric excess (entry 7). By using the chiral Lewis acid derived from the bis-tosylated cyclohexane diamine ligand $\mathbf{4 5 b}$ good yields of 24a were obtained. The enantiomeric excesses were however poor, and the product had the opposite absolute configuration (entries 8 and 9).

\subsection{Mechanistic considerations}

It was remarkable that not only two equivalents of the Lewis acid, but also at least two equivalents of the base were needed to effect complete conversion in the rearrangement of 23a. To explain these results, a proposed pathway was suggested based on the previous DFT calculations and NMR investigations of the $\mathrm{BBr}_{3}$-mediated rearrangement (Scheme 35). In this mechanism, the amide oxygen in 23a would first coordinate to the Lewis acid to form complex A. This complex is suggested to be in equilibrium with the cyclic complex $\mathbf{B}$, which is formed by displacement of the bromide on boron. Due to unfavorable steric interactions between the bulky ligand and the substituents on the nitrogen atom in complex $\mathbf{B}$, the $\mathbf{A}-\mathbf{B}$ equilibrium is probably shifted towards the left. To force

${ }^{98}$ PhMe: $70 \%$, >97\% ee; $\mathrm{Et}_{2} \mathrm{O}: 27 \%$ yield, $>97 \%$ ee; $\mathrm{THF}: 15 \%$, $84 \%$ ee. 
the equilibrium to the right, one additional Lewis acid molecule has to assist in displacing the bromide, in a similar way to the assembling of the $\mathrm{BF}_{2}^{+}$-complex 34 (see Chapter 2.6.1). Once the base deprotonates B, the neutral complex $\mathbf{C}$ rearranges to $\mathbf{D}$, after which acidic hydrolysis produces the homoallylic amine 24a and the ligand 45a.
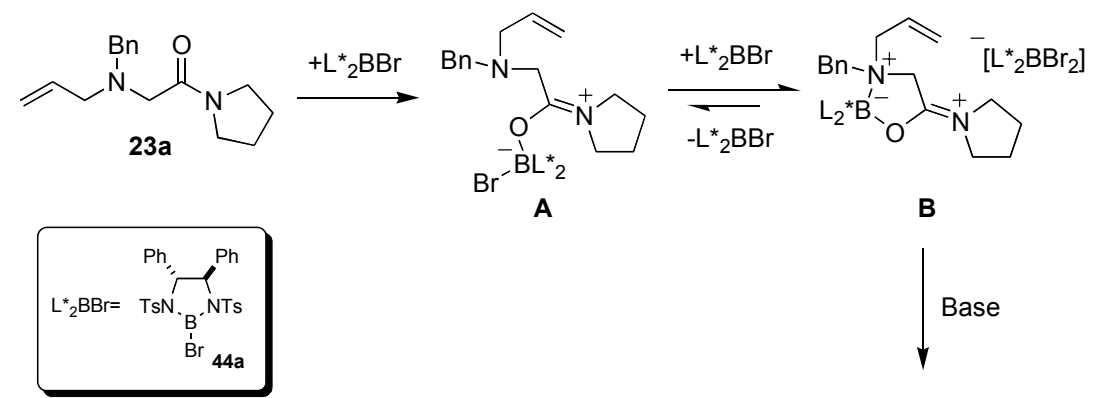

A

B

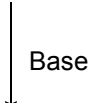

$\checkmark$

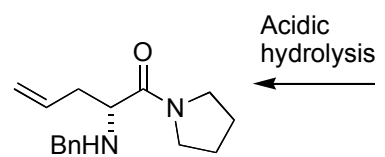

$24 a$

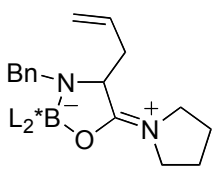

D

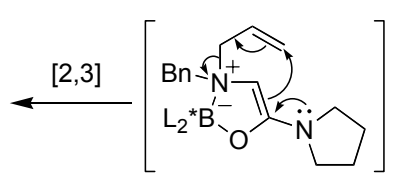

C

Scheme 35. Probable mechanism of the rearrangement (base $=\mathrm{Et}_{3} \mathrm{~N}, 25$, etc.).

To explain the additional equivalent of base, an entrapment of the base by the Lewis acid adduct $\mathbf{4 6}$ could be envisioned (Scheme 36). The base would then act as a nucleophile substituting one of the bromides. This is supported by ${ }^{1} \mathrm{H}$ NMR investigations of the formed complex $\mathbf{B}$. No deprotonation of complex $\mathbf{B}$ could be observed after adding 0.4 equivalents of $\mathrm{Et}_{3} \mathrm{~N} .{ }^{99}$ Instead a doublet of quartet was seen at $3.1 \mathrm{ppm}$, most likely arising from the diastereotopic methylene protons of the $\mathrm{Et}_{3} \mathrm{~N}-\mathbf{4 4 a}$ adduct, along with a triplet at $2.4 \mathrm{ppm}$, from the methyl protons.

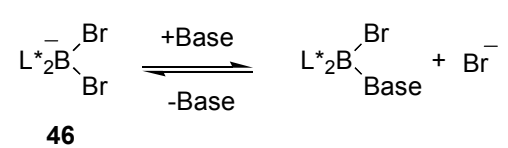

Scheme 36. Capture of the base by the Lewis acid 44a.

It was reasoned that silver(I) salts could be introduced to displace the bromide anion from $\mathbf{A}$ by precipitation of $\mathrm{AgBr}$. This would make it feasible to use only one equivalent of both the Lewis acid 44a and the base. Thus, to a mixture of the Lewis acid (1.2 equiv.) and 23a in $\mathrm{CH}_{2} \mathrm{Cl}_{2}$ was transferred $\mathrm{AgBF}_{4}$ (2.0 equiv.). As previously, the solution was stirred for 1-2 hours before the base was added (2.0 equiv., although in theory 1.0 equiv. should suffice). Surprisingly, only $39 \%$ of racemic 24a was obtained, together with 58\% starting material. How a

${ }^{99}$ No signals from the free or protonated $\mathrm{Et}_{3} \mathrm{~N}$ were visible in ${ }^{1} \mathrm{H}$ NMR. 
racemic product was formed is unclear. Application of $\mathrm{AgPF}_{6}$ gave only recovered starting material.

In an attempt to see whether the formation of rearrangement precursor $\mathbf{B}$ was slower by employing one equivalent of Lewis acid than two equivalents, a 1:1 mixture of 44a and 23a was allowed to stir for 17 hours instead of 1-2 hours before the base was added. However, this was detrimental to the rearrangement, as it gave no conversion of 23a and only recovered starting material.

\subsection{Scope and limitations of the asymmetric rearrangement}

With optimized rearrangement conditions at hand, the focus was turned to examine the scope and limitations of the asymmetric rearrangement, as well as to establish a transition state model to explain the observed diastereo- and enantiomeric excesses. A series of allylic amines was chosen to reflect electronic properties and steric bulk of the allyl moiety (Scheme 37). Four types of $(E) /(Z)$ olefin pairs (23b-d and $\mathbf{f}-\mathbf{j}$ ) were synthesized as the anti:syn-selectivity obtained in the rearrangements would give a valuable insight into sterical and electronical interactions in the transition state. Furthermore, the more sterically hindered substrates 23k, substituted with a methyl group at the allylic C2-position, and trisubstituted olefin 23e were included in the study. The allylic amines were prepared from the corresponding allylic alcohols in analogy with the syntheses of 23a-e (see Scheme 23). ${ }^{100}$

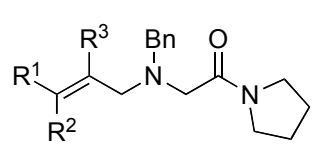

23

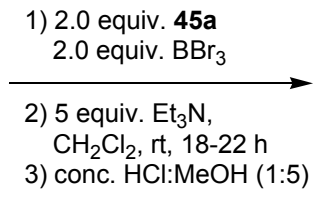

i: $\mathrm{R}^{1}=\mathrm{SiMe}_{2} \mathrm{Ph}, \mathrm{R}^{2}=\mathrm{H}, \mathrm{R}^{3}=\mathrm{H}$

j: $\mathrm{R}^{1}=\mathrm{H}, \mathrm{R}^{2}=\mathrm{SiMe}_{2} \mathrm{Ph}, \mathrm{R}^{3}=\mathrm{H}$

k: $\mathrm{R}^{1}=\mathrm{H}, \mathrm{R}^{2}=\mathrm{H}, \mathrm{R}^{3}=\mathrm{Me}$

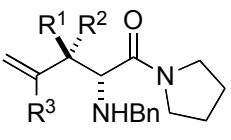

24

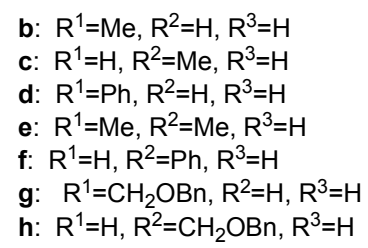

Scheme 37. Optimized reaction conditions for rearranging the allylic amines $\mathbf{2 3}$ to the corresponding homoallylic amines 24 .

As an additional advantage, silyl-substituted olefins $\mathbf{2 3 i}$ and $\mathbf{2 3} \mathbf{j}$ could furnish interesting amines containing an allylsilane moiety. This functionality can be further derivatized by a number of transformations, including allylation reactions of aldehydes or imines and intramolecular cyclizations. ${ }^{101}$ Moreover, the silyl functionality can serve as a masked hydroxyl group. ${ }^{102}$

${ }^{100}$ The syntheses of amines $\mathbf{2 3 b}$-e are provided in Paper II and $\mathbf{2 3 f - k}$ in Paper IV. 
The (E)-olefin 23b gave a smooth rearrangement under the optimized conditions, affording $82 \%$ of $\mathbf{2 4 b}$ in a 79:21 anti:syn ratio and an excellent enantiomeric excess of the major diastereomer (Scheme 37 and Table 14, entry 1). The absolute configuration of the anti-and syn-diastereomers was established by chemical correlation to be $2 R, 3 R$ and $2 R, 3 S$, respectively (see Chapter 3.6). Unexpectedly, the asymmetric rearrangement gave the opposite major diastereomer and a lower diastereoselectivity compared to the $\mathrm{BBr}_{3}$-mediated rearrangement $(<5: 95$ anti:syn). An attempt to improve the selectivity by running the reaction at $-20{ }^{\circ} \mathrm{C}$ gave the same diastereoselectivity and low conversion (entry 2). Exchanging the reaction solvent to PhMe gave a poorer diastereoselectivity and poor conversion (entry 3 ).

Gratifyingly, the isomeric (Z)-olefin 23c gave the opposite major diastereomer, syn-24c, with similar enantiomeric excess and an almost identical but reversed anti:syn ratio (20:80, entry 4). This should be compared to the racemic, $\mathrm{BBr}_{3}$-mediated rearrangement of $\mathbf{2 3 c}$, which gave virtually no diastereoselectivity (45:55 anti:syn). The anti-24c and syn-24c diastereomers had the same absolute configuration as anti- and syn-24b, respectively.

Pursuing the asymmetric rearrangement with the $(E) /(Z)$-isomeric pair of the cinnamyl amines $23 \mathbf{d} / \mathbf{f}$ and the benzyloxy methylene olefins $23 \mathrm{~g} / \mathbf{h}$ provided the corresponding homoallylic amines in good yields and excellent enantiomeric excesses (entries 5-9). The diastereoselectivities showed the same trend as for the $\mathbf{2 3 b}$ /c isomeric pair; the $(E)$-olefins gave anti as major diasteromer, while the $(Z)$-olefins gave syn. The $(E) /(Z)$-cinnamyl amines 23d,f and $(Z)$-olefin $23 \mathbf{h}$ afforded the corresponding homoallylic amines in rather modest diastereoselectivities (roughly 2:1, entries 5-7 and 9). Moreover, ( $Z$ )-cinnamyl amine $23 f$ had to be rearranged at $-20{ }^{\circ} \mathrm{C}$ to suppress the formation of a byproduct. This resulted in slightly better diastereoselectivity than at rt (entries 6 and 7). On the other hand, the $(E)$-olefin $23 \mathrm{~g}$ provided the rearranged amines anti-24g:syn-24g with a good diastereomeric ratio (88:12, entry 8).

Moving on to the asymmetric rearrangement of the $(E)$ - and $(Z)$-silyl substituted olefins $\mathbf{2 3 i}$ and $\mathbf{2 3}$ j gave one satisfying result and one inadequate outcome. While the $(E)$-olefin 23 i provided essentially one diastereomer in $99 \%$ $e e$ and $52 \%$ yield (entry 10 ), the isomeric (Z)-olefin $\mathbf{2 3 j}$ failed to give the corresponding [2,3]-rearranged product and instead a [1,2]-rearrangement product was formed (entry 11, vide supra).

The asymmetric rearrangement conditions continued to provide high selectivities with the amines $\mathbf{2 3 k}$ and $\mathbf{e}$, which after rearrangement afforded the homoallylic amines $\mathbf{2 4 k}$ and $\mathbf{e}$ in $99 \%$ and $96 \%$ ee, respectively (entries 12 and 13). The absolute configurations of amines $\mathbf{2 4 d} \mathbf{d} \mathbf{i}, \mathbf{k}$ and $\mathbf{e}$ were assigned by analogy with the rearrangement of $\mathbf{2 3 b}$ to $\mathbf{2 4 b}$.

\footnotetext{
${ }^{101}$ For reviews of reactions of allylsilanes: (a) Masse, C. E.; Panek, J. S. Chem. Rev. 1995, 95, 1293-1316; (b) Chabaud, L.; James, P.; Landais, Y. Eur. J. Org. Chem. 2004, 31733199. For an intramoloecular iminium ion cyclization of a very similar substrate, see: Huang, H.; Spande, T. F.; Panek, J. S. J. Am. Chem. Soc. 2003, 125, 626-627.

102 Jones, G. R.; Landais, Y. Tetrahedron 1996, 52, 7599-7662.
} 
Table 14. Asymmetric [2,3]-sigmatropic rearrangement of amines $\mathbf{2 3}^{\mathrm{a}}$

\begin{tabular}{|c|c|c|c|c|c|}
\hline Entry & Amine & Product & $\begin{array}{l}\text { Yield } \\
(\%)^{b}\end{array}$ & Anti:syn ${ }^{\mathrm{c}}$ & Ee anti: ee $\operatorname{syn}(\%)^{\mathrm{d}}$ \\
\hline 1 & 23b & $24 b$ & 82 & $79: 21$ & $96(2 R, 3 R): 75(2 R, 3 S)^{\mathrm{e}}$ \\
\hline 2 & 23b & $24 b$ & $46^{\mathrm{f}}$ & $80: 20$ & $96(2 R, 3 R):$.d. $^{\mathrm{e}}$ \\
\hline 3 & 23b & $24 b$ & $<10^{\mathrm{g}}$ & $67: 33$ & n.d. \\
\hline 4 & $23 c$ & $24 c$ & 85 & $20: 80$ & $82(2 R, 3 R): 98(2 R, 3 S)^{\mathrm{e}}$ \\
\hline 5 & 23d & 24d & 92 & $67: 33$ & $97: 77^{\mathrm{h}}$ \\
\hline 6 & $\mathbf{2 3 f}^{\mathrm{i}}$ & $24 f$ & $57^{\mathrm{j}}$ & $37: 63$ & $92: 93^{\mathrm{h}}$ \\
\hline 7 & $\mathbf{2 3 f}^{\mathrm{i}}$ & $24 f$ & $65^{\mathrm{f}, \mathrm{k}}$ & $30: 70$ & $94: 88^{\mathrm{h}}$ \\
\hline 8 & $23 g$ & $24 g$ & 70 & $88: 12^{\mathrm{h}}$ & 93:n.d. ${ }^{\text {h }}$ \\
\hline 9 & $23 \mathrm{~h}$ & $24 \mathrm{~h}$ & 71 & $29: 71^{\mathrm{h}}$ & $98: 99^{\mathrm{h}}$ \\
\hline 10 & $23 \mathbf{i}$ & $24 \mathbf{i}$ & 52 & $95: 5^{h}$ & 99:n.d. \\
\hline 11 & $23 \mathbf{j}$ & \multicolumn{4}{|c|}{ See Table 15} \\
\hline 12 & $23 k$ & $24 k$ & 80 & - & $99^{\mathrm{h}}$ \\
\hline 13 & $23 e$ & $24 \mathrm{e}$ & 64 & - & $96^{\mathrm{h}}$ \\
\hline
\end{tabular}

${ }^{a}$ Reaction conditions: To a premade solution of Lewis acid at rt was added 23 (1 equiv.) and the resultant solution was stirred for $1 \mathrm{~h} . \mathrm{Et}_{3} \mathrm{~N}$ (5 equiv.) was added and reaction mixture was stirred for 18-22 h. ${ }^{b}$ Isolated yield of diastereomeric mixture. Conversions in italics. ${ }^{\mathrm{c}}$ Determined by ${ }^{1} \mathrm{H}$ NMR analysis of the crude product. ${ }^{d}$ Determined by HPLC analysis of crude products, see Supporting information of Paper III. ${ }^{\mathrm{e}}$ The absolute configuration was established via chemical correlation, see Chapter 3.6. ${ }^{\mathrm{f}}$ The reaction was run at $-20{ }^{\circ} \mathrm{C} .{ }^{\mathrm{g}}$ The reaction was run in PhMe. ${ }^{\mathrm{h}}$ Stereochemistry assigned by analogy with the rearrangements of $\mathbf{2 3 b} .{ }^{i} E: Z 1: 10 .{ }^{j}$ A byproduct was formed, see Table $15 .{ }^{\mathrm{k}} 14 \%$ Recovered $\mathbf{2 3 f}$.

The [1,2]-sigmatropic rearrangement can be a serious side reaction to the [2,3]-sigmatropic rearrangement of ammonium ylides, in particular at elevated temperatures or when the [2,3]-pathway is sterically hindered (see Chapter 1.2). In the [1,2]-rearrangement, the homolytical cleavage of a $\mathrm{C}-\mathrm{N}$ bond creates a radical pair, which recombines to form a new $\mathrm{C}-\mathrm{C}$ bond at the $\alpha$-carbon (Scheme 2). In our $\mathrm{BBr}_{3}$-mediated rearrangements no or very small amounts of product arising from the [1,2]-rearrangement was observed, probably due to minor sterical interactions between the reacting allyl moiety and the bromine atoms in the transition state, thereby favoring the [2,3]-pathway (Scheme 26). When applying the chiral and far bulkier Lewis acid 44a, this side reaction became significant for some amines. In the rearrangement of $(Z)$-silyl olefin $\mathbf{2 3 j}$ the sole product arose from a [1,2]-rearrangement of the benzyl group, affording $\mathbf{4 7} \mathbf{j}$ in $72 \%$ yield and in $61 \%$ ee (Table 15 , entry 1 ). Since the phenyl group stabilizes the radicals more than the vinyl group does, the $N$-benzylic carbon bond will preferentially cleave to give a benzyl radical. Trying to suppress this byproduct by running the reaction at $-20^{\circ} \mathrm{C}$ made no difference to the outcome. 
Table 15. [1,2]-Sigmatropic rearrangement of (Z)-olefins 23c, $\mathbf{f}, \mathbf{h}$ and $\mathbf{j}^{\mathrm{a}}$

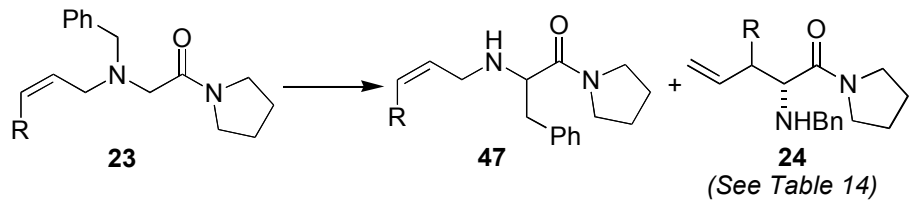

\begin{tabular}{|c|c|c|c|c|}
\hline \multirow[t]{2}{*}{ Entry } & \multirow[t]{2}{*}{ Amine } & \multirow{2}{*}{$\begin{array}{l}\mathrm{T} \\
\left({ }^{\circ} \mathrm{C}\right)\end{array}$} & \multicolumn{2}{|c|}{ Conversions $(\%)^{\mathrm{b}}$} \\
\hline & & & 47 & 24 \\
\hline 1 & 23j $\left(\mathrm{R}=\mathrm{SiMe}_{2} \mathrm{Ph}\right)$ & $\mathrm{rt}$ & $\sim 100^{\mathrm{c}}$ & - \\
\hline 2 & $23 f(R=P h)$ & $\mathrm{rt}$ & 20 & 77 \\
\hline 3 & $23 f(\mathrm{R}=\mathrm{Ph})$ & -20 & 6 & 78 \\
\hline 4 & $23 c(\mathrm{R}=\mathrm{Me})$ & $\mathrm{rt}$ & 5 & 95 \\
\hline 5 & 23h $\left(\mathrm{R}=\mathrm{CH}_{2} \mathrm{OBn}\right)$ & $\mathrm{rt}$ & 3 & 97 \\
\hline
\end{tabular}

The $(Z)$-olefins $\mathbf{2 3 c}, \mathbf{f}$ and $\mathbf{h}$ also rearranged in a [1,2]-fashion, although the major product came from the [2,3]-rearrangement (entries 2-5). ${ }^{103}$ Especially with cinnamyl amine $23 f$ the [1,2]-rearrangement became a concern (entry 2), but by lowering the reaction temperature to $-20{ }^{\circ} \mathrm{C}$, the $[2,3]$-sigmatropic rearrangement prevailed (entry 3). The (E)-olefins $\mathbf{2 3} \mathbf{b}, \mathbf{d}, \mathbf{g}$ and $\mathbf{i}$ gave insignificant amounts of the corresponding [1,2]-rearranged products, indicating a relatively unhindered $[2,3]$-sigmatropic rearrangement pathway.

The rearrangement conditions were also attempted on the $N$-substituted 1,2,5,6-tetrahydropyridine 48, which would give an efficient entry to substituted pyrrolidines (Scheme 38). ${ }^{104,105}$ Unfortunately, no product could be detected and the starting material was recovered. This can be explained by examining the formed spirocyclic structure of the rearrangement precursor 49, which imposes too much strain on the allylic moiety to adopt the proper conformation for rearrangement.
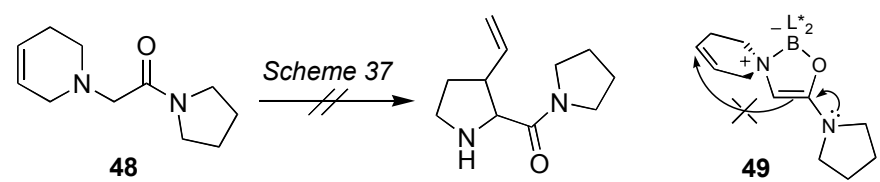

Scheme 38. An attempt to rearrange the 1,2,5,6-tetrahydropyridine 48.

By introduction of a substituent at the $\alpha$-carbon, homoallylic amines with an adjacent quaternary stereogenic center should be conveniently obtained. Additionally, it was important to study the influence of an adjacent stereogenic

\footnotetext{
${ }^{103}$ The structures of $[1,2]-$ rearranged $\mathbf{2 3} \mathbf{c}, \mathbf{f}$ and $\mathbf{h}$ were confirmed by COSY.

${ }^{104}$ For the preparation of $\mathbf{4 8}$, see Supporting Information in Paper IV.

${ }^{105} \mathrm{~N}$-Alkyl 1,2,5,6-tetrahydropyridines have been utilized in [2,3]-sigmatropic rearrangements of ammonium ylides before, see Chapter 1.4.2.
} 
center on the asymmetric rearrangement. Thus, allylic amino amides rac- and (S)-37 were synthesized through standard transformations from DL- and Lalanine methyl esters, respectively. ${ }^{106}$

However, when rac- and (S)-37 were subjected to the optimized rearrangement conditions, the [2,3]-sigmatropic rearrangement was disfavored and only the benzylic [1,2]-rearrangement took place (39, Scheme 39). The conversion of the $\mathrm{rac}-\mathbf{3 7}$ was surprisingly low, whereas $(S)-37$ rearranged in good yield and with good enantiomeric excess. The poor reactivity of $\mathrm{rac}-37$ could not be explained and has to be reevaluated before any certain conclusions can be made.

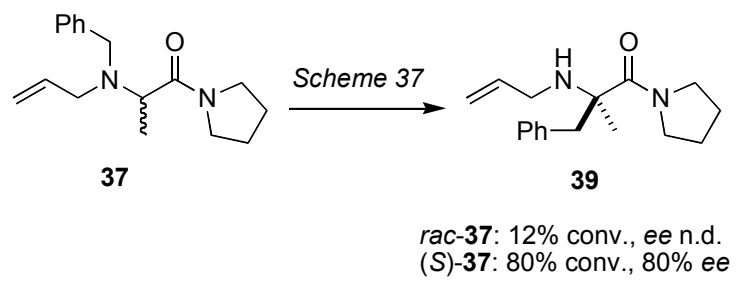

Scheme 39. Benzylic [1,2]-rearrangement of 37 (absolute configuration in analogy with $[2,3]$-rearrangements above).

Apparently, the additional methyl group at the $\alpha$-carbon made the benzylic $[1,2]$-rearrangement more feasible than the [2,3]-sigmatropic rearrangement. To solve that matter, the benzyl group was replaced with an allyl group to furnish the diallyl amines 50. ${ }^{106}$ Subjecting both $\mathrm{rac}$ - and $(S)-\mathbf{5 0}$ to the rearrangement conditions gave at least $20 \%$ conversion of starting material after 20 hours. However, by allowing the reaction mixtures to stir for four days the diallylic amines rac-50 and $(S)-\mathbf{5 0}$ could be converted into $59 \%$ and $78 \%$ yield of rac-51 and $(S)-51$, respectively (Scheme 40). Unfortunately, the enantiomeric excesses of the rearrangements could not be determined. ${ }^{107}$ It should be noted that rearrangement of the allyl group via either a [1,2]- or a [2,3]-rearrangement would provide the same product. One way to distinguish between the two pathways is to have a substituent at the terminal allylic carbon $\left(R^{1}\right.$ or $R^{2} \neq H$, Scheme 37), in which case the [1,2]-rearrangement and the [2,3]-rearrangement will give different products (see Scheme 24, page 24).

\footnotetext{
${ }^{106}$ The experimental data of (S)-37, (S)-50 and $\mathbf{5 1}$ are provided in Supporting Information of Paper IV.

${ }^{107}$ It was not possible to separate the enantiomers on the following normal phase HPLCcolumns (hexane:i-PrOH): Chiralcel OJ, OD, OD-H and Chiralpak AD.
} 


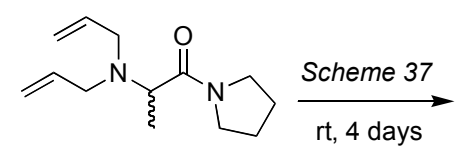

50

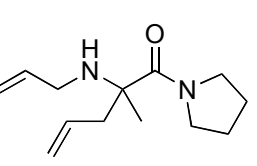

51

rac-50: $59 \%(20 \% 50)$, ee n.d.

(S)-50: $78 \%(21 \% 50)$, ee n.d.

Scheme 40. Attempted asymmetric rearrangement of $\mathbf{5 0}$.

\subsection{Determination of absolute configuration of $24 a-c$}

The absolute configurations of $\mathbf{2 4 a - c}$ were determined by transformation into the Boc-protected amines $\mathbf{5 2}$ and comparing their optical rotations with the optical rotations acquired from the amides 53 (Scheme 41). The amides $\mathbf{5 3}$ were prepared from the commercially available Boc-protected amino acids 52. As evident in Table 16, the optical rotations of 52a-c and 53a-c, respectively, were similar in quantity, but with opposite signs. Thus, the absolute configurations were determined to be $(2 R)-\mathbf{2 4} \mathbf{a},(2 R, 3 R)-\mathbf{2 4} \mathbf{b}$ and $(2 R, 3 S)-\mathbf{2 4 c} .^{108}$
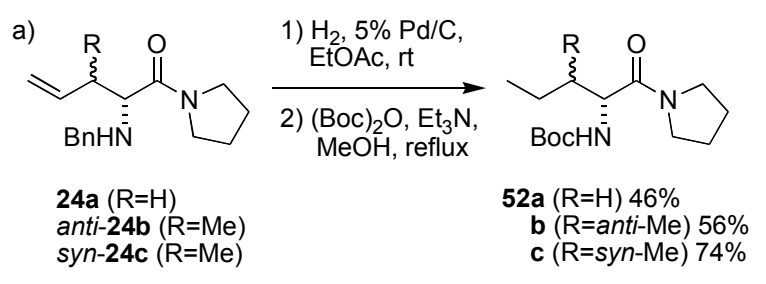

b)

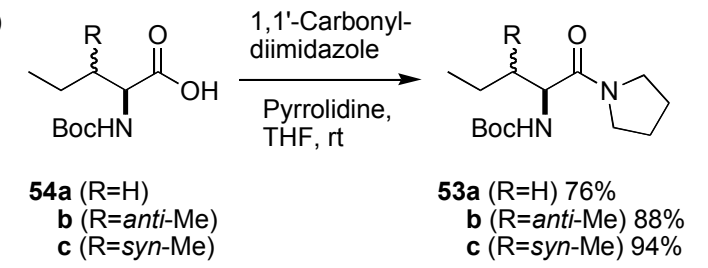

Scheme 41. Determination of the absolute configuration by comparisons of the optical rotations of the products from a) the hydrogenolysis and subsequent Bocprotection of rearranged amines $\mathbf{2 4 a - c}$ and b) the aminolysis of the commercially available amino acids $\mathbf{5 4}$.

Table 16. Comparisons of the optical rotations

\begin{tabular}{c|ccc} 
Optical rotations & $\mathbf{a}$ & $\mathbf{b}$ & $\mathbf{c}$ \\
\hline $\begin{array}{c}\text { From commercially } \\
\text { available 54 }\end{array}$ & {$[\alpha]_{\mathrm{D}}{ }^{20}+4.7$} & {$[\alpha]_{\mathrm{D}}{ }^{20}+4.3$} & {$[\alpha]_{\mathrm{D}}{ }^{20}+22.2$} \\
$\left(\mathrm{c}=1.91, \mathrm{CH}_{2} \mathrm{Cl}_{2}\right)$ & $\left(\mathrm{c}=0.80, \mathrm{CH}_{2} \mathrm{Cl}_{2}\right)$ & $\left(\mathrm{c}=1.51, \mathrm{CH}_{2} \mathrm{Cl}_{2}\right)$ \\
\hline $\begin{array}{c}\text { From rearranged } \\
\text { products 24 }\end{array}$ & {$[\alpha]_{\mathrm{D}}{ }^{20}-4.0$} & {$[\alpha]_{\mathrm{D}}{ }^{20}-4.3$} & {$[\alpha]_{\mathrm{D}}{ }^{20}-19.3$} \\
$\left(\mathrm{c}=0.30, \mathrm{CH}_{2} \mathrm{Cl}_{2}\right)$ & $\left(\mathrm{c}=0.32, \mathrm{CH}_{2} \mathrm{Cl}_{2}\right)$ & $\left(\mathrm{c}=0.62, \mathrm{CH}_{2} \mathrm{Cl}_{2}\right)$ \\
\hline
\end{tabular}

${ }^{108}$ For experimental details and characterizations, see Supporting Information in Paper III. 


\subsection{Rationalization of the asymmetric induction}

We envisioned two possible reaction pathways to explain the observed stereoselectivities. The first model suggests a kinetically controlled stereoselection, in which the stereoselectivities are established prior to the rearrangement. The second pathway has a thermodynamically controlled stereoselection, where the selectivities are established after the rearrangement. The two pathways can lead to the same product outcome, with respect to both absolute and relative configuration, and will be discussed separately below. To find support for either pathway an NMR investigation of the complexes prior to and after the rearrangement was performed. In addition, the remarkably stable complex $\mathbf{D}(\mathrm{R}=\mathrm{H})$ was isolated and characterized, as discussed in Chapter 3.7.4.

\subsubsection{Kinetically controlled stereoselectivity}

To account for the obtained stereoselectivities, two different kinetic processes were considered. First, a diastereoselective complexation of Lewis acid 44a to 23 would preferably lead to complex B (Scheme 42). Subsequent deprotonation to form $\mathbf{C}$ and ensuing rearrangement would proceed via exo-transition state $\mathbf{T S}$ to provide rearranged complex D. Acidic hydrolysis would furnish $(2 R, 3 R)$-anti-24, the isomer that is experimentally observed. The minor diastereomer $(2 R, 3 S)$-syn24 would originate from the corresponding endo-transition state.

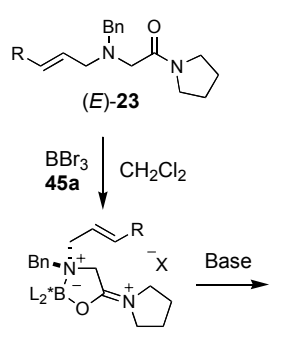

B

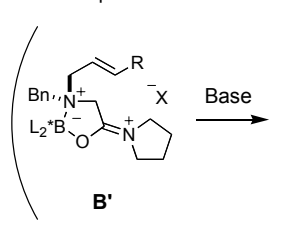

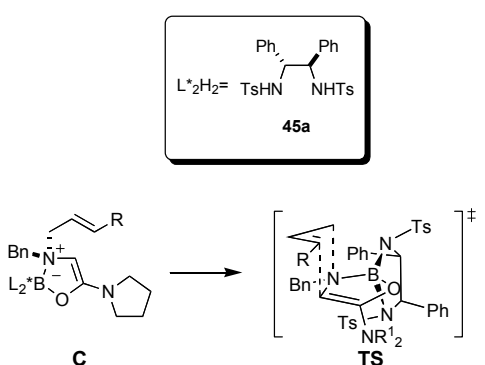

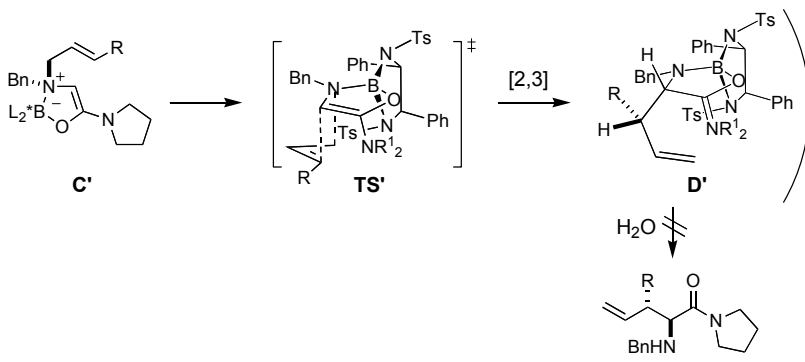

$(2 S, 3 S)$-anti-24 not observed

Scheme 42. Rationalization of the stereoselectivity via diastereoselective formation of $\mathbf{B}$ (only exo-TS shown and the charges are omitted on TS and TS' for clarity; $\mathrm{X}=\mathrm{L}_{2}{ }_{2} \mathrm{BBr}_{2}$ or $\mathrm{Br}$ ). 
However, as the benzyl and allyl groups are sterically and electronically relatively similar, it seemed unlikely to obtain a diastereoselective complexation to exclusively form $\mathbf{B}$. Thus, the second considered process suggests unselective formation of both complexes $\mathbf{B}$ and B' (Scheme 43). Upon deprotonation to $\mathbf{C}$ and $\mathbf{C}^{\prime}$ the B-N bond could be cleaved and reformed via ring-opened $\mathbf{5 5}$, possibly assisted by bromide anions or base, resulting in an equilibrium between $\mathbf{C}$ and $\mathbf{C}$ '. Hence, the energy difference between transition states TS and TS' will determine the outcome of the reaction. In TS', the Ts-group efficiently blocks the $\mathrm{Si}$-face of the enolate double bond in the oxazaborocycle, while the Ts-moiety will not interfere in TS. Consequently, the energy barrier to provide the rearranged complex $\mathbf{D}$, is lower than that leading to $\mathbf{D}^{\prime}$, implying that the rearranged complex D is more stable than D' (DFT-calculations established that D $(\mathrm{R}=\mathrm{H})$ is $10 \mathrm{kcal} / \mathrm{mole}$ more stable than $\left.\mathbf{D}^{\prime}\right)$. Thus, the rearrangement will be channeled through transition state TS via the proposed equilibrium, affording (2R,3R)-24.

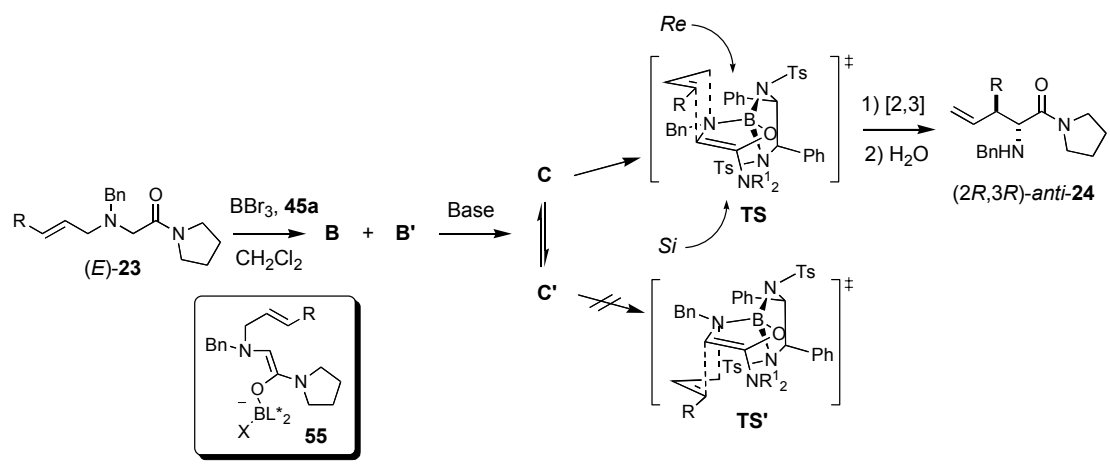

Scheme 43. Rationalization of the stereoselectivity via an equilibrium between the deprotonated complexes $\mathbf{C}$ and $\mathbf{C}^{\prime}$ (the charges are omitted on TS and TS' for clarity).

An alternative B-B' equilibrium via ring-opened $\mathbf{5 6}$ could also be envisioned. Since $\mathbf{C} / \mathbf{C}^{\prime}$ (and $\mathbf{5 5}$ ) practically are enolates, an acid-base equilibrium could be established between $\mathbf{B} / \mathbf{B}^{\prime}$ and $\mathbf{C} / \mathbf{C}^{\prime}$ (or $\mathbf{5 5}$ and 56). Consequently, $\mathbf{C}$ and $\mathbf{C}$ ' could be equilibrated by a dynamic process, enforced via the proposed acid-base and B-B' equilibriums (Scheme 44).

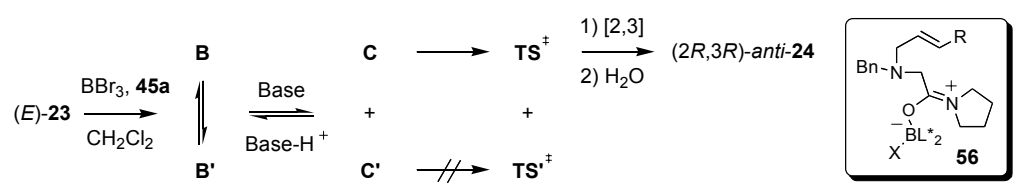

Scheme 44. Rationalization of the stereoselectivity via a dynamic process, in which $\mathbf{C}$ and $\mathbf{C}$ ' are equilibrated via an equilibrium between $\mathbf{B}$ and $\mathbf{B}$ '. 
The dynamic process is very likely when $\mathrm{Et}_{3} \mathrm{~N}$ is involved, since its conjugate acid is relatively acidic $\left(\mathrm{pK}_{\mathrm{a}}=9, \mathrm{DMSO}\right) .{ }^{109}$ The conjugate acid of $\mathbf{2 5}$ (see Figure 6), however, is probably not acidic enough to be deprotonated by $\mathbf{C} / \mathbf{C}^{\prime}$ or $\mathbf{5 5}$, thus making the proposed C-C' equilibrium more likely. To complicate matters further, both pathways could be involved depending on the $\mathrm{pK}_{\mathrm{a}}$ of the conjugate base operating in the reaction.

The proposed equilibriums find support in the literature, were a crystallization-induced asymmetric transformation (AT) of a diastereomeric mixture of $\mathbf{5 7}$ and $\mathbf{5 8}$ has been presented (Scheme 45). ${ }^{73}$ The diastereomic mixture was crystallized to afford only $\mathbf{5 7}$ and it was reasoned that the mixture undergoes equilibration via B-N bond cleavage, followed by AT. This account suggests that the above-proposed equilibriums may well be present.

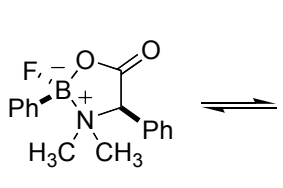

57

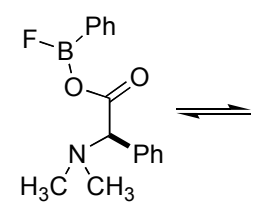

$\mathrm{H}_{3} \mathrm{C} \mathrm{C}^{\prime} \mathrm{CH}_{3}$<smiles>C[N+]1(C)C(c2ccccc2)C(=O)O[B-]1(F)P</smiles>

58

Scheme 45. Equilibrium between two diastereomeric boron-amino acid complexes via B-N bond cleavage.

If the stereoselectivity is kinetically controlled as suggested above, the absolute configuration at the C2-carbon is established via $R e$ or $S i$-face selectivity in the TS/TS' transition states, whereas the absolute configuration at the C3-carbon (giving the anti:syn-selectivity) is generated via the exo:endo orientation of the allyl moiety (Scheme 46).

The rearrangements of the $(E)$-olefins were anti-selective and must consequently proceed via the exo-TS transition state to provide $(2 R, 3 R)-\mathbf{2 4}$. This can be readily understood by the reduced steric interactions of the allyl group in the exo-transition state compared to the endo-transition state. Both the $\mathrm{R}$ substituent and the allylic C2-carbon are oriented away from the bulky interior of the oxazaborocycle. Although the endo-transition state seems to be very sterically encumbered, a significant amount of syn-isomer is obtained, particularly from 23b $(\mathrm{R}=\mathrm{Me}, 21 \%)$ and 23d $(\mathrm{R}=\mathrm{Ph}, 33 \%)$. One plausible rationalization for these results arises from favorable electronical interactions between the allyl moiety and the oxazaborocycle moiety in the endo-transition state (compare with the results relating to Scheme 26). Increased steric bulk of the $\mathrm{R}$ substituent diminishes the electronical interactions, as can be seen in the diastereoselectivities in going from 23b $(\mathrm{R}=\mathrm{Me}, 79: 21$ anti:syn) via $\mathbf{2 3 g}$ $\left(\mathrm{R}=\mathrm{CH}_{2} \mathrm{OBn}, 88: 12\right)$ to $\mathbf{2 3 i}\left(\mathrm{R}=\mathrm{SiMe}_{2} \mathrm{Ph}, 95: 5\right)$.

${ }^{109}$ http://evans.harvard.edu/pdf/evans_pKa_table.pdf 


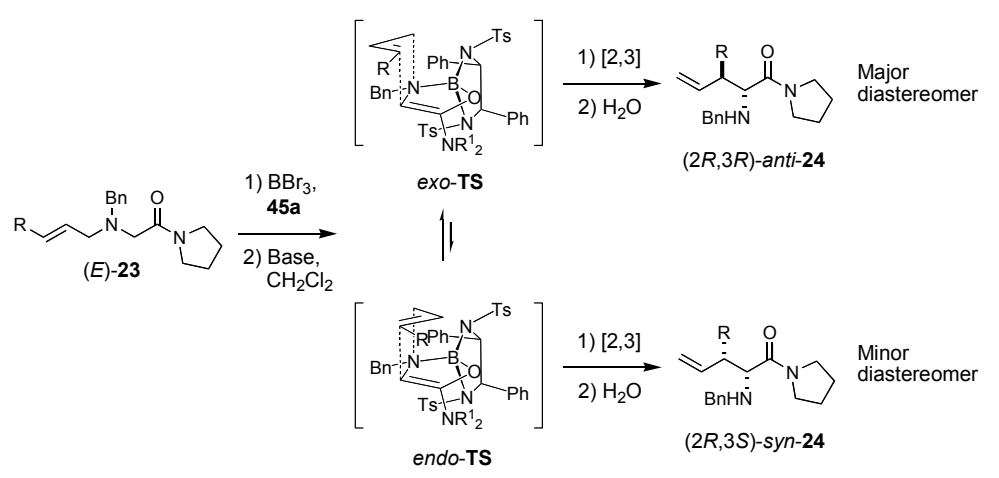

Scheme 46. Transition state models elucidating the diastereoselectivity in the kinetically controlled rearrangement of $(E)$-olefins $\mathbf{2 3}$ (the charges are omitted for clarity).

The rearrangements of the (Z)-olefins afforded lower and opposite diastereoselectivities than the corresponding $(E)$-olefins. This observation can be explained by the fact that both the exo- and endo-transition states are unfavorable (Scheme 47).

In the exo-transition state unfavorable sterical interactions from the R-substituent arise, whereas the endo-transition state is destabilized by interaction of the allylic $\mathrm{C} 2$-carbon with the bulky interior of the oxazaborocycle.

There is a slight preference for the exo-transition state, though that seems to be lessened with larger substituents on the olefin; 23c $(\mathrm{R}=\mathrm{Me}, 20: 80$ anti:syn) and 23h $\left(\mathrm{R}=\mathrm{CH}_{2} \mathrm{OBn}, 29: 71\right)$. With $\mathbf{2 3} \mathbf{j}\left(\mathrm{R}=\mathrm{SiMe}_{2} \mathrm{Ph}\right)$ severe sterical interactions in both the exo and the endo-transition state lead to no or very little product from the [2,3]-sigmatropic rearrangement and instead the benzylic [1,2]rearrangement turns out to be the favorable pathway (see Table 15).

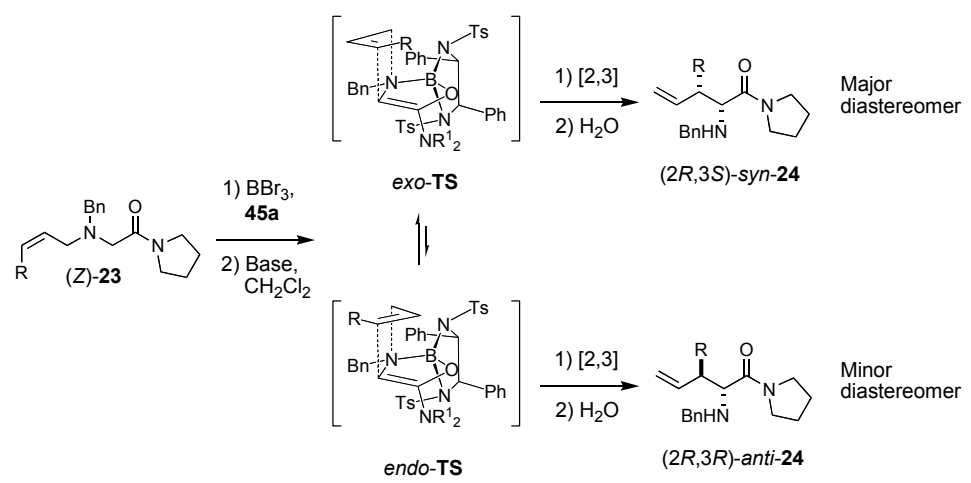

Scheme 47. Transition state models elucidating the diastereoselectivity in the kinetically controlled rearrangement of $(Z)$-olefins $\mathbf{2 3}$ (the charges are omitted for clarity). 


\subsubsection{Thermodynamically controlled stereoselectivity}

Alternatively, the stereoselection can be thermodynamically controlled. In this case, the focus would be on the rearranged complexes D and D' (Scheme 48). The basic conditions applied in the rearrangement should lead to deprotonation of the relatively acidic $\mathbf{D}$ and $\mathbf{D}$ ', thus establishing equilibriums between $\mathbf{D}$ and F, and D' and F', respectively. Due to unfavorable steric interactions with the Ts-group from the Si-face (see Scheme 43), the complexes D' and F will be destabilized compared to $\mathbf{D}$ and $\mathbf{F}$ '. Thus, upon acidic hydrolysis, complex $\mathbf{D}$ will give the observed major product $(2 R, 3 R)$-anti-24, whereas the thermodynamically less stable complex $\mathbf{F}$ will provide the minor product $(2 S, 3 R)$-syn-24. Likewise, complex F' gives $(2 R, 3 S)$-syn-24 and D' yields minor product $(2 S, 3 S)$-anti-24. Although this rationale concerns rearrangement of $\mathbf{C}$ and $\mathbf{C}^{\prime}$ via an exo-transition state, the analogous event via an endo-transition state will merely give opposite product outcome (D will instead provide $(2 R, 3 S)$ syn-24, whereas $\mathbf{F}$ ' will give $(2 R, 3 R)$-anti-24, i.e. the experimentally observed products).

To confirm this rationale, DFT-calculations were performed on complexes $\mathbf{D}$ $\left(\mathrm{R}=\mathrm{H}\right.$, same as $\left.\mathbf{F}^{\prime}\right)$ and $\mathbf{D}^{\prime}(\mathrm{R}=\mathrm{H}$, same as $\mathbf{F}){ }^{{ }^{110}}$ These calculations established that the complex $\mathbf{D}(\mathrm{R}=\mathrm{H})$ is $10 \mathrm{kcal} / \mathrm{mole}$ more stable than $\mathbf{D}^{\prime}(\mathrm{R}=\mathrm{H})$, thereby substantiating the rationale.

In this scenario, the absolute configuration at the $\mathrm{C} 2$-carbon is established under thermodynamic control during the base-induced equilibrium after the rearrangement. The absolute configuration at the $\mathrm{C} 3$-carbon is established from the relative formation of complexes $\mathbf{D} / \mathbf{D}$ ' and the exo/endo-preference in the transition states.
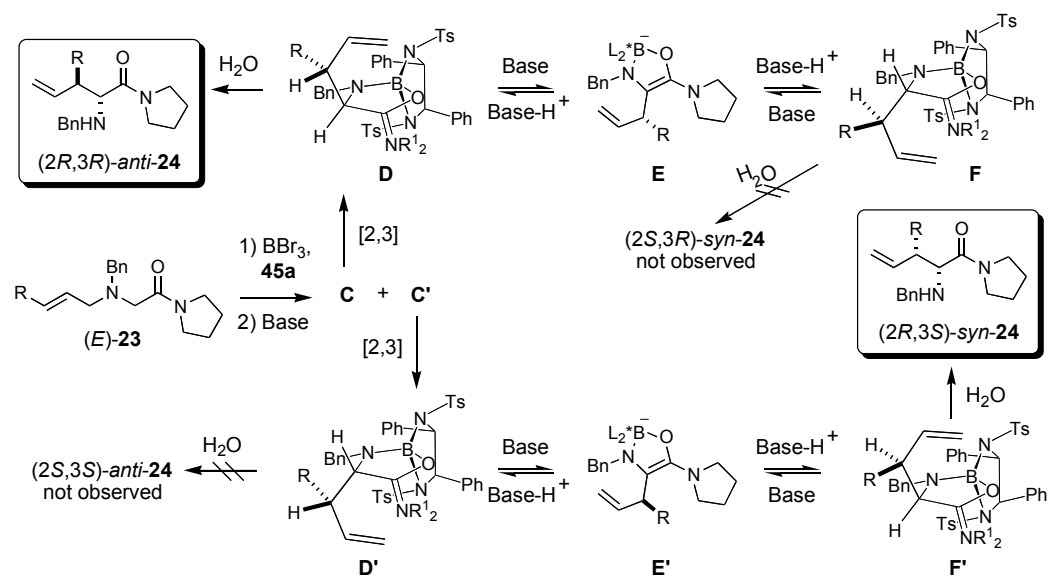

Scheme 48. Stereoselectivities arising from a thermodynamically controlled reaction pathway (only rearrangement from the exo-transition state considered and the charges are omitted on $\mathbf{D}, \mathbf{D}^{\prime}, \mathbf{F}$, and $\mathbf{F}^{\prime}$ for clarity).

${ }^{110}$ For details, see Paper III. 
An irreversible deprotonation to provide $\mathbf{E}$ and E' could also envisioned, but during hydrolysis the proton will most likely be delivered from the least hindered $R e$-face of the enolate double bond in complexes $\mathbf{E}$ and $\mathbf{E}$ ', thus providing the $S$ configuration at $\mathrm{C} 2$, which is the opposite absolute configuration of the experimentally observed products. As an irreversible deprotonation is expected with phosphazene base 25, a thermodynamic controlled process is not likely under these circumstances.

\subsubsection{NMR investigation of the transient rearrangement species.}

With the objective to clarify the mechanistic details of the rearrangement and in particularly to verify a kinetic pathway, an NMR investigation of the complex formed between $\mathbf{4 4 a}$ and $\mathbf{2 3 b}$ along with the formation of the anticipated deprotonated and rearranged complexes $\mathbf{C} / \mathbf{C}^{\prime}$ and exo-D/endo-D, respectively, was initiated (Scheme 49). Thus, the complex between 44a and $\mathbf{2 3 b}$ was formed as previously described and monitored by ${ }^{1} \mathrm{H}$ and ${ }^{11} \mathrm{~B}$ NMR spectroscopy.

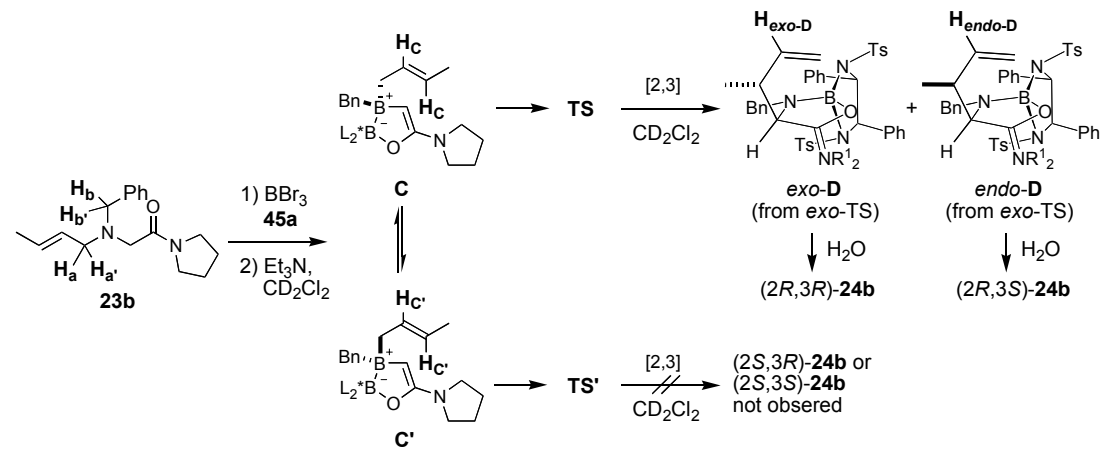

Scheme 49. The proposed transient rearrangement species (observed protons in ${ }^{1} \mathrm{H}$ NMR in bold and charges omitted on exo-D and endo-D for clarity).

By the up-field change in chemical shift of the signals from the diastereotopic protons of the $N$-allyl and $N$-benzyl substituents $\left(\mathrm{H}_{\mathrm{a}}\right.$ and $\left.\mathrm{H}_{\mathrm{b}}\right)$, it was anticipated that the substrate $\mathbf{2 3 b}$ was converted into the proposed complexes $\mathbf{B}$ and/or B'. It was difficult from ${ }^{1} \mathrm{H}$ NMR to establish whether a mixture of the complexes formed or whether an equilibrium between them existed (Figure 15, NMR 1). ${ }^{111}$ ${ }^{11} \mathrm{~B}$ NMR revealed a broad singlet at $10.4 \mathrm{ppm}$ and two very broad signals at 23.5 and $27.3 \mathrm{ppm}$, respectively. The first boron signal most likely arose from the complexes $\mathbf{B} / \mathbf{B}$ ', while the latter two were probably originating from residual chiral Lewis acid. To that solution was added $>2$ equivalents $\mathrm{Et}_{3} \mathrm{~N}$ and the ${ }^{1} \mathrm{H}$ NMR spectrum was instantly recorded (NMR 2). Two signals around $6.0 \mathrm{ppm}$, interpreted as the $\mathbf{H}_{\mathbf{C} / \mathbf{C}}$, protons on the double bond of $\mathbf{C}$ and $\mathbf{C}$ ' (either both or one of the protons on the double bond), had emerged along with a broad signal at $5.6 \mathrm{ppm}$, later attributed to reformed starting material $\mathbf{2 3 \mathbf { b }}$. How $\mathbf{2 3 \mathbf { b }}$ formed is unclear, but the relative integral maintained constant during the experiment

${ }^{111}$ The full spectras of the NMR investigation are provided in Appendix C. 
(NMR 3-6). The signals corresponding to $\mathbf{C}$ and $\mathbf{C}^{\prime}$ had a 2:1 ratio throughout the NMR experiment and were slowly diminishing relative to the other signals and disappeared within 5-6 hours. The boron signal at $10.4 \mathrm{ppm}$ had endured, but now only one very broad signal appeared at $22.8 \mathrm{ppm}$. While the signals corresponding to complexes $\mathbf{C} / \mathbf{C}^{\prime}$ ' diminished, two new signals at 6.2 and 6.3 ppm appeared and were interpreted as the $\mathbf{H}_{\text {exo-D }}$ and $\mathbf{H}_{\text {endo-D }}$ protons on the allylic C2-carbon of the rearranged complexes exo-D and endo-D, respectively (NMR 3). The ratio between the two signals was $4: 1$ and remained constant during the experiment (NMR 3-5). During this time the signal at $10.4 \mathrm{ppm}$ in the ${ }^{11} \mathrm{~B}$ NMR spectrum also diminished and was replaced by a signal at approximately 9 ppm, probably arising from the rearranged complexes D. This signal is in agreement with the boron signal from the isolated rearranged complex $\mathbf{D}\left(\mathrm{R}=\mathrm{H}\right.$, vide infra). Moreover, by measurement of the ${ }^{1} \mathrm{H}$ integrals, it could be established the relative amount between the complexes and amine $\mathbf{2 3 b}$ remained constant during the acquisitions of NMR 2-6.

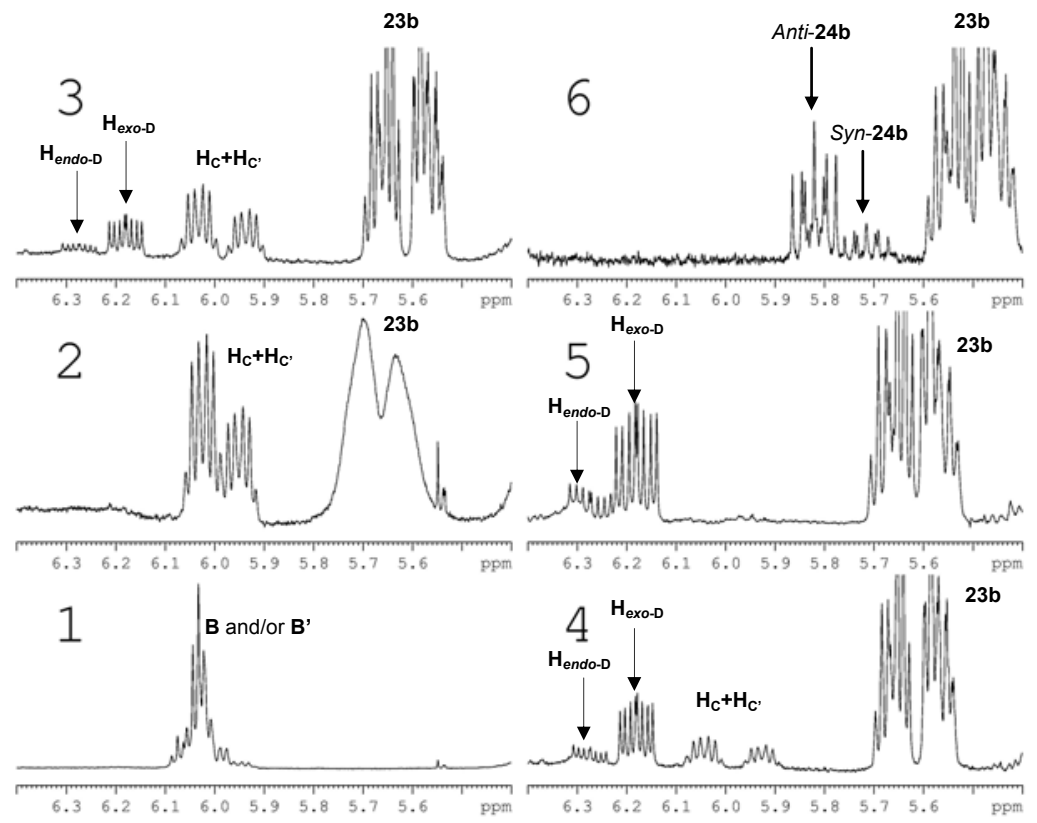

Figure 15. NMR investigation of the transient rearrangement species. 1; Complex(es) formed by mixing 23b (1 equiv.) and chiral Lewis acid 44a (2 equiv.). 2; After addition of $\mathrm{Et}_{3} \mathrm{~N}$ ( $>2$ equiv.). 3; After 90 min. 4; After 2 hours. 5; After 5-6 hours. 6; After acidic hydrolysis and work-up.

Our rationalization of the observed signals in the NMR investigation is as follows; the complex $\mathbf{C}$ and $\mathbf{C}^{\prime}$ existed in a slow equilibrium in a 2:1 relationship (NMR time scale, NMR 2-4). The complexes could also be equilibrated via the dynamic process described above, in which a $\mathbf{B} / \mathbf{B}$ '-equilibrium was involved. 
Nevertheless, in the kinetic scenario only complex $\mathbf{C}$ rearranged, either via the exo- or endo-transition state, to provide a 80:20 diastereomeric ratio of rearranged complexes exo-D and endo-D (Scheme 49). After the rearrangement was complete (NMR 5), acidic hydrolysis and work up provided $(2 R, 3 R)$ 24b:(2R,3S)-24b in a 80:20 diastereoselectivity and $>97$ and $82 \%$ ee, respectively, together with recovered starting material (NMR 6). Consequently, the NMR investigation suggests that a kinetic pathway as the one described in Chapter 3.7.1 may well be responsible for the stereochemical outcome.

\subsubsection{Structure of the rearranged complex $\boldsymbol{D}(R=H)$}

The early asymmetric rearrangement attempts revealed a remarkable stability of the rearranged complex $\mathbf{D}(\mathrm{R}=\mathrm{H})$. Consequently, it seemed feasible to isolate and characterize that complex. Thus, 23a was rearranged under optimized reaction conditions and when the reaction was considered complete (20 hours), washed with saturated $\mathrm{NaHCO}_{3}$ instead of the usual acidic hydrolysis. The resultant crude solid was purified by chromatography, which afforded the complex $\mathbf{D}(\mathrm{R}=\mathrm{H})$ in $93 \%$ yield as the only diastereomer. An aliquot was recrystallized to provide X-ray quality crystals of $\mathbf{D}$ (Figure 16). ${ }^{112}$ The complex was shelf-stable at least for a couple of months. Both the X-ray and DFTcalculated structures confirms that one of the Ts-groups efficiently shields the $\mathrm{Si}$-face of the enolate double bond in the oxazaborocycle, thereby supporting the transition state analysis of the kinetic pathway. Interestingly, the nitrogen in the oxazaborocycle is very close to a planar configuration, making the nitrogen nearly $\mathrm{sp}^{2}$-hybridized.

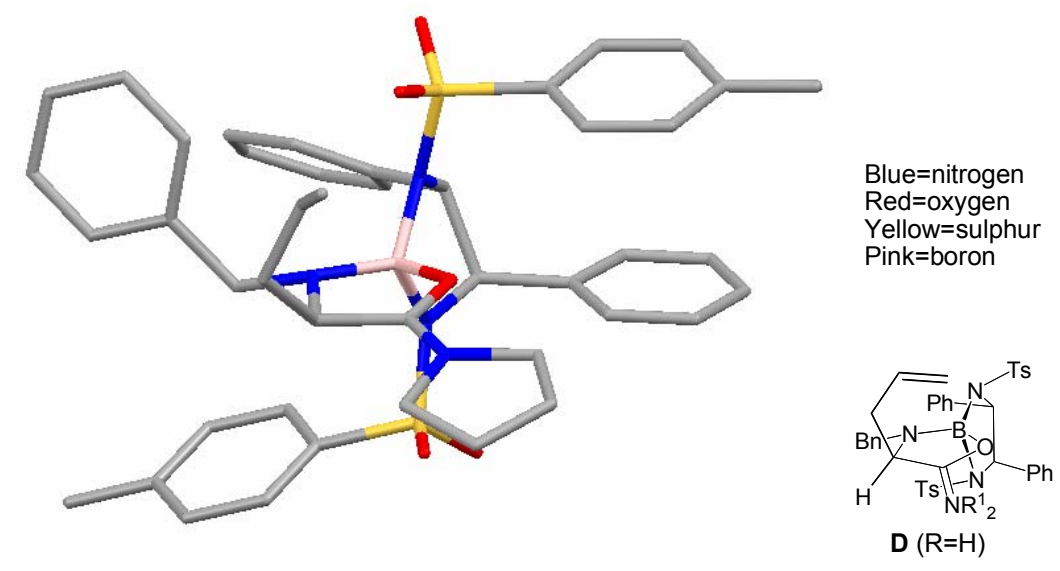

Figure 16. Crystal structure of $\mathbf{D}(\mathrm{R}=\mathrm{H})$. Hydrogens omitted for clarity.

To verify whether $\mathrm{Et}_{3} \mathrm{~N}$ would be basic enough to deprotonate complex $\mathbf{D}$ $\left(\mathrm{R}=\mathrm{H}\right.$, see Scheme 48), the complex was dissolved in $\mathrm{CH}_{2} \mathrm{Cl}_{2}$ and subjected to $\mathrm{Et}_{3} \mathrm{~N}$ (>10 equiv.) and $\mathrm{D}_{2} \mathrm{O}(>20$ equiv.). After stirring at room temperature for

${ }^{112}{ }^{1} \mathrm{H},{ }^{13} \mathrm{C}$ and ${ }^{11} \mathrm{~B}$ NMR; see Supporting Information of Paper IV. 
19 hours the solvents were removed under reduced pressure. From ${ }^{1} \mathrm{H}$ NMR it was evident that the complex had not incorporated any deuterium. Although this does not prove that an equilibrium between the rearranged complexes $\mathbf{D}$ and $\mathbf{F}$ (see Scheme 48) is absent, it strongly suggests that the thermodynamically controlled pathway is not likely.

\subsection{Conclusions}

An asymmetric [2,3]-sigmatropic rearrangement of achiral allylic amines has been realized by employing the chiral Lewis acid 44a. The scope of the rearrangement was demonstrated on several amines, affording the corresponding homoallylic secondary amines $\mathbf{2 4}$ in excellent enantiomeric excesses and decent to good diastereoselectivities. A detailed study of the diastereoselectivity was provided by four different $(E) /(Z)$-olefinc pairs, revealing an exo preference in the transition state of the rearrangement. The obtained stereoselectivities were rationalized by invoking either a kinetic or thermodynamic pathway. The kinetically pathway was favored in light of the results from a $\mathrm{D}_{2} \mathrm{O}$-quenching experiment of the isolated rearranged complex $D(R=H)$ and a NMR investigation of the transient rearrangement species. 


\section{Concluding remarks}

An asymmetric [2,3]-sigmatropic rearrangement of achiral allylic amines into optically pure homoallylic amines has been realized. Quaternization of the amines with a chiral diazaborolidine and subsequent treatment with a mild base furnished the rearranged amines in modest to good diastereoselectivities and excellent enantiomeric excesses. The asymmetric rearrangement was initially developed by an investigation of various achiral Lewis acids on an allylic $\alpha$ amino amide, revealing the boron halides as appropriate Lewis acids. From the results of this study a suitable chiral boron-based Lewis acid was chosen. NMR studies and DFT-calculations together with the experimental results established that the rearrangement proceeds via oxazaborolidine complex, in which the amine coordinates to the boron atom as a bidentate ligand.

The high enantiomeric excesses and good diastereoselectivities together with the diverse functionalities of some of the investigated amines, makes this transformation an attractive candidate as a key step in future applications toward total synthesis of natural products. 


\section{Acknowledgements}

Denna avhandling hade aldrig varit möjlig utan den uppmuntran jag fätt av vänner och kollegor. Ett stort tack riktas till...

Peter för att du antog mig som doktorand och för det stöd du gav mig.

Hela PS-gruppen för en stimulerande och lärorik miljö. Ett speciellt tack till Berit för ordningen på labbet och att du lärde mig laborativ organisk kemi, samt Pavel för tiden i "vårt" lab och Tessie för allt kämpande med "metathesis"-reaktionerna.

Daniel, Per och Staffan - ACS meeting in Philadelphia.

Avdelningen organisk kemi med kollegor.

Berit, Olaf, Per, Staffan, Peter och Ki för korrekturläsningen.

KTH, Vetenskapsrådet, Knut och Alice Wallenbergs stiftelsen, AulinErdtman stiftelsen och Ångpanneföreningen för finansiering.

All den kärlek och lycka jag får från min egen familj; min dotter Linn och min fru Therése, ni är mitt allt. 


\section{Appendix A}

The following is a description of my contribution to papers I to IV, as requested by KTH:

I. I performed all the experimental work and wrote the article.

II. I performed all the experimental work and wrote the article, except the DFT part, which was calculated and written by Peter Brandt.

III. I performed all the experimental work, except for the syntheses and rearrangements of $\mathbf{2 3 f}$ and $\mathbf{j}$, which were made by Olaf Panknin. I shared writing of the article with Peter Somfai. DFT-calculations were made by Timofei Privalov.

IV. I performed all the lab work, except for the syntheses and rearrangements of $\mathbf{2 3 f}$ and $\mathbf{j}$, and wrote the manuscript. The X-ray structure of $\mathbf{D}(\mathrm{R}=\mathrm{H})$ was provided by Andreas Fischer. 


\section{Appendix B}

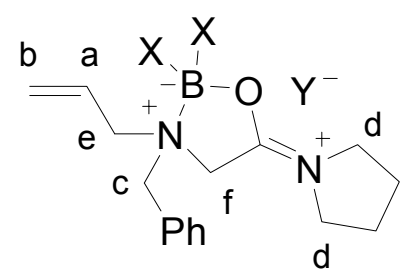

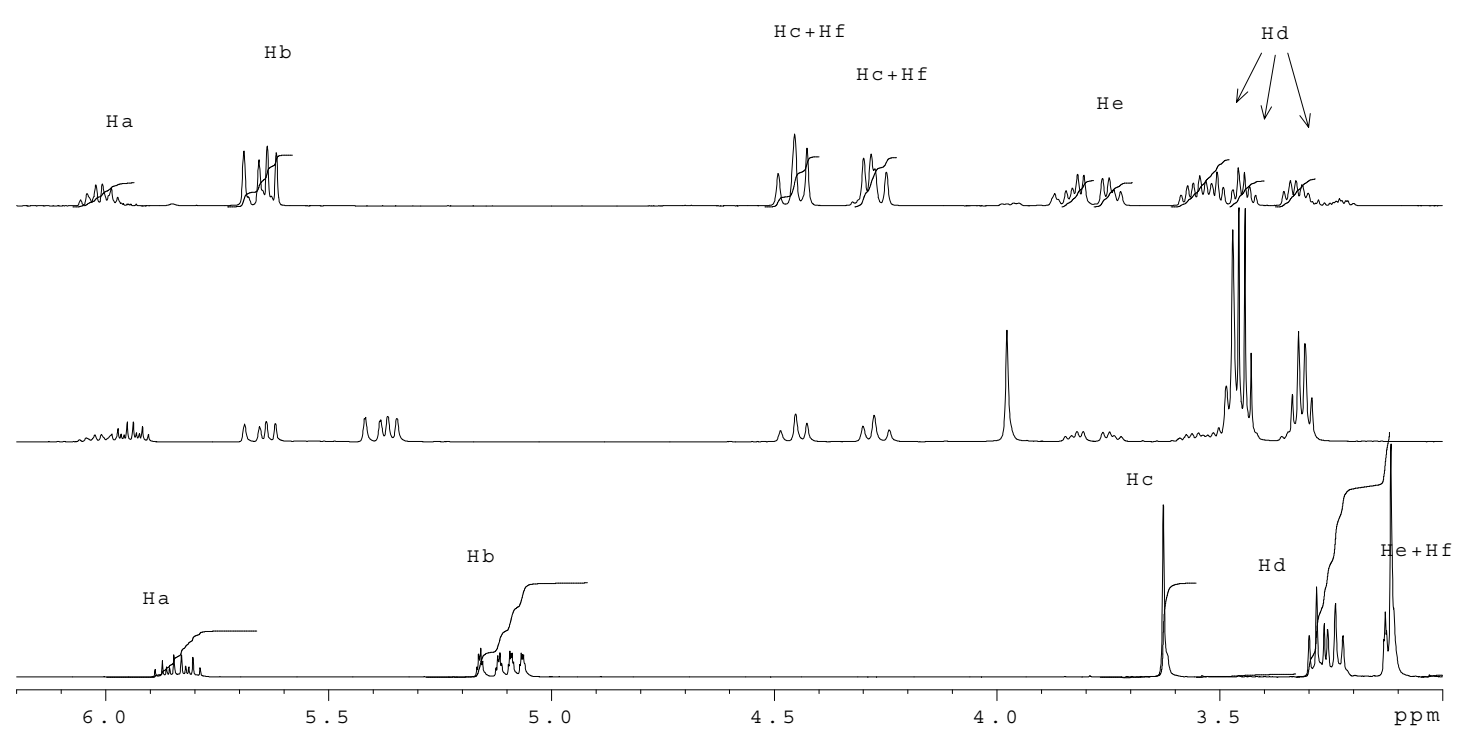

$\mathrm{BF}_{2}{ }^{+}$-complex $34\left(\mathrm{X}=\mathrm{F}, \mathrm{Y}=\mathrm{BF}_{4}\right)$. Top spectrum: 2 eq $\mathrm{BF}_{3}+\mathbf{2 3 a}$

Middle spectrum: 1 eq of $\mathrm{BF}_{3}+\mathbf{2 3 a}$ (contains $\mathrm{Et}_{2} \mathrm{O}$ )

Bottom spectrum: Substrate 23a
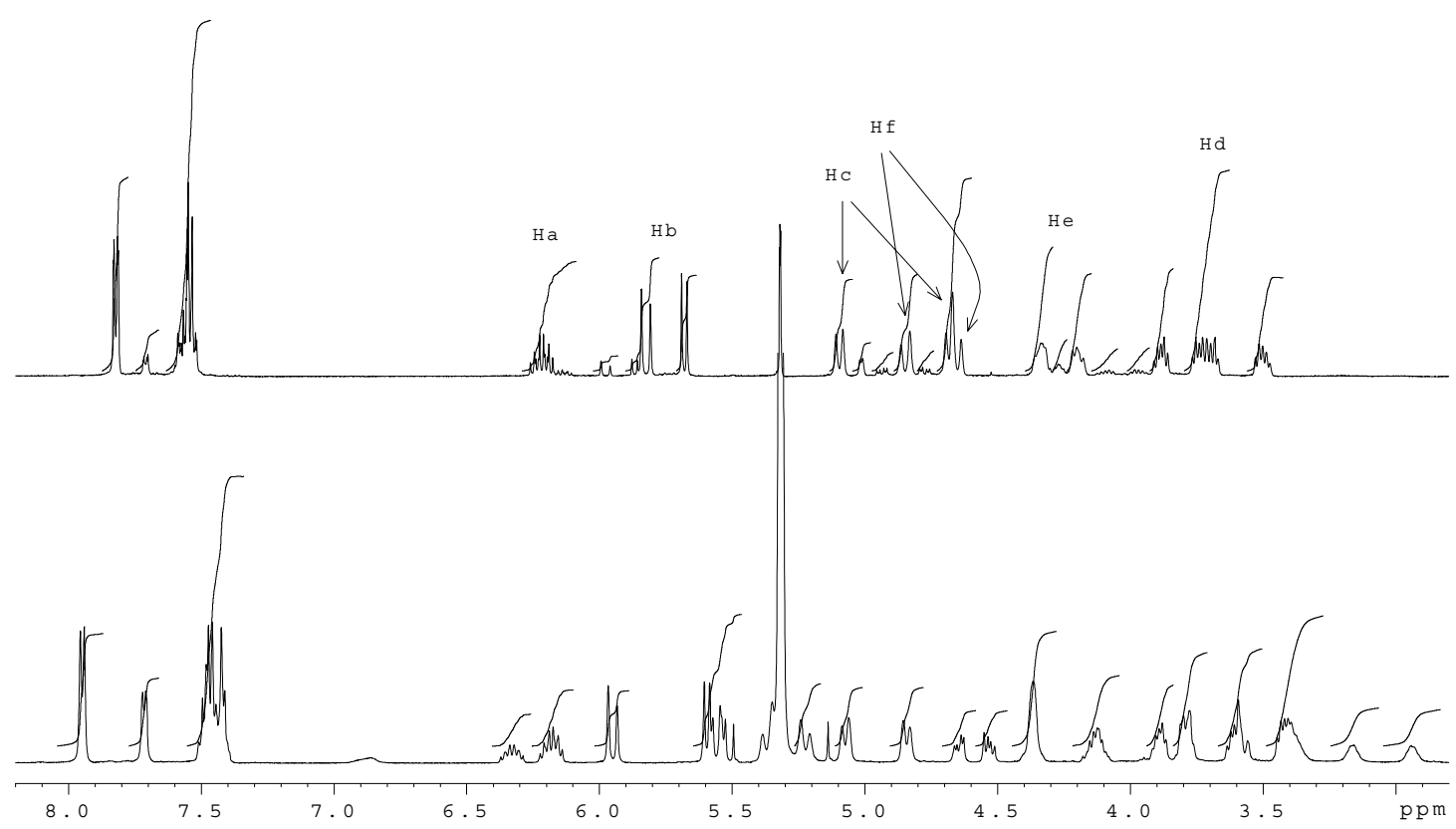

$\mathrm{BBr}_{2}{ }^{+}$-complex $35(\mathrm{X}, \mathrm{Y}=\mathrm{Br})$. Top spectrum: 3 eq $\mathrm{BBr}_{3}+\mathbf{2 3 a}$

Bottom spectrum: 1 eq $\mathrm{BBr}_{3}+\mathbf{2 3 a}$ 


\section{Appendix C}

${ }^{1} \mathrm{H}$ NMR of the NMR investigation discussed in Chapter 3.7.3.
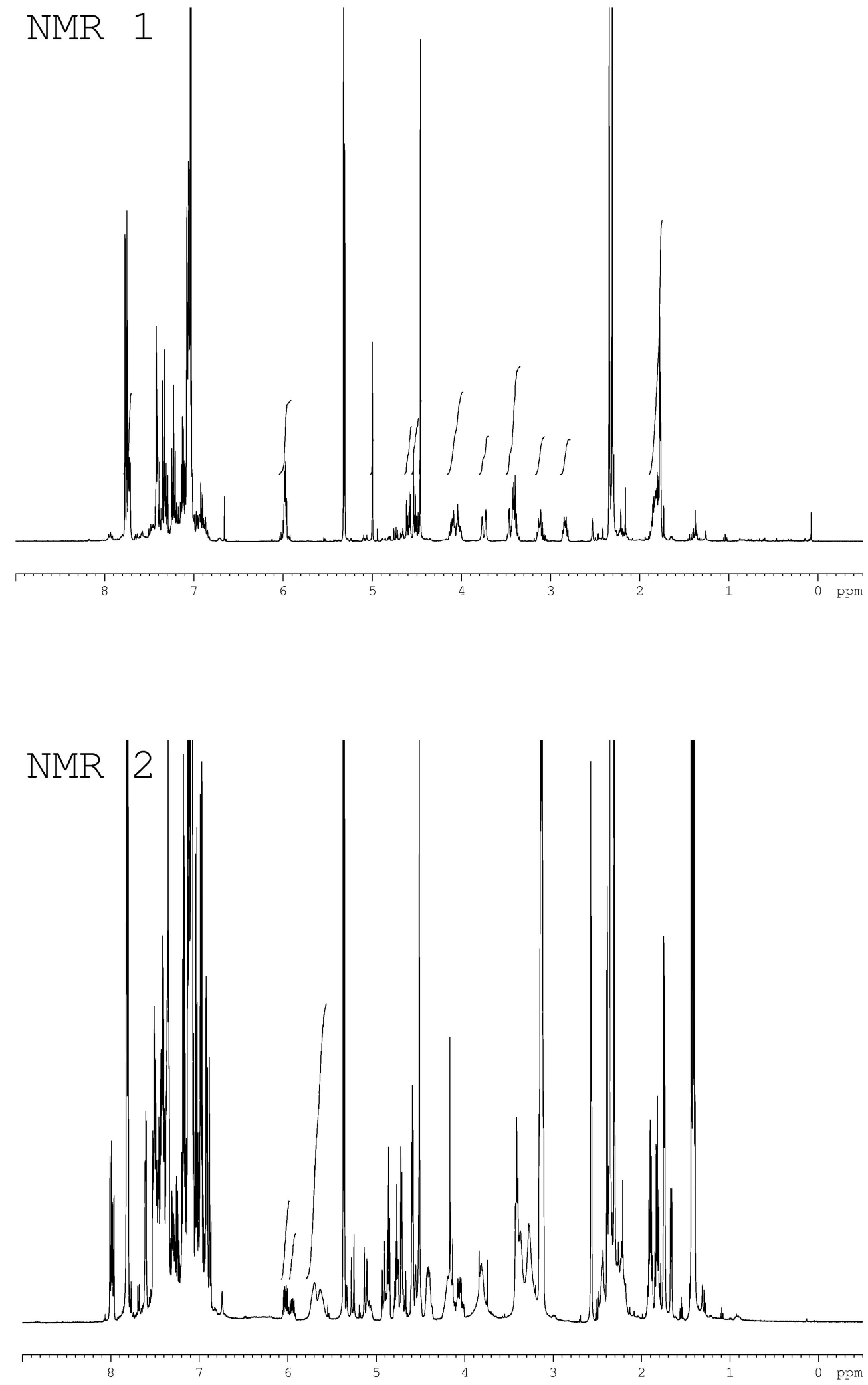

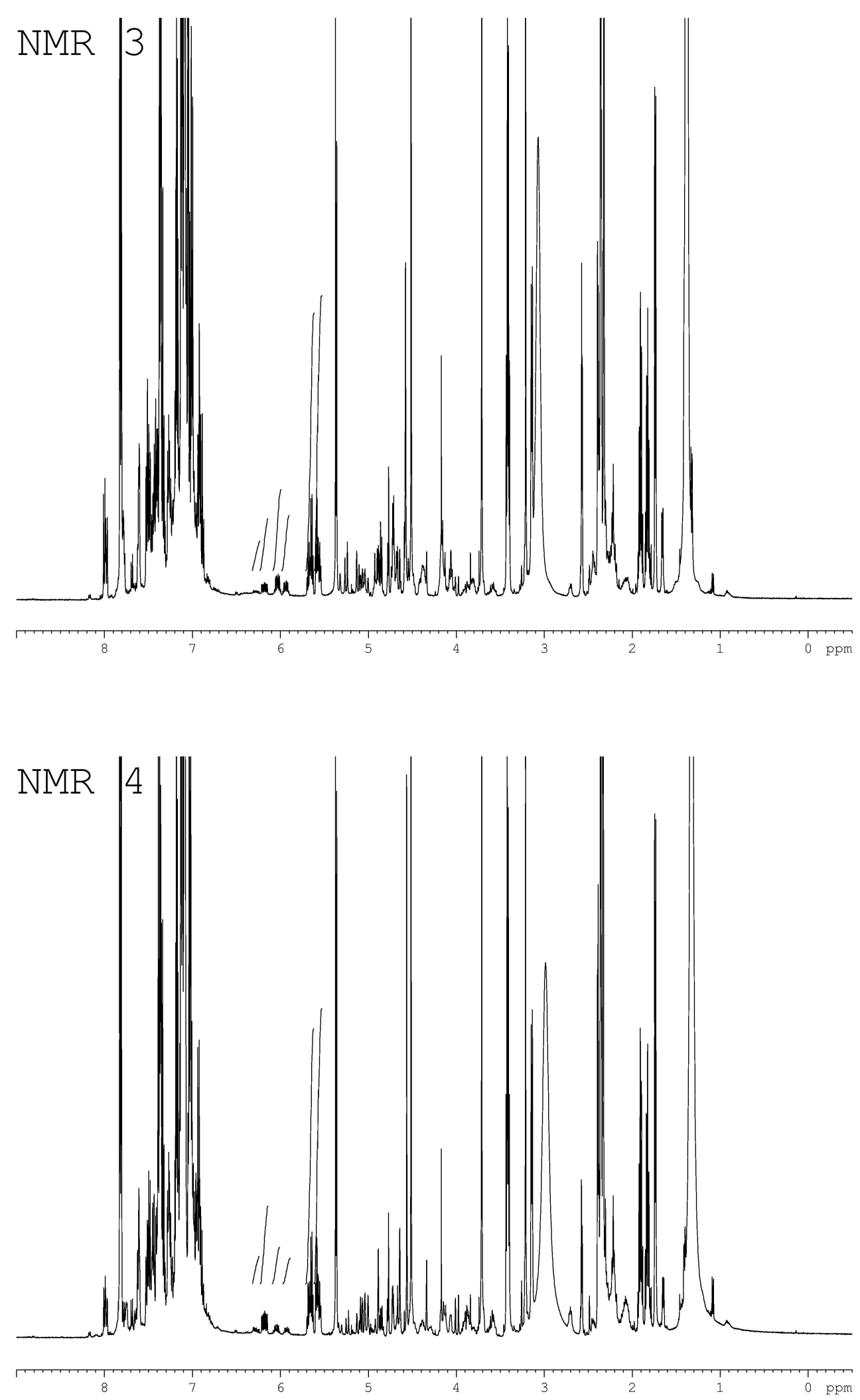

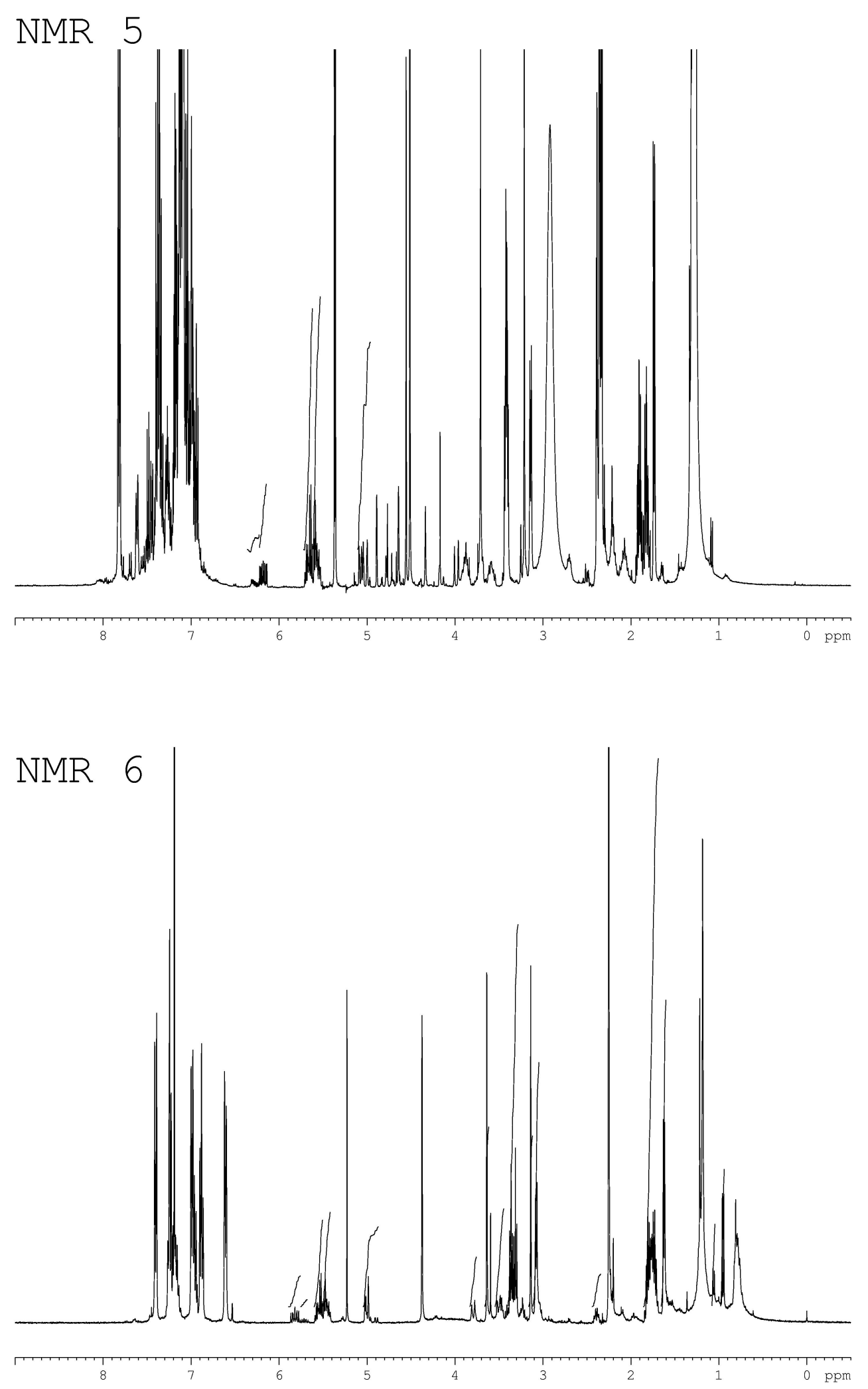
${ }^{11} \mathrm{~B}$ NMR of the NMR investigation

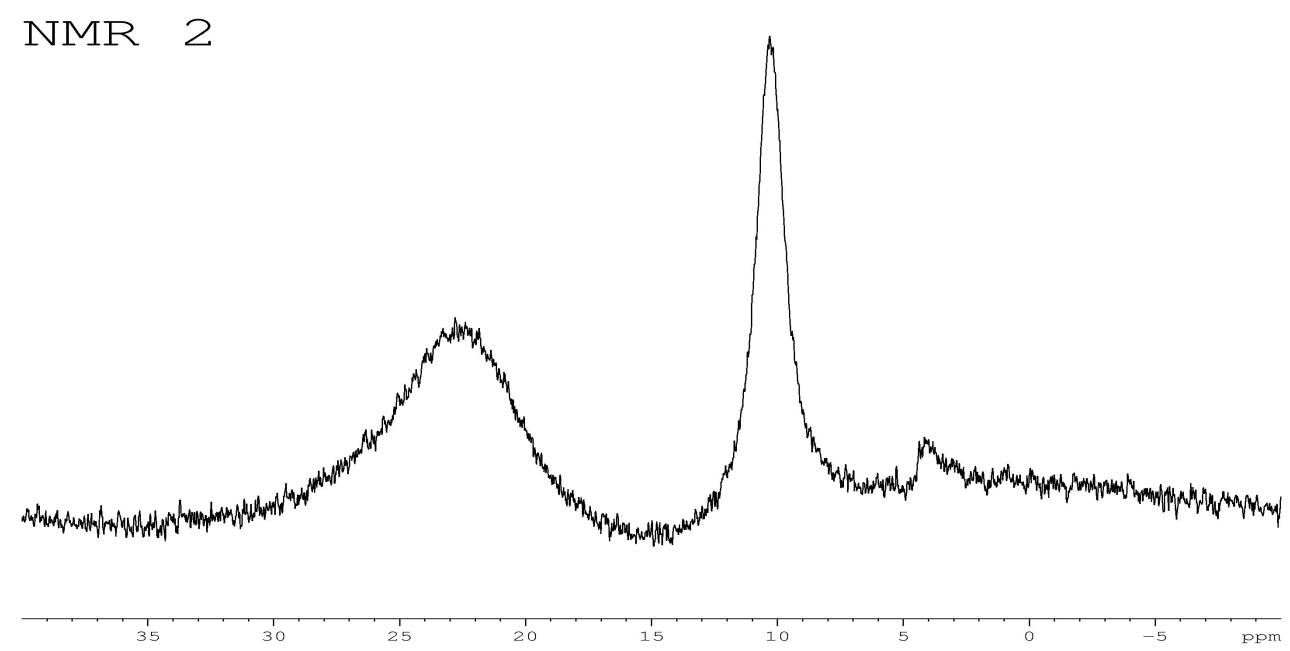

NMR 3
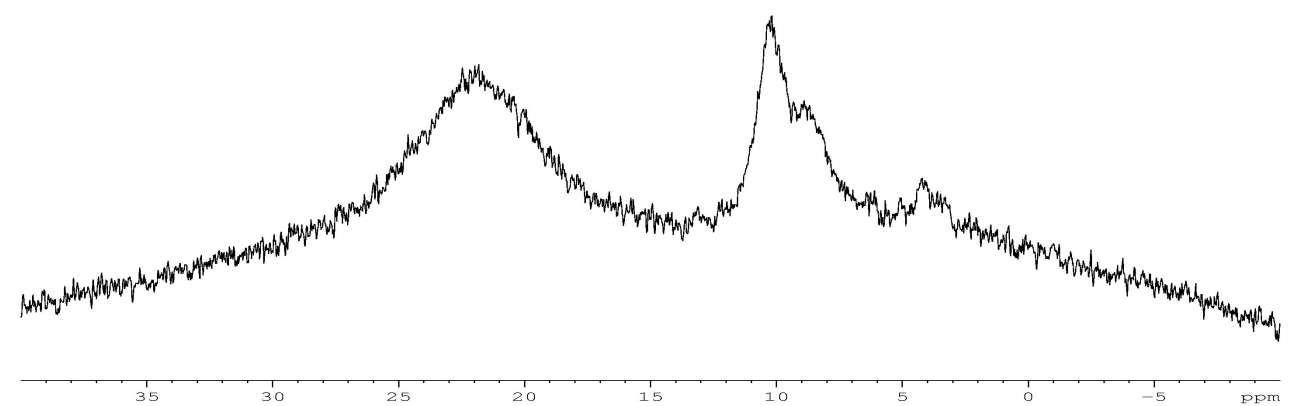

NMR 6

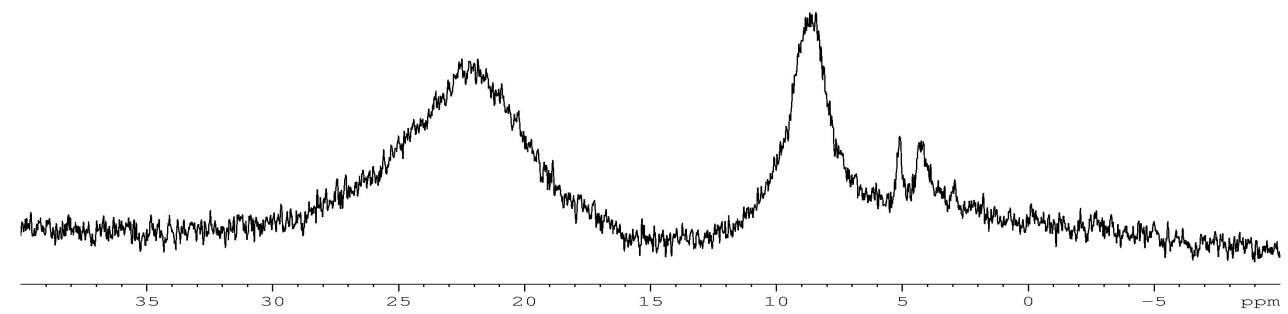

